Aus der Abteilung Klinische Neurophysiologie

(Prof. Dr. med. W. Paulus)

im Zentrum Neurologische Medizin

der Medizinischen Fakultät der Universität Göttingen

\title{
Nikotinerger Einfluss auf die durch gepaarte assoziative Stimulation ausgelöste \\ fokale inhibitorische Neuroplastizität bei Rauchern und Nichtrauchern
}

Inaugural - Dissertation

zur Erlangung des Doktorgrades

der Medizinischen Fakultät

der Georg-August-Universität zu Göttingen

vorgelegt von

Anne Drees

aus Berlin

Göttingen 2013 
Dekan: Prof. Dr. rer. nat. Kroemer

I. Berichterstatter: Prof. Dr. med. Nitsche

II. Berichterstatter: Priv.-Doz. Dr. rer. nat. Helms

III. Berichterstatter: Prof. Dr. med. Oppermann

Tag der mündlichen Prüfung: 28. Januar 2014 


\section{Inhaltsverzeichnis}

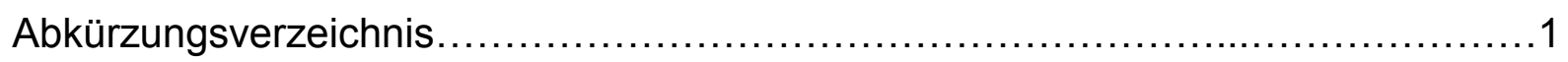

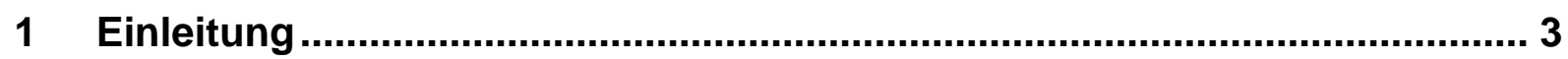

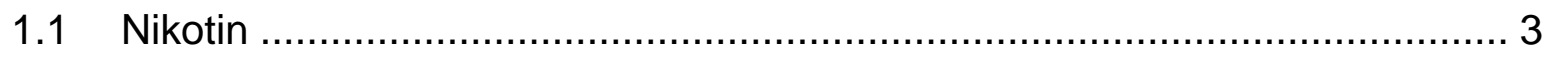

1.1.1 Nikotinstruktur und Pharmakokinetik......................................... 3

1.1.2 Nikotinerge Acetylcholin-Rezeptoren (nAChR) .............................. 3

1.1.3 Wirkung von Nikotin auf nikotinerge Acetylcholin-Rezeptoren ............. 5

1.1.4 Effekte des Nikotins auf Aufmerksamkeit und Lernprozesse ...............6 6

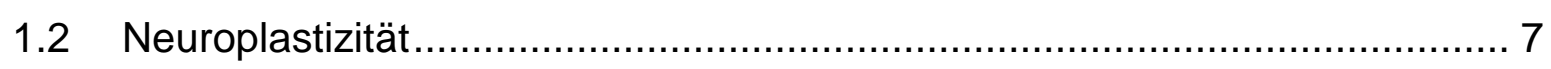

1.3 Grundlagen und Ziele dieser Arbeit ............................................. 11

2 Material und Methoden ...................................................................................

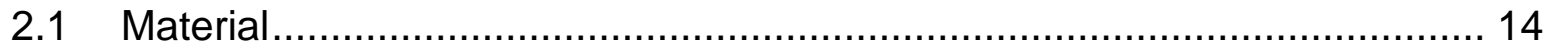

2.1.1 Probanden und Auswahlkriterien .............................................. 14

2.1.2 Ermittlung des Grades der Nikotinabhängigkeit mit dem FagerströmTest .............................................................................. 15

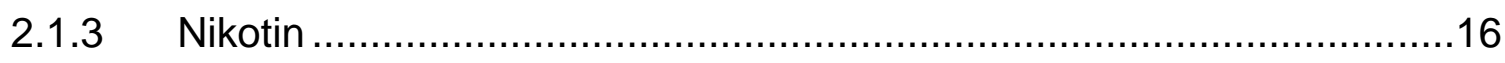

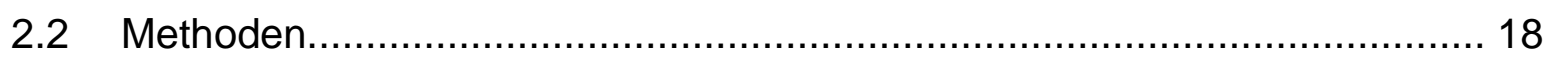

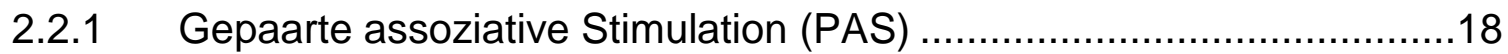

2.2.2 Transkranielle Magnetstimulation (TMS) ..................................... 19

2.2.2.1 Grundlagen zur Transkraniellen Magnetstimulation (TMS) .......... 19

2.2.2.2 Optimaler Stimulationspunkt ........................................... 19

2.2.2.3 Bestimmung der Baseline ................................................. 20

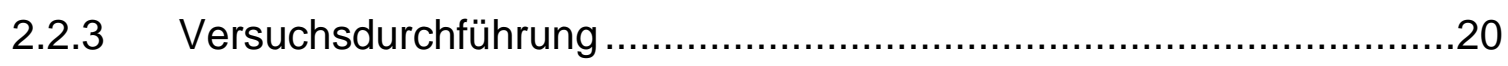

2.2.3.1 Untersuchung mit Nikotinnasenspray ............................... 21

2.2.3.2 Untersuchung mit Nikotinpflaster ..................................... 21

2.2.3.3 Untersuchung ohne Nikotin (Grundbedingung) ....................... 22

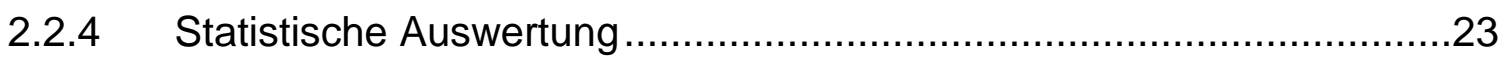

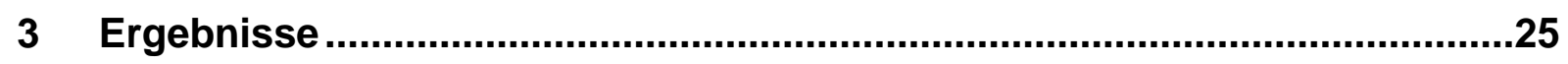

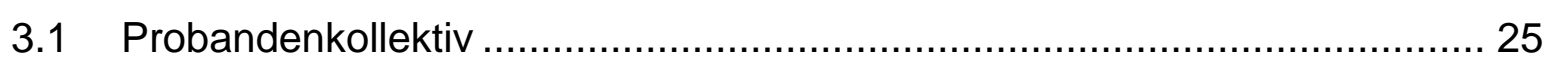

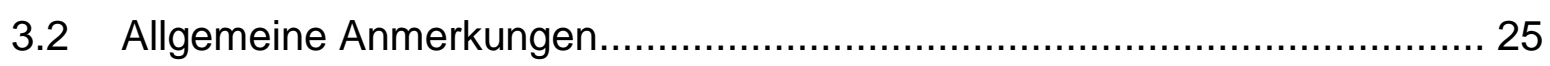

3.3 Beeinflussung der PAS-induzierten inhibitorischen kortikalen Erregbarkeitsveränderungen durch Nikotin bei Nichtrauchern .......................... 26

3.3.1 Untersuchung ohne Nikotin (Grundbedingung) .............................26 
3.3.2 Vergleich der Untersuchungen ohne Nikotin und mit Nikotinnasenspray .26

3.3.3 Vergleich der Untersuchungen ohne Nikotin und mit Nikotinpflaster....27

3.3.4 Vergleich der Untersuchung mit Nikotinspray und Nikotinpflaster ........29

3.3.5 Fazit .30

3.4 Beeinflussung der PAS-induzierten inhibitorischen kortikalen Erregbarkeitsveränderungen durch Nikotin bei Rauchern.

3.4.1 Untersuchung ohne Nikotin (Grundbedingung) .....

3.4.2 Vergleich der Untersuchungen ohne Nikotin und mit Nikotinnasenspray

3.4.3 Vergleich der Untersuchungen ohne Nikotin und mit Nikotinpflaster....32

3.4.4 Vergleich der Untersuchungen mit Nikotinspray und Nikotinpflaster ....34

3.4.5 Fazit

3.5 Vergleich der Beeinflussung der PAS-induzierten inhibitorischen kortikalen Erregbarkeitsveränderungen durch Nikotin bei Nichtrauchern und Rauchern ...... 36

3.5.1 Untersuchung ohne Nikotin (Grundbedingung) ................................36

3.5.2 Untersuchung mit Nikotinnasenspray .............................................

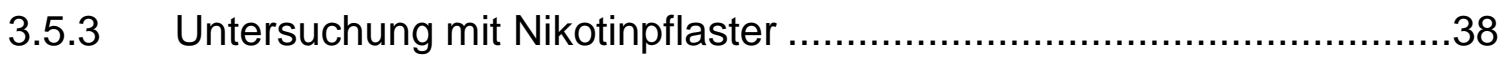

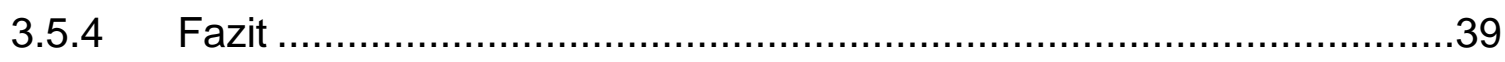

4 Diskussion

4.1 Beeinflussung der PAS-induzierten inhibitorischen kortikalen Erregbarkeitsveränderungen durch Nikotin bei Nichtrauchern

4.2 Beeinflussung der PAS-induzierten inhibitorischen kortikalen Erregbarkeitsveränderungen durch Nikotin bei Rauchern.....

4.3 Vergleich der Beeinflussung der PAS-induzierten inhibitorischen kortikalen Erregbarkeitsveränderungen durch Nikotin bei Nichtrauchern und Rauchern ...... 44 4.4 Vergleich mit Studien zur Auslösung PAS-induzierter exzitatorischer kortikaler Erregbarkeitsveränderungen durch Nikotin

4.4.1 Neurophysiologische Grundlage der inhibitorischen und exzitatorischen PAS.

4.4.2 Einfluss von Nikotin auf PAS-induzierte exzitatorische kortikale Erregbarkeitsveränderungen.

4.5 Validität der PAS und weitere mögliche Einflussfaktoren auf die Untersuchungsergebnisse 


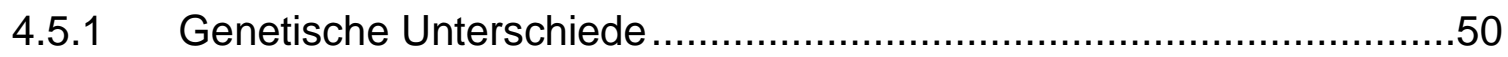

4.5.2 Inter- und intraindividuelle Variabilität .............................................51

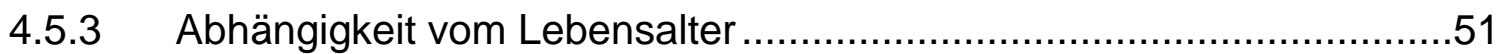

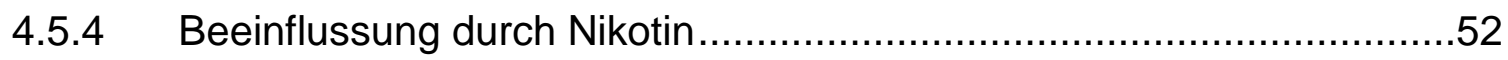

4.5.5 Beeinflussung durch andere Neurotransmitter ..................................53

4.6 Auswirkungen des nikotinergen Einflusses auf kognitive Leistungen .......... 53

5 Zusammenfassung und Ausblick ..............................................................55

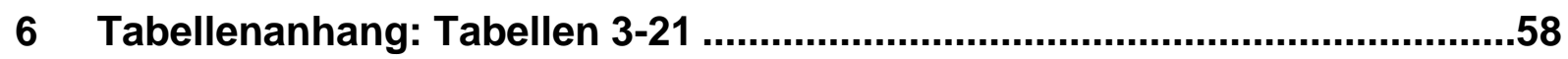

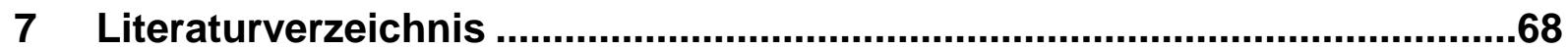




\section{Abkürzungsverzeichnis}

ACh

AChR

ADM

$\mathrm{Ag}-\mathrm{AgCl}$

AMPA

ANOVA

bzw.

CYP2A6

CYP2B6

CYP2E1

df

D2-Rezeptor

$\mathrm{F}$

fMRT

GABA

$\mathrm{Hz}$

$\mathrm{kHz}$

LSD

LTD

LTP

$\mathrm{m}$

MEP

$\mathrm{mg}$

$\mathrm{ml}$

$\mathrm{mm}$

MRT

$\mathrm{ms}$

$\mu \mathrm{s}$

$\mathrm{mV}$

MW

nA

$\mathrm{nM}$
Acetylcholin

Acetylcholin-Rezeptor

Musculus abductor digiti minimi

Silber-Silberchlorid

a-Amino-3-Hydroxy-5-Methyl-4-Isoxazol-4-Propionsäure

Varianzanalyse (Analysis of Variance)

beziehungsweise

Cytochrom P450, Familie 2, Subfamilie A, Polypeptid 6

Cytochrom P450, Familie 2, Subfamilie B, Polypeptid 6

Cytochrom P450, Familie 2, Subfamilie E, Polypeptid 1

Freiheitsgrade (degrees of freedom)

Dopamin-2-Rezeptor

F-Wert

funktionelle Magnetresonanztomographie

y-Aminobuttersäure (gamma-amino-butyric-acid)

Hertz

Kilohertz

geringster signifikanter Unterschied (least significant difference)

Langzeit-Depression (Long term depression)

Langzeit-Potenzierung (Long term potentiation)

männlich

Motorisch evozierte(s) Potential(e)

Milligramm

Milliliter

Millimeter

Magnetresonanztomographie

Millisekunden

Mikrosekunden

Millivolt

Mittelwert

nächster Abend

nächster Morgen 


$\begin{array}{ll}\text { nAChR } & \text { nikotinerge/r Acetylcholin-Rezeptor/en } \\ \text { NMDA } & \text { N-Methyl-D-Aspartat } \\ \mathrm{p} & \text { Signifikanzniveau (probability) } \\ \text { PAS } & \text { gepaarte assoziative Stimulation (Paired associative stimulation) } \\ \text { PET } & \text { Positronen-Emissions-Tomographie } \\ \text { s } & \text { Sekunden } \\ \text { SD } & \text { Standardabweichung } \\ \text { STDP } & \text { vom zeitlichen Eintreffen des Impulses abhängige Plastizität } \\ & \text { (Spike timing-dependent plasticity) } \\ \text { t } & \text { t-Wert } \\ \text { tDCS } & \text { Transkranielle Gleichstromstimulation (transcranial direct current } \\ & \text { stimulation) } \\ \text { TMS } & \text { Transkranielle Magnetstimulation } \\ \text { w } & \text { weiblich } \\ \text { z. B. } & \text { zum Beispiel } \\ \text { ZNS } & \text { Zentrales Nervensystem }\end{array}$




\section{Einleitung}

\subsection{Nikotin}

\subsubsection{Nikotinstruktur und Pharmakokinetik}

Nikotinkonsum ist der häufigste vermeidbare Grund für Krankheit und frühzeitigen Tod. Im Tabakrauch konnten über tausend toxische Stoffe nachgewiesen werden, von denen Nikotin als Hauptverantwortlicher für die Abhängigkeit verursachende Wirkung gilt.

Nikotin ist ein tertiäres Amin, das aus einem Pyridin- und einem Pyrrol-Ring besteht. Es liegt im Tabakrauch zum Großteil in Form des (S)-Enantiomers vor und bindet selektiv an den nikotinergen Acetylcholin-Rezeptor (nAChR) (Benowitz 1996). Je nach Applikationsform - Zigarette, Kaugummi, Pflaster oder Nasenspray - wird Nikotin in unterschiedlicher Geschwindigkeit vom Körper resorbiert und vom Gehirn aufgenommen. Am schnellsten wird Nikotin durch Inhalation über die Lungenalveolen aufgenommen. Von dort überwindet es die Blut-Hirn-Schranke und erreicht binnen weniger Sekunden das Gehirn (Benowitz 1996), wo es an nikotinerge Acetylcholin-Rezeptoren bindet. Nikotin unterliegt einem hepatischen Metabolismus und wird vor allem über das Enzym CYP2A6, in geringerem Maße auch durch die Enzyme CYP2B6 und CYP2E1, zu seinen beiden Metaboliten Cotinin und 3Hydroxycotinin abgebaut (Hukkanen et al. 2005). Die periphere Halbwertszeit des Nikotins beträgt zwei bis drei Stunden (Benowitz 1996), wobei die Halbwertszeit im Gehirn nur etwa eine Stunde beträgt (Ghosheh et al. 1999). Durch Inhalation des Zigarettenrauches wird der hepatische Metabolismus zunächst umgangen, so dass auf diesem Wege das Anfluten im Gehirn am schnellsten und die Nikotinkonzentration am größten ist, was zu den von Rauchern gewünschten Effekten durch die Droge Nikotin führt (Benowitz 2008). Die derzeit erhältlichen Nikotinersatztherapien in Form von Kaugummi und Pflastern führen zu einer langsamen Abgabe von Nikotin in den Blutkreislauf, wodurch die für Raucher befriedigende Wirkung des Nikotins durch das fehlende schnelle Anfluten ausbleibt.

\subsubsection{Nikotinerge Acetylcholin-Rezeptoren (nAChR)}

Nikotinerge Acetylcholin-Rezeptoren sind ligandengesteuerte lonenkanäle, die zum einen an der neuromuskulären Endplatte der Skelettmuskulatur zu finden sind, zum 
anderen im zentralen und peripheren Nervensystem an der synaptischen Übertragung beteiligt sind.

Die neuronalen nAChR haben eine pentamere Struktur mit individuell zusammengesetzten Untereineinheiten. Jeder Rezeptor besteht aus fünf Untereinheiten, die einen wassergefüllten, für Kationen durchgängigen Kanal umgeben. Derzeit sind 12 verschiedene nAChR-Unterheiten bekannt, $\alpha 2-\alpha 10$ und $\beta 2$ - $\beta 4$, die im gesamten zentralen Nervensystem verteilt sind. Die pharmakologische und funktionelle Vielfalt der nAChR in vivo ist auf die unterschiedliche Zusammensetzung und Verteilung von alpha- und betaUntereinheiten zurückzuführen (Dani und Bertrand 2007; Gotti et al. 2007; McKay et al. 2007).

Die im menschlichen Gehirn am weitesten verbreiteten Rezeptor-Subtypen sind die heterooligomerischen $\alpha 4 \beta 2$ - und $\alpha 3 \beta 4-$ Rezeptoren, sowie der homooligomerische a7-Rezeptor. Knock-out-Mäuse, bei denen die $\beta 2$-Untereinheit ausgeschaltet ist, zeigen eine reduzierte eigenständige Zufuhr von Nikotin und ein vermindertes Ansprechen der mesenzephalen dopaminergen Neurone auf Nikotin (Picciotto et al. 1998). Wird die fehlende $\beta 2$-Untereinheit den Knock-out-Mäusen wieder eingesetzt, sind die oben genannten Effekte reversibel und es wird eine Verbesserung der kognitiven Funktionen durch Nikotin erlangt (Maskos et al. 2005). Der a7-Rezeptor spielt eine wichtige Rolle in der Ausbildung von Neuroplastizität im zentralen Nervensystem, beeinflusst Gedächtnis- und Lernprozesse und hat verstärkende Effekte auf das natürliche Belohnungssystem, welches bei abhängigen Rauchern durch den Nikotinkonsum stimuliert wird (Broide und Leslie 1999). a7-Rezeptoren gehören zu den durch das Schlangengift $\alpha$-Bungarotoxin inhibierbaren nAChR. Sie haben eine hohe Kalzium-Permeabilität (Castro und Albuquerque 1995; Seguela et al. 1993) und besitzen die Fähigkeit zur schnellen Desensibilisierung (Fenster et al. 1997). Durch diese Eigenschaften sind präsynaptisch lokalisierte $\alpha 7$-Rezeptoren in der Lage, die Ausschüttung von verschiedensten anderen Neurotransmittern zu modulieren. Die ligandengesteuerte Aktivierung von nAChR bewirkt über direkte und indirekte Mechanismen eine Erhöhung der intrazellulären Kalzium-Konzentration. Bei präsynaptisch lokalisierten Rezeptoren führt dies zur Ausschüttung von Neurotransmittern wie Glutamat (McGehee et al. 1995), GABA (Yang et al. 1996; Zhu und Chiappinelli 1999), Serotonin (Westfall et al. 1983), Dopamin und Noradrenalin (Clarke und Reuben 1996). An postsynaptisch lokalisierten Rezeptoren 
kommt es über die Modulation diverser sekundärer Botenstoffe (second messenger) zur Aktivierung intrazellulärer Signalmechanismen und Gentranskription (Dani und De Biasi 2001).

\subsubsection{Wirkung von Nikotin auf nikotinerge Acetylcholin-Rezeptoren}

Chronischer Nikotinkonsum führt zu einer vermehrten Anzahl von nAChR auf der Zellmembran. Dieser paradoxe Effekt widerspricht zunächst dem in der Rezeptorphysiologie gültigen Mechanismus, nach dem die Exposition gegenüber einem Agonisten zu einer Rezeptorabnahme, die Exposition gegenüber einem Antagonisten zu einer Rezeptorzunahme führt. Eine Erklärung für die unerwartete Rezeptorzunahme ist, dass es durch die permanente Rezeptoraktivierung durch Nikotin zu einer Desensibilisierung der nAChR kommt, wodurch ein temporäres cholinerges Defizit entsteht, welches wiederum durch eine langfristige Hochregulation im Sinne einer Rezeptorzunahme ausgeglichen werden soll (Corringer et al. 2006; Dani und Heinemann 1996). Nach dieser Hypothese entsteht durch diesen Mechanismus ein pathologisches cholinerges System, welches der Raucher durch regelmäßige Nikotinzufuhr zu regulieren versucht (Dani und Heinemann 1996). Die Nikotin-induzierte Hochregulation von nAChR ist RezeptorSubtypen-spezifisch (Quick und Lester 2002) und von verschiedenen Faktoren, wie Anflutungsgeschwindigkeit, Nikotinkonzentration und Temperatur abhängig (Govind et al. 2009). Obwohl eine nAChR-Zunahme in weiten Teilen des menschlichen Gehirns beobachtet werden kann, wird für die Nikotingewöhnung vor allem das ventrale tegmentale Areal verantwortlich gemacht.

Nikotin gilt als starker Neuromodulator im zentralen Nervensystem, da viele seiner Effekte durch die Nikotin-induzierte Freisetzung anderer Neurotransmitter oder modulatoren hervorgerufen werden. Wie die meisten Abhängigkeit verursachenden Drogen bewirkt Nikotin seine Effekte unter anderem über die Beeinflussung des mesokortikolimbischen Dopamin-Systems (Corrigall et al. 1994; McGehee et al. 1995). Die Aktivierung präsynaptischer $\alpha 7-n A C h R$ führt zu einer vermehrten Glutamatausschüttung und Aktivierung von N-Methyl-D-Aspartat (NMDA)Rezeptoren auf dopaminergen Neuronen. Die dadurch induzierten lang anhaltenden Erregbarkeitsveränderungen haben Auswirkungen auf Lernmechanismen und das Belohnungssystem und tragen damit entscheidend zur Entwicklung und Aufrechterhaltung von Nikotinabhängigkeit bei (Mansvelder und McGehee 2000; Schilström et al. 1998; Vezina et al. 2007). Die drei pharmakokinetischen 
Eigenschaften von nAChR - Aktivierung, Desensibilisierung und Hochregulation sind an den durch chronischen Nikotinkonsum hervorgerufenen Neuroplastizitätsveränderungen in hohem Maße beteiligt (Govind et al. 2009) und haben dadurch Auswirkungen auf Gedächtnis, Aufmerksamkeit, Lernen und weitere kognitive Prozesse.

\subsubsection{Effekte des Nikotins auf Aufmerksamkeit und Lernprozesse}

Da Nikotin über die Nikotin-induzierte Freisetzung von anderen Neurotransmittern und -modulatoren einen Einfluss auf die Ausbildung von kortikaler Plastizität hat und diese die neurophysiologische Grundlage für Lern- und Gedächtnisvorgänge darstellt, ergibt sich für Nikotin ein weitreichender Einfluss in neuronalen Netzwerken und damit eine komplexe Wirkung auf kognitive Leistungen wie Aufmerksamkeit, Gedächtnis, Lernen und Abhängigkeit (Kenney und Gould 2008; Wonnacott 1997).

Eine Ursache für die Beibehaltung des Nikotinkonsums trotz der allgemein bekannten schädlichen Wirkungen sind die von abhängigen Rauchern oft beklagten kognitiven Defizite während einer Nikotinabstinenz. Ob diese Defizite die schädliche Wirkung des Nikotins auf das Gehirn widerspiegeln, oder aber vorbestehende kognitive Defizite zu einer Nikotinabhängigkeit führen, konnte bisher nicht genau differenziert werden. Die kognitiven Leistungen sind bei Rauchern im Nikotinentzug beeinträchtigt, durch anschließende Nikotingabe oder das Rauchen einer Zigarette können diese jedoch wieder verbessert werden (Bell et al. 1999). In verschiedenen Studien an Menschen und Tieren konnte gezeigt werden, dass Nikotin Aufmerksamkeit, Langzeitgedächtnis, Reaktionszeit, Effektivität und Präzision in verschiedenen Aufgabenstellungen sowohl bei Rauchern als auch bei Nichtrauchern verbessert (Ernst et al. 2001; Froeliger et al. 2009; Hahn und Stolerman 2002; Kumari et al. 2003). Da beide Gruppen betroffen sind, lässt sich dieser Effekt nicht nur auf die unspezifischen Effekte einer Reduzierung der Entzugssymptome im Nikotinentzug zurückführen, sondern beruht eher auf einer durch die akute Nikotingabe bedingten Verbesserung der physiologischen Grundlagen der entsprechenden Funktionen (Heishman et al. 2010). Für einen direkten Effekt des Nikotins spricht auch, dass die Auswirkungen auf die kognitive Leistungsfähigkeit in beiden Gruppen ähnlich sind, während sich die Auswirkungen auf die Stimmung und die subjektiv empfundene Aktivität zwischen Rauchern und Nichtrauchern deutlich unterscheiden (Waters und Sutton 2000). Eine Studie an jugendlichen Rauchern erbrachte Hinweise für eine neurotoxische Wirkung von Nikotin auf das sich 
entwickelnde Gehirn, indem sie zeigte, dass kognitive Defizite umso stärker ausgeprägt sind, je eher die Nikotinabhängigkeit in der Entwicklung beginnt (Jacobsen et al. 2005).

Für viele neurologisch-psychiatrische Krankheitsbilder, wie Schizophrenie oder Morbus Alzheimer, wird ein Ungleichgewicht im Transmittersystem zu Ungunsten des Acetylcholins angenommen. Ein Großteil der Patienten mit Schizophrenie ist nikotinabhängig. In verschiedenen Studien konnte nachgewiesen werden, dass die Effekte von Nikotin auf die kognitive Leistungsfähigkeit bei Rauchern mit Schizophrenie ausgeprägter sind als bei Rauchern ohne psychiatrische Grunderkrankung (Jacobsen et al. 2004; Sacco et al. 2005). Es wird angenommen, dass die mit einer Schizophrenie einhergehenden kognitiven Defizite durch einen erhöhten Nikotinkonsum ausgeglichen werden sollen, wodurch sich die hohe Rate an Rauchern unter schizophrenen Patienten erklären ließe.

\subsection{Neuroplastizität}

Unser Gehirn hat die Fähigkeit, sich verändernden äußeren Gegebenheiten anzupassen und sich das ganze Leben über zu reorganisieren. Diese Fähigkeit zur kortikalen Reorganisation wird als Neuroplastizität bezeichnet. Die Neuroplastizität beruht auf funktionellen und morphologischen Veränderungen des Kortex durch Ausbildung von neuen Synapsen und Nervenverbindungen (Donoghue et al. 1996). Diese synaptischen Modifikationen werden Langzeit-Potenzierung (LTP) und Langzeit-Depression (LTD) genannt. Sie stellen die neurophysiologische Basis für Lernen und Gedächtnisvorgänge dar.

Als Prototyp für die synaptische Plastizität gelten die NMDA-Rezeptor-abhängige LTP und LTD in der CA1-Region des Hippokampus, die am intensivsten in der Vergangenheit erforscht wurden (Bliss und Collingridge 1993; Linden 1994; Perkel et al. 1993). Aktivitätsveränderungen im Sinne von LTP- und LTD-artigen Mechanismen können allerdings an jeder Synapse im Gehirn vorkommen. Bei der Induktion und Konsolidierung von glutamaterger LTP und LTD spielen vor allem NMDA- und AMPA (a-Amino-3-Hydroxy-5-Methyl-4-Isoxazol-4-Propionsäure)-Rezeptoren eine Rolle. Als unabdingbarer Trigger für die Ausbildung von LTP und LTD gilt eine Erhöhung der intrazellulären Kalzium-Konzentration. Verantwortlich hierfür ist ein von einer Kalzium-Kalmodulin-Kinase abhängiger Signaltransduktionweg, der über Veränderungen des Phosphorylierungsstatus zu einer Inaktivierung oder einer Aktivierung bzw. zu einem verminderten oder vermehrten Einbau von AMPA- 
Rezeptoren in die postsynaptische Membran führt. Vermittelt durch die ProteinPhosphatase-1 kommt es durch eine leichtgradige Kalzium-Erhöhung zu einer Dephosphorylierung und Inaktivierung der Kalzium-Kalmodulin-Kinase II, was eine Inaktivierung von AMPA-Rezeptoren an der Zellmembran und damit die Auslösung von LTD zur Folge hat. Starke Kalzium-Erhöhungen wiederum aktivieren die Kalzium-Kalmodulin-Kinase II und führen daher über eine Phosphorylierung zu einer Aktivierung bzw. einem vermehrten Einbau vom AMPA-Rezeptoren in die subsynaptische Membran, was zu einem LTP-Mechanismus führt (D'Alcantara et al. 2003). Sehr starke intrazelluläre Kalzium-Erhöhungen ziehen keine Plastizität nach sich, da über eine zusätzliche Dephosphorylierung von hyperpolarisierenden KaliumKanälen diese aktiviert werden, was zu einer reduzierten neuronalen Aktivität führt (Misonou et al. 2004).

Auch der neuromodulatorische Einfluss von dopaminergen, cholinergen, serotoninergen und adrenergen Substanzen auf die Neuroplastizität wird zunehmend beachtet ( $\mathrm{Gu}$ 2002). Die cholinerge Modulation erfolgt zum einen über NMDAabhängige Mechanismen, wobei vor allem die Höhe der intrazellulären KalziumKonzentration (Lisman 2001), die Lokalisation (prä- oder postsynaptisch, auf Interneuronen oder an Nervenzellkörpern) und der Zeitpunkt der Aktivierung von nAChR (Ge und Dani 2005; Ji et al. 2001) ausschlaggebend dafür sind, ob synaptische Plastizität in Richtung einer Erregbarkeitssteigerung oder -minderung geht. Zum anderen können cholinerge Neurone über nicht-NMDA-abhängige Mechanismen an der Induktion von Neuroplastizität mitwirken. Durch die Desensibilisierung von präsynaptischen $\alpha 7-n A C h R$ führt Nikotin zu einer Verminderung des inhibitorischen GABAergen Einflusses an NMDA-Rezeptoren und erleichtert damit die Ausbildung von Neuroplastizität im Sinne einer Langzeitpotenzierung (Yamazaki et al. 2005).

Bereits 1973 konnten Bliss und Lomo zeigen, dass durch repetitive elektrische Stimulation von Nervenfasern die synaptische Transmissionsrate erhöht werden kann (Bliss und Lomo 1973). Tierexperimentell werden von den verschiedenen elektrischen Stimulationsprotokollen zur Auslösung von LTP vor allem die tetanische Stimulation, bei der eine hochfrequente Serie von 50-100 Stimuli mit 100 Hertz $(\mathrm{Hz})$ abgegeben wird, und die Theta-burst-Stimulation, bei der mehrere Serien von 3-5 Stimuli mit $100 \mathrm{~Hz}$ in kurzen Intervallen abgegeben werden, angewendet. Daran angelehnt wurde für die Auslösung von Neuroplastizität beim Menschen die 
schmerz- und nebenwirkungsarme Methode der repetitiven transkraniellen Magnetstimulation (rTMS) entwickelt, bei der es abhängig von der Frequenz der TMS-Impulse zu unterschiedlichen lang anhaltenden Erregbarkeitsveränderungen kommt. Eine hochfrequente Stimulation ( $>3 \mathrm{~Hz}$ ) führt zu LTP-ähnlichen Mechanismen (Berardelli et al. 1998), während eine niedrigfrequente Stimulation $(<1$ $\mathrm{Hz}$ ) zu LTD-ähnlichen Mechanismen (Chen et al. 1997) führt. Neben dieser von der Frequenz der Stimuli abhängigen Plastizität konnte gezeigt werden, dass die Ausbildung von Neuroplastizität im Sinne von LTP oder LTD bei spezifischen Stimulationsprotokollen davon abhängt, zu welchem Zeitpunkt prä- und postsynaptische Impulse an der Synapse eintreffen (Bi und Poo 1998; Jacob et al. 2007). Ein postsynaptischer Impuls, der nach der präsynaptischen Aktivierung eintrifft, führt zu LTP, während ein Eintreffen des postsynaptischen Impulses vor der präsynaptischen Aktivierung LTD auslöst (Bi und Poo 1998). Diese Form der Plastizität, bei der synaptische Verbindungen, abhängig von der zeitlichen Reihenfolge des prä- und postsynaptischen Impulses, entweder verstärkt oder geschwächt werden, wird als spike timing-dependent plasticity (STDP), also als eine vom zeitlichen Eintreffen der Impulse abhängige Plastizität, bezeichnet.

Die STDP und die rTMS sind zwei Stimulationsverfahren, die die natürlich vorkommende neuronale Aktivierung im Rahmen von Lernvorgängen imitieren. Der wesentliche Mechanismus, über den neue Erfahrungen, Verhaltensweisen und Lernvorgänge auf neuronaler Ebene beeinflusst und gesteuert werden, ist die synaptische Modifikation durch lang anhaltende Aktivitätsveränderungen, also LTP und LTD. LTP und LTD stellen neuronale Korrelate von Lernprozessen dar (RioultPedotti et al. 1998; Rioult-Pedotti et al. 2000).

Neben der oben genannten rTMS sind für die Induktion von Neuroplastizität beim Menschen die transkranielle Gleichstromstimulation (tDCS; transcranial direct current stimulation) und die gepaarte assoziative Stimulation (PAS; Paired associative stimulation) von besonderer Bedeutung. Diese beiden nicht invasiven Stimulationstechniken erzeugen lang anhaltende NMDA-Rezeptor- und Kalziumabhängige kortikale Erregbarkeitsveränderungen (Nitsche et al. 2003; Stefan et al. 2002; Wolters et al. 2003). Da bei der transkraniellen Gleichstromstimulation ein Großteil der Neurone unter den Stimulationselektroden beeinflusst wird, gilt diese Methode als eine Technik zur Erzeugung nicht-fokaler kortikaler Erregbarkeitsveränderungen. Im Gegensatz dazu stellt die gepaarte assoziative 
Stimulation (PAS) ein Mittel zur Erzeugung fokaler kortikaler Erregbarkeitsveränderungen dar, die vor allem auf synaptischen Modifikationen zwischen somatosensorischen und motorischen kortikalen Verbindungen beruhen.

Unter gepaarter assoziativer Stimulation, die ähnlich der tierexperimentell verwendeten oben beschriebenen spike timing-dependent plasticity ist, versteht man die Kombination aus überschwelliger Stimulation afferenter somatosensorischer Nervenfasern und transkranieller Magnetstimulation (TMS) über dem entsprechenden Areal des motorischen Kortex. Ob durch die PAS eine kortikale Erregbarkeitssteigerung oder -abnahme ausgelöst wird, ist von dem zeitlichen Abstand der beiden applizierten Stimuli abhängig. Da ein afferentes Signal, welches im Bereich des Handgelenkes im Nervus ulnaris entsteht, etwa 20 ms benötigt, um den somatosensorischen Kortex, und von dort weitere $4 \mathrm{~ms}$, um den motorischen Kortex zu erreichen, kann man davon ausgehen, dass bei einem 10 ms dauernden Intervall zwischen den beiden Stimuli die somatosensorische afferente Information den motorischen Kortex später erreicht als die durch den TMS-Impuls ausgelösten Effekte, was eine asynchrone Stimulation von kortikalen Motoneuronen und damit eine Erregbarkeitsabnahme zur Folge hat. Wählt man ein Inter-Stimulus-Intervall von $25 \mathrm{~ms}$, kommt es durch nahezu zeitgleiches Eintreffen des TMS-Impulses und des afferenten somatosensorischen Signals im motorischen Kortex durch die synchrone Stimulation zu einer Erregbarkeitssteigerung (Wolters et al. 2003). Durch das zeitlich synchrone Eintreffen zweier Signale an prä- und postsynaptischer Nervenendigung kommt es zu einem stärkeren Kalzium-Einstrom nach intrazellulär als bei einem asynchronen Eintreffen der beiden Signale (Koester und Sakmann 1998). Die Höhe der intrazellulären Kalzium-Konzentration ist dafür verantwortlich, ob eine inhibitorische, eine exzitatorische oder keine Plastizität induziert wird. Eine leichtgradige Erhöhung führt zu LTD, eine starke Erhöhung zu LTP, während mittelgradige und sehr starke intrazelluläre Kalzium-Erhöhungen keine neuroplastischen Veränderungen kortikaler Erregbarkeit zur Folge haben (Lisman 2001; Misonou et al. 2004).

Die durch PAS ausgelöste Neuroplastizität beruht auf LTP- bzw. LTD-ähnlichen Mechanismen. Sie ist NMDA-Rezeptor-abhängig (Stefan et al. 2002) und topographisch auf das stimulierte Kortexareal begrenzt (Weise et al. 2006). Die durch PAS ausgelösten lang anhaltenden Erregbarkeitsveränderungen des motorischen 
Kortex entwickeln sich schnell, persistieren für etwa 90 Minuten und sind nach 120 Minuten komplett reversibel (Stefan et al. 2000; Wolters et al. 2003).

Um Erregbarkeits- und Aktivitätsveränderungen der Hirnrinde beim Menschen darzustellen, ist neben bildgebenden Verfahren wie der Positronen-EmissionsTomographie (PET) oder der funktionellen Magnetresonanztomographie (fMRT) die Methode der Transkraniellen Magnetstimulation (TMS) geeignet. Letztere erlaubt auf eine nicht invasive und nicht schmerzhafte Art die Erfassung kortikaler Erregbarkeitsveränderungen. Bei der 1985 von Barker und Mitarbeitern entwickelten Methode wird über eine flach auf den Kopf des Probanden aufgelegte Spule ein Magnetimpuls gezielt über einem bestimmten Areal des motorischen Kortex abgegeben (Barker et al. 1985). Der Vorteil dieser Methode liegt darin, dass im Gegensatz zur elektrischen Stimulation keine kutanen Schmerzrezeptoren erregt werden. Daher lassen sich mit der transkraniellen Magnetstimulation auf schmerzund nebenwirkungsarme Weise erregende und hemmende Einflüsse auf die kortikale Erregbarkeit erfassen. Der applizierte kurze Magnetimpuls erzeugt ein magnetisches Feld und führt zur Induktion eines Stromflusses in der Hirnrinde mit nachfolgender Depolarisation von Neuronen. Dies wiederum bewirkt eine Kontraktion der im stimulierten Kortexareal repräsentierten peripheren Zielmuskeln. Die daraus entstehenden Muskelsummenaktionspotentiale können als motorisch evozierte Potentiale (MEP) über Oberflächenelektroden abgeleitet werden. Die Höhe der MEPAmplitude gibt Aufschluss über die Gesamterregbarkeit des kortikospinalen Systems (Abbruzzese und Trompetto 2002).

\subsection{Grundlagen und Ziele dieser Arbeit}

In der Vergangenheit wurde in einigen Pilot-Studien der cholinerge und nikotinerge Einfluss auf neuroplastische lang anhaltende kortikale Erregbarkeitsveränderungen beim Menschen untersucht. Dieser soll die neurophysiologische Grundlage für die Effekte des Nikotins auf Kognition, Aufmerksamkeit und Lernprozesse darstellen. In diesen Studien wurde der motorische Kortex gewählt, um die Neuroplastizität zu untersuchen. Neuroplastizität des motorischen Kortex wurde durch lang anhaltende Erregbarkeitsveränderungen der motorischen Hirnrinde operationalisiert, indem die Amplituden der durch TMS mit konstanter Intensität ausgelösten motorisch evozierten Potentiale erfasst wurden.

Der cholinerge Einfluss wurde durch den Einsatz von Cholinesterase-Inhibitoren untersucht. Rivastigmin und Tacrin führen zu einer reduzierten intrakortikalen 
Inhibition, verstärken fokale, Synapsen-spezifische, durch PAS ausgelöste Erregbarkeitssteigerungen und vermindern nicht-fokale lang anhaltende Erregbarkeitssteigerungen, die durch tDCS induziert werden (Korchounov et al. 2005; Kuo et al. 2007). Interessanterweise werden durch Dopamin ähnliche Effekte erreicht, was dadurch zu erklären ist, dass cholinerge und dopaminerge Neurone eng verknüpft sind und zum Teil ähnliche Funktionen im neuronalen Netzwerk ausüben (Kuo et al. 2008). Diese Ergebnisse zeigen, dass cholinerge Aktivierung Auswirkungen auf die Ausbildung von Neuroplastizität hat. In welcher Weise der nikotinerge Acetylcholin-Rezeptor im menschlichen Gehirn zu diesen cholinergen Effekten beiträgt, war bislang noch nicht vollständig geklärt. In einer Studie an langjährigen Rauchern führte chronischer Nikotinkonsum zu einer verstärkten kortikalen Inhibition und einer verminderten kortikalen Exzitation (Lang et al. 2008). Des Weiteren konnte gezeigt werden, dass die durch intermittierende Theta-burstStimulation ausgelösten lang anhaltenden neuroplastischen Veränderungen kortikospinaler Erregbarkeit durch Nikotin verstärkt und verlängert werden (Swayne et al. 2009).

Da neuroplastische kortikale Erregbarkeitsveränderungen als neurophysiologisches Korrelat von Lernmechanismen und kognitiven Fähigkeiten angesehen werden können und Nikotin für die Ausbildung von LTD im Tierexperiment eine wichtige Rolle spielt (Fujii und Sumikawa 2001; Partridge et al. 2002), stellt sich die Frage, ob sich für Nikotin auch ein Einfluss auf erregbarkeitsvermindernde Neuroplastizität erzeugende Stimulationsprotokolle beim Menschen nachweisen lässt.

In unserer Studie haben wir die Effekte von Nikotin auf fokale, durch PAS generierte Erregbarkeitsverminderung bei Rauchern und Nichtrauchern untersucht.

Bisher wurde vor allem der nikotinerge Einfluss auf erregbarkeitssteigernde Stimulationsprotokolle, im Sinne von LTP, untersucht, während es nur wenige Studien gibt, die den nikotinergen Einfluss auf inhibitorische Erregbarkeitsveränderungen, und somit LTD-Mechanismen, betrachten. $\mathrm{Da}$ tierexperimentell gezeigt werden konnte, dass auch LTD an bestimmten Formen von Hippokampus-assoziierten Lernvorgängen beteiligt ist (Brigman et al. 2010; Dong et al. 2013), kann basierend auf der Hypothese, dass abhängige Raucher den Nikotinkonsum benötigen, um vorbestehende kognitive Defizite auszugleichen und einer Desensibilisierung nikotinerger Rezeptoren entgegenzuwirken, angenommen werden, dass Raucher im Nikotinentzug nicht in der Lage sind, inhibitorische 
Neuroplastizität auszubilden und diese Fähigkeit erst durch die zusätzliche Gabe von Nikotin wiedererlangen, ebenso wie sich die kognitiven Fähigkeiten bei Rauchern durch Nikotingabe bessern. Demnach könnte angenommen werden, dass die Raucher in unserer Studie mit Nikotin ähnlich auf die Applikation von PAS reagieren wie die Nichtraucher ohne Nikotin. Wir nehmen zudem an, dass die Effekte auf die kortikalen Erregbarkeitsveränderungen durch das schnelle Anfluten von Nikotin nach intranasaler Sprayapplikation initial ausgeprägter sind, durch den kontinuierlich erhöhten Nikotinspiegel nach Pflasterapplikation jedoch länger anhalten.

Wir haben in dieser Studie versucht, tiefer gehende Erkenntnisse über die Rolle des Nikotins bei der Ausbildung fokaler neuroplastischer lang anhaltender kortikaler Erregbarkeitsveränderungen zu erhalten. Diese können dazu beitragen, die Einflüsse des Nikotins auf Veränderungen physiologischer Hirnfunktionen, und perspektivisch auch auf Lernprozesse, Aufmerksamkeit und Gedächtnis sowie seine Abhängigkeit verursachenden Eigenschaften, von denen vermutet wird, dass sie eng mit den zentralnervösen Auswirkungen des Nikotin verknüpft sind, besser zu verstehen. Durch Kenntnis dieser Mechanismen möchten wir zu einem besseren Verständnis über die Vorgänge, die zur Nikotinabhängigkeit führen, zur Aufrechterhaltung des Nikotinkonsums beitragen und für die hohen Rückfallquoten nach einer gewissen Zeit der Abstinenz verantwortlich sind, beitragen.

Die Ergebnisse dieser Arbeit sind in folgende Publikationen eingegangen und veröffentlicht worden:

Grundey J, Thirugnanasambandam N, Kaminsky K, Drees A, Skwirba AC, Lang N, Paulus W, Nitsche MA (2012 a): "Neuroplasticity in cigarette smokers is altered under withdrawal and partially restituted by nicotine exposition." $\mathrm{J}$ Neurosci 32(12): 4156-4162

Grundey J, Thirugnanasambandam N, Kaminsky K, Drees A, Skwirba AC, Lang N, Paulus W, Nitsche MA (2012 b): "Rapid effect of nicotine intake on neuroplasticity in non-smoking humans." Front Pharmacol $\underline{3}$ : 186

Thirugnanasambandam N, Grundey J, Adam K, Drees A, Skwirba AC, Lang N, Paulus W, Nitsche MA (2011 a): "Nicotinergic impact on focal and non-focal neuroplasticity induced by non-invasive brain stimulation in non-smoking humans." Neuropsychopharmacology $\underline{36}(4):$ 879-886 


\section{Material und Methoden}

\subsection{Material}

\subsubsection{Probanden und Auswahlkriterien}

Die verschiedenen Experimente wurden an 24 gesunden Probanden (12 Raucher und 12 Nichtraucher) durchgeführt. Als Einschlusskriterium für die Raucher galt ein aktueller Nikotinkonsum von mindestens 15 Zigaretten pro Tag.

Bei Vorliegen eines der unten genannten Gründe war eine Teilnahme an der Studie nicht möglich:

1. Herzschrittmacher

2. Metallimplantate im Kopfbereich (z. B. Clips nach Operation eines intrazerebralen Aneurysmas, Implantation einer künstlichen Hörschnecke)

3. Alter $<18$ oder $>75$ Jahre

4. Hinweise auf eine chronische oder Residuen einer neurologischen Erkrankung in der Vorgeschichte

5. Intrazerebrale Ischämien in der Vorgeschichte

6. Hinweise auf einen epileptischen Anfall in der Vorgeschichte

7. Vorliegen einer gravierenden internistischen oder psychiatrischen Vorerkrankung, insbesondere Schizophrenie oder Manie

8. Schwangerschaft oder Stillperiode

9. Medikamenten-, Alkohol- und/oder Drogenabhängigkeit

10. Rezeptive oder globale Aphasie

11. Teilnahme an einer anderen klinischen Prüfung innerhalb der letzten 8 Wochen. Als Kontraindikationen für die Gabe von Nikotin galten:

1. Überempfindlichkeit gegenüber Nikotin oder einem anderen Bestandteil des Pflasters oder des Nasensprays

2. Myokardinfarkt innerhalb der letzten 3 Monate, Verengung der Herzkranzgefäße, Prinzmetal-Angina, schwere Herzrhythmusstörungen

3. Zerebrale Ischämie oder Blutung

4. Nicht eingestellter Arterieller Hypertonus

5. Magen- und Duodenalulzera, Entzündungen der Speiseröhre

6. Schwere Leber- oder Milzerkrankungen

7. Erkrankungen der Atemwege, insbesondere Asthma bronchiale 
8. Schilddrüsenüberfunktion, Phäochromozytom, Diabetes mellitus

9. Chronische Hautentzündungen, Schuppenflechte, Nesselsucht.

Die Probanden wurden sowohl mündlich als auch schriftlich über die Experimente, die Medikation und deren Nebenwirkungen aufgeklärt. Alle Probanden gaben ihr schriftliches Einverständnis.

Die Untersuchungsvorhaben wurden der Ethikkommission der Universität Göttingen unter der Antragsnummer 15/10/00 vorgelegt und von dieser genehmigt.

2.1.2 Ermittlung des Grades der Nikotinabhängigkeit mit dem Fagerström-Test Um die Ausprägung der Nikotinabhängigkeit der einzelnen Raucher beurteilen zu können, verwendeten wir den 1989 von Fagerström entwickelten und 1991 von Heatherton erweiterten Fagerström-Test für Nikotinabhängigkeit, welcher in klinischen Studien weit verbreitet ist (Fagerström und Schneider 1989; Heatherton et al. 1991). Der Fagerström-Test beinhaltet Fragen nach der Anzahl der gerauchten Zigaretten pro Tag, der Zeit vom Aufstehen bis zum Rauchen der ersten Zigarette, der Schwierigkeit, bei Krankheit nicht zu rauchen, und nach tageszeitlichen Unterschieden im Verlangen nach Nikotin. Tabelle 1 gibt den Fragebogen des Fagerström-Tests wieder. Tabelle 2 zeigt die Auswertung des Fagerström-Tests und gibt den Grad der Nikotinabhängigkeit je nach erreichter Punktzahl an. 


\begin{tabular}{|c|c|c|}
\hline Frage & Antwort & Punktzahl \\
\hline \multirow{4}{*}{$\begin{array}{c}\text { Wann nach dem Aufwachen rauchen Sie Ihre erste } \\
\text { Zigarette? }\end{array}$} & 0-5 Minuten & 3 \\
\hline & 6-30 Minuten & 2 \\
\hline & 31-60 Minuten & 1 \\
\hline & Nach 60 Minuten & 0 \\
\hline \multirow{2}{*}{$\begin{array}{l}\text { Finden Sie es schwierig, an Orten, an denen das } \\
\text { Rauchen verboten ist, nicht zu rauchen (z.B. in der Kirche, } \\
\text { in der Bibliothek, im Kino etc.)? }\end{array}$} & $\mathrm{Ja}$ & 1 \\
\hline & Nein & 0 \\
\hline \multirow{2}{*}{$\begin{array}{l}\text { Auf welche Zigarette würden Sie nicht verzichten } \\
\qquad \text { wollen? }\end{array}$} & Die erste am Morgen & 1 \\
\hline & Andere & 0 \\
\hline \multirow{4}{*}{$\begin{array}{l}\text { Wie viele Zigaretten rauchen Sie im Allgemeinen pro } \\
\qquad \text { Tag? }\end{array}$} & Bis 10 & 0 \\
\hline & $10-20$ & 1 \\
\hline & $21-30$ & 2 \\
\hline & 31 oder mehr & 3 \\
\hline \multirow{2}{*}{$\begin{array}{l}\text { Rauchen Sie am Morgen im Allgemeinen mehr als am } \\
\qquad \text { Rest des Tages? }\end{array}$} & $\mathrm{Ja}$ & 1 \\
\hline & Nein & 0 \\
\hline \multirow{2}{*}{$\begin{array}{c}\text { Kommt es vor, dass Sie rauchen, wenn Sie so krank } \\
\text { sind, dass Sie den Tag überwiegend im Bett verbringen } \\
\text { müssen? }\end{array}$} & $\mathrm{Ja}$ & 1 \\
\hline & Nein & 0 \\
\hline
\end{tabular}

Tabelle 1: Fragebogen des Fagerström-Tests für Nikotinabhängigkeit (nach Heatherton et al. 1991, S. 1125)

\begin{tabular}{|c|c|}
\hline Punktzahl & Abhängigkeitsgrad \\
$0-2$ & sehr geringe Abhängigkeit \\
$3-4$ & geringe Abhängigkeit \\
5 & mittelschwere Abhängigkeit \\
$6-7$ & schwere Abhängigkeit \\
$8-10$ & sehr schwere Abhängigkeit
\end{tabular}

Tabelle 2: Auswertung des Fagerström-Tests zur Bestimmung des Abhängigkeitsgrades

\subsubsection{Nikotin}

Den Probanden wurde Nikotin in Form eines Nikotinpflasters oder -nasensprays verabreicht. Das Nikotinspray diente der Untersuchung auf die akuten Wirkungen des Nikotins, mit dem Nikotinpflaster sollten die lang anhaltenden Wirkungen untersucht werden.

Per Nasenspray wurde das Nikotin durch einen Hub in jedes Nasenloch verabreicht. In dem von uns verwendeten Nicorette ${ }^{\circledR}$ Nasal Spray von Pfizer enthalten $10 \mathrm{ml}$ Nasenspray $10 \mathrm{mg} / \mathrm{ml}$ Nikotin, wobei jeder Hub 0,5 mg Nikotin freisetzt. Die 
intranasale Applikation ist der Mechanismus, bei dem das Nikotin, außer durch Inhalation, am schnellsten anflutet und die maximale Wirkkonzentration nach 10 Minuten erreicht wird. Daher wird die akute Nikotinwirkung, welche durch einen inhalativen Zug an der Zigarette entsteht, am besten durch die Anwendung eines Nasensprays imitiert. Als Nebenwirkung traten bei allen Probanden nach Anwendung des Nikotinnasensprays wenige Minuten anhaltende Symptome wie Niesen, Husten, eine laufende Nase und tränende Augen auf. Zusätzlich berichteten einige Probanden über Kopfschmerzen, Schwindel und Übelkeit. Die Versuche mussten jedoch bei keinem Probanden abgebrochen werden.

Das transdermale Nicorette ${ }^{\circledR}$ Pflaster von Pfizer mit einer Dosierung von 16,6 mg und einer durchschnittlichen Wirkstofffreigabe von $10 \mathrm{mg} / 16$ Stunden wurde auf eine trockene, saubere und unverletzte Hautstelle am Oberarm geklebt. Trotz einer durchschnittlichen Wirkdauer von nur 16 Stunden wurde das Pflaster bis zum Abschluss der letzten Messung am nächsten Abend belassen, um eine Verfälschung der Messungen durch einen möglichen Nikotinabfall zu verhindern. Um den bekannten Nikotin-Nebenwirkungen wie Übelkeit, Erbrechen und Beschwerden im Magen-Darm-Bereich entgegenzuwirken, bekamen die Nichtraucher zeitgleich mit dem Aufkleben des Pflasters und erneut nach weiteren vier Stunden je $10 \mathrm{mg}$ Domperidon per os verabreicht. Domperidon ist ein Dopamin-Antagonist, der die Blut-Hirn-Schranke allenfalls zu einem sehr geringen Anteil überwindet (Barone 1999) und dessen Wirkungen daher weitestgehend auf die Peripherie beschränkt sind. Domperidon besitzt sowohl antiemetische als auch prokinetische Eigenschaften. Die antiemetische Wirkung beruht auf der Blockade von Dopamin-2(D2)-Rezeptoren in der für "zentrales Erbrechen“ verantwortlichen Region Area postrema, welche außerhalb der Blut-Hirn-Schranke liegt. Neben der Verminderung des Brechreizes führt die Blockade von $\mathrm{D}_{2}$-Rezeptoren peripher zu einer verstärkten Magen- und Dünndarmmotorik sowie zu einer Tonuserhöhung des unteren Ösophagussphinkters, wodurch die orthograde Magenentleerung beschleunigt wird. Diese prokinetische Wirkung verstärkt den antiemetischen Effekt. Ein in unserem Labor in einem anderen Zusammenhang durchgeführtes Experiment konnte einen Effekt von Domperidon auf Messparameter, die die Erregbarkeit des kortikospinalen Systems erfassen, ausschließen (Grundey et al. 2013). Aufgrund dieser Ergebnisse und der weitestgehend fehlenden Wirkung auf das zentrale Nervensystem konnten wir davon ausgehen, dass Domperidon keinen Einfluss auf das zentrale 
Transmittersystem, die kortikale Erregbarkeit und durch Stimulation erzeugte lang anhaltende Erregbarkeitsveränderungen hat und die Ergebnisse daher nicht beeinflusst.

Um schwankende Nikotinspiegel wie auch Überdosierungen bei den Rauchern zu verhindern, war das Rauchen von 10 Stunden vor Beginn des Versuches bis zum Abschluss der letzten Messung am nächsten Abend nicht erlaubt.

\subsection{Methoden}

Im Folgenden werden die gepaarte assoziative Stimulation (PAS) als Methode zur Auslösung fokaler, lang anhaltender und somit Neuroplastizität repräsentierender Exzitabilitätsveränderungen im Bereich des motorischen Kortex und die Transkranielle Magnetstimulation (TMS) als Methode zur Erfassung der kortikalen Erregbarkeitsveränderungen dargestellt.

\subsubsection{Gepaarte assoziative Stimulation (PAS)}

Die gepaarte assoziative Stimulation, eine Kombination aus peripherer somatosensorischer Nervenstimulation und transkranieller Magnetstimulation, eignet sich zur Erzeugung fokaler Erregbarkeitsveränderungen im Bereich des motorischen Kortex. Mittels PAS ist sowohl eine Erhöhung als auch eine Verminderung der kortikalen Erregbarkeit zu erreichen, wobei es vor allem auf den zeitlichen Abstand zwischen den beiden applizierten Stimuli ankommt.

Für unsere Versuche verwendeten wir ein PAS-Protokoll, bei dem der TMS-Impuls mit einem Intervall von $10 \mathrm{~ms}$ auf die periphere Nervenstimulation folgt (PAS(10ms)) und damit zu einer asynchronen Erregung des motorischen Kortex führt. Unter diesen Bedingungen kommt es zu einer Verminderung der Amplituden der TMSinduzierten motorisch evozierten Potentiale (MEP) (Wolters et al. 2003).

Die Stimulation des rechten Nervus ulnaris erfolgte im Bereich des Handgelenkes mittels Digitimer D185 Stimulator (Digitimer Ltd., Welwyn Garden City, UK). Der standardisierte Stimulationsblock, bei dem die Kathode proximal angeordnet ist, hat eine Stimulationsweite von $200 \mu$ s. Die Stimulationsintensität wurde auf den dreifachen Wert der Wahrnehmungsschwelle, welche als gerade noch vom Probanden wahrgenommene Stimulationsintensität definiert ist, eingestellt. Der transkranielle Magnetstimulationsimpuls wurde über dem den rechten Musculus abductor digiti minimi (ADM) präsentierenden Gebiet des motorischen Kortex mit der 
vorher festgelegten Intensität zum Auslösen von MEP-Amplituden von im Mittel $1 \mathrm{mV}$ appliziert.

Über einen Zeitraum von 30 Minuten wurden 90 gepaarte Stimuli mit $0,05 \mathrm{~Hz}$ abgegeben, wobei die periphere Nervenstimulation dem TMS-Impuls mit einem Intervall von 10 ms voraus ging (Stefan et al. 2000; Wolters et al. 2003).

\subsubsection{Transkranielle Magnetstimulation (TMS)}

\subsubsection{Grundlagen zur Transkraniellen Magnetstimulation (TMS)}

Die Transkranielle Magnetstimulation (TMS) eignet sich zur Erfassung der kortikalen Exzitabilität. Das Prinzip dieser Methode beruht auf der Erzeugung eines magnetischen Feldes über dem motorischen Kortex und nachfolgender Induktion eines Stromflusses im Kortex, welcher zu einer Depolarisation von Nervenzellen und nach Umschaltung von Pyramidenbahnzellen auf das 2. Motoneuron auf Rückenmarksebene zu anschließender Muskelkontraktion führt. Diese, in unseren Versuchen im Musculus abductor digiti minimi (ADM) ausgelösten, motorisch evozierten Potentiale (MEP) werden über Oberflächenelektroden abgeleitet und graphisch dargestellt. Eine kortikale Erregbarkeitserniedrigung zeigte sich in einer Verminderung, eine Erregbarkeitssteigerung in einer Erhöhung der MEP-Amplitude.

Die Magnetimpulse wurden von einem Magstim 200 Magnetstimulator (The Magstim Company, Whitland, Dyfed, UK), welcher mit einer achtförmigen Spule verbunden war, erzeugt. Die beiden Windungen der Spule haben einen Durchmesser von 70 mm und die maximale Stimulationsintensität der Spule beträgt 2,2 Tesla.

\subsubsection{Optimaler Stimulationspunkt}

Zum Auffinden des optimalen Stimulationspunktes wurde die Spule tangential über der linken Hemisphäre positioniert, wobei der Griff nach hinten-seitlich in einem $45^{\circ}$ Winkel von der Mittellinie gehalten wurde. In dieser Position fließen die elektrischen Ströme von postero-lateral nach antero-medial und lösen bevorzugt Aktionspotentiale in den horizontal ausgerichteten neuronalen Strukturen, wie Interneuronen, Pyramidenbahn-Axon-Kollateralen und afferenten Axonen von kortikalen und subkortikalen Bereichen aus (Day et al. 1989). Die Aktivierung von kortikospinalen Nervenzellen durch TMS erfolgt vorwiegend transsynaptisch über die Erregung von Interneuronen, da diese parallel zur Oberfläche angeordnet sind, im Gegensatz zu den senkrecht zum Gyrus praecentralis verlaufenden 
Pyramidenbahnzellen, welche auf die Hand-Motoneurone projizieren (Abbruzzese und Trompetto 2002).

Die Spule wurde in kleinen Abständen über die Schädeldecke geschoben, wobei überschwellige Magnetimpulse appliziert wurden. Als optimaler Stimulationspunkt wurde die Stelle definiert, bei der im Mittel die höchsten MEP-Amplituden im Musculus abductor digiti minimi auftreten. Dieser Punkt wurde mit einem wasserfesten Stift direkt auf der Kopfhaut markiert, um eine Stimulation an gleicher Stelle für die folgenden Messungen garantieren zu können.

\subsubsection{Bestimmung der Baseline}

Zur Festlegung der MEP-Baseline wurde diejenige Stimulationsintensität bestimmt, welche zum Erreichen einer MEP-Amplitude von im Mittel $1 \mathrm{mV}$ aus 25 Stimuli benötigt wird. Die Stimulationsintensität wird in Prozent der maximalen Stimulatorleistung angegeben, wobei 100\% der maximalen Ausgangsleistung des Magstim 200 Stimulators entsprechen. Die Einzelimpulsstimulation erfolgte bei 0,25 $\mathrm{Hz}$. Da eine Vorkontraktion des Muskels zu einer erhöhten MEP-Amplitude führt, war die völlige Entspannung des Muskels absolute Voraussetzung bei der BaselineBestimmung.

Die Stimulationsintensität wurde vor jedem Versuch individuell für jeden Probanden bestimmt und als Referenzwert während der Messung beibehalten.

\subsubsection{Versuchsdurchführung}

Während der Versuche saßen die Probanden in einem bequemen Sessel mit Kopfstütze, um eine größtmögliche Entspannung und Stabilität zu erreichen. Der Arm, an dem die Messungen durchgeführt wurden, lag auf einer gepolsterten Armlehne, um eine maximal entspannte Armhaltung zu garantieren. Vom rechten Musculus abductor digiti minimi wurde mittels Silber-Silberchlorid (Ag-AgCl)Elektroden eine Oberflächen-Elektromyographie abgeleitet. Die differente Elektrode wurde über dem Muskelbauch, die indifferente Elektrode am Sehnenansatz des kleinen Fingers angebracht. Eine weitere Elektrode wurde zur Erdung am Unterarm positioniert. Das von den Oberflächenelektroden abgeleitete Signal wurde vorverstärkt und mit einer Zeitkonstante von $10 \mathrm{~s}$ und einem Tiefenpassfilter von 2,5 $\mathrm{kHz}$ gefiltert. Die Signale wurden mit einer analog-zu-digital Rate von $5 \mathrm{kHz}$ unter Nutzung der Signal Software und der CED 1401 Hardware (Cambridge Electronic Design, Cambridge, UK) auf einen Laborcomputer übertragen. 
Nach Auffinden und Markierung des optimalen Stimulationspunktes, Festlegen der TMS-Stimulationsintensität und Bestimmung der MEP-Baseline wurde der Stimulationsblock des Digitimers mit einem Gummiband am Handgelenk im Bereich des Nervus ulnaris befestigt. Daraufhin wurde die Wahrnehmungsschwelle bestimmt und deren dreifache Intensität für die periphere Nervenstimulation am Digitimer eingestellt.

\subsubsection{Untersuchung mit Nikotinnasenspray}

In diesem Versuch sollte die Auswirkung von schnell anflutendem Nikotin auf kortikale Erregbarkeitsveränderungen nach inhibitorischer PAS untersucht werden.

Dazu wurde nach Bestimmung der MEP-Baseline Nikotin per Nasenspray durch einen Hub in jedes Nasenloch verabreicht. Nach 10 Minuten wurde eine erneute Bestimmung der MEP-Baseline vorgenommen, um einen möglichen alleinigen Einfluss von Nikotin auf die Baseline erfassen zu können. Anschließend wurde das interventionelle PAS(10ms)-Protokoll gestartet. Dazu wurden 90 gepaarte Stimuli mit $0,05 \mathrm{~Hz}$ über einen Zeitraum von 30 Minuten mit einem Inter-Stimulus-Intervall von $10 \mathrm{~ms}$ abgegeben, wobei die periphere Nervenstimulation der TMS-Stimulation voraus ging. Nach Beendigung der PAS erfolgte die Aufzeichnung von 25 TMSStimuli bei $0,25 \mathrm{~Hz}$ alle 5 Minuten über eine halbe Stunde, sowie alle 30 Minuten bis 2 Stunden und erneut 4 Stunden nach Ende der PAS, sowie am Morgen und am Abend des Folgetages. Die Elektrodenposition an der Hand wurde mit einem wasserfesten Stift markiert, um eine Ableitung der MEP von der gleichen Stelle wie am Vortag garantieren zu können.

\subsubsection{Untersuchung mit Nikotinpflaster}

In diesem Versuch sollte die Auswirkung eines kontinuierlich hohen Nikotinspiegels auf kortikale Erregbarkeitsveränderungen nach inhibitorischer PAS untersucht werden. Dazu wurde im Anschluss an die Bestimmung der MEP-Baseline ein Nikotinpflaster aufgeklebt. Zur Erfassung eines möglichen alleinigen Einflusses von Nikotin auf die Baseline wurde nach sechs Stunden eine erneute Bestimmung der MEP-Baseline vorgenommen, da erst nach diesem Zeitraum ausreichend hohe Nikotinkonzentrationen durch das transdermale Pflaster zu erwarten waren. Anschließend wurde das interventionelle PAS-Protokoll gestartet. Der weitere Versuchsablauf ist dem in der oben beschriebenen Untersuchung mit Nikotinnasenspray gleichzusetzen. 


\subsubsection{Untersuchung ohne Nikotin (Grundbedingung)}

In diesem Versuch sollte die Auswirkung der inhibitorischen PAS auf kortikale Erregbarkeitsveränderungen ohne Nikotin untersucht werden, um eine Grundbedingung für den Vergleich mit Nikotin zu schaffen. Der Versuchsablauf ist dem mit Nikotinpflaster gleichzusetzen. Nach Beendigung der PAS erfolgte eine Aufzeichnung von 25 TMS-Stimuli jedoch nur bis 2 Stunden nach Ende der PASStimulation, da ohne Nikotin länger andauernde Erregbarkeitsveränderungen nicht zu erwarten waren (Wolters et al. 2003).

Zwischen den einzelnen Versuchen wurde eine Pause von mindestens einer Woche eingehalten, um kumulative Effekte ausschließen zu können.

In Abbildung 1 ist die zeitliche Abfolge des Versuchsablaufs dargestellt.

TMS Plastizitäts-

induzierende

Stimulation

$\begin{array}{cc}\text { Baseline- } & \text { Keine } \\ \text { bestimmung } & \text { Nikotingabe }\end{array}$

Baseline-

bestimmung

Nikotinspray 10 Min

Baseline-

bestimmung
Nikotinpflaster $\quad 6$ Std.
PAS (10 ms)

PAS (10 ms)

MEP bis zum nächsten Abend nach Stimulation

MEP bis zum nächsten Abend nach Stimulation

Zeitverlauf

\section{Abbildung 1: Zeitliche Abfolge des Versuchsablaufs}

Nach Bestimmung der Baseline mittels TMS wurde kein Nikotin, Nikotinspray oder Nikotinpflaster verabreicht, danach 10 Minuten bzw. 6 Stunden gewartet, bis das PAS-Protokoll mit einem Inter-Stimulus-Intervall von $10 \mathrm{~ms}$ gestartet wurde. Im Anschluss wurden die MEP bis 120 Minuten (ohne Nikotin) bzw. bis zum nächsten Abend nach Stimulation (mit Nikotin) zur Erfassung kortikaler Erregbarkeitsveränderungen aufgezeichnet.

MEP: Motorisch evozierte(s) Potential(e); PAS: gepaarte assoziative Stimulation; TMS: Transkranielle Magnetstimulation. 


\subsubsection{Statistische Auswertung}

Auf dem Labor-Computer wurden mit dem SIGNAL-Programm 25 MEP-Impulse pro Messzeitpunkt (Baseline und Zeitpunkte der Nachmessungen) aufgezeichnet. Deren anschließende Auswertung erfolgte mit dem Nucursor-Programm. Dabei wurde zunächst die peak-to-peak-Ampltiude der MEP-Impulse bestimmt. Für jeden Probanden wurde vor der PAS der Mittelwert aus 20 aufeinanderfolgenden MEPAmplituden gebildet und als Baseline festgelegt. Diese sollte bei 1,0 +/- 0,2 mV liegen. Artefaktgestörte MEP-Amplituden durch unerwünschte Willkürinnvervation wurden nicht mit in die Auswertung einbezogen. Für die weiteren Messungen wurde für jeden Probanden der Mittelwert aus 20 aufeinander folgenden MEP-Amplituden für jeden Zeitpunkt (0, 5, 10, 15, 20, 25, 30, 60, 90, 120 und 240 Minuten nach Stimulation und am Morgen und Abend des Folgetages) unter den verschiedenen Bedingungen (ohne Nikotin, Nikotinpflaster, Nikotinspray) gebildet.

Mit dem StatView-Programm wurden die postinterventionell bestimmten Werte prozentual zu der individuellen Baseline berechnet und somit standardisiert. Mit Hilfe des SPSS-Programmes erfolgte die statistische Auswertung der Daten. Eine Messwiederholungs-ANOVA wurde mit dem abhängigen Faktor MEP-Amplitude, den unabhängigen Meßwiederholungs-Faktoren Zeitpunkt und Wirkstoff und dem Zwischengruppenfaktor Raucherstatus durchgeführt. Ergaben sich signifikante Ergebnisse in der ANOVA, wurden gepaarte oder ungepaarte t-Tests für die posthoc-Analyse durchgeführt. Um den Zeitverlauf der MEP-Veränderungen statistisch darzustellen, wurde für jeden Zeitpunkt die MEP-Amplitude nach inhibitorischer PAS mit der Baseline-MEP-Amplitude vor Intervention mittels gepaarter t-Tests verglichen. Zusätzlich wurden die MEP-Amplituden der Grundmessung mit denen der jeweiligen Nikotinbedingungen (Spray/Pflaster) sowie die beiden Nikotinbedingungen untereinander (Spray/Pflaster) für jeden einzelnen Zeitpunkt mittels gepaarter t-Tests verglichen. Der Vergleich von Rauchern und Nichtrauchern unter den verschiedenen Bedingungen (ohne Nikotin, Nikotinspray, Nikotinpflaster) erfolgte durch ungepaarte t-Tests. Die post-hoc t-Tests waren explorativ und wurden somit nicht für multiple Vergleiche adjustiert. Ergänzend wurde daher für alle oben genannten Konstellationen Fisher's LSD (geringster signifikanter Unterschied; least significant difference) zur Korrektur für multiple post-hoc Paarvergleiche bei primärer statistischer Testung mittels ANOVA mit dem StatView-Programm berechnet. 
Des Weiteren wurden mittels unabhängiger t-Tests die beiden Gruppen (Raucher/Nichtraucher) bezüglich des Alters der Probanden und den MEPAmplituden der jeweils selben Bedingungen (Grundbedingung ohne Nikotin, vor und nach Nikotinspray, vor und nach Nikotinpflaster) verglichen. Innerhalb einer Gruppe wurden mittels gepaarter t-Tests die MEP-Baselines vor und nach Nikotingabe verglichen.

Für alle statistischen Berechnungen wurde ein $p$-Wert von $<0,05$ als signifikant angenommen. 


\section{Ergebnisse}

\subsection{Probandenkollektiv}

In dieser Studie wurden 24 Probanden (12 Raucher und 12 Nichtraucher) untersucht. Von diesen wurden jeweils drei Mess-Reihen angefertigt. Das Alter lag zwischen 21 und 31 Jahren, der Altersmedian war 26 Jahre. Von den 12 untersuchten Nichtrauchern waren 7 (58,33 \%) weiblich. Das Alter lag zwischen 22 und 29 Jahren, der Altersmedian war 26 Jahre. Als Einschlusskriterium für die Nichtraucher galt, dass diese niemals oder zumindest während der letzten fünf Jahre nicht mehr geraucht hatten. Von den 12 untersuchten Rauchern waren 5 (41,66 \%) weiblich. Das Alter lag zwischen 21 und 31 Jahren, der Altersmedian war 26 Jahre. Für den Altersdurchschnitt zeigte sich im t-Test für unabhängige Stichproben kein statistisch signifikanter Unterschied zwischen der Raucher- und Nichtraucher-Gruppe ( $p$-Wert: 0,874). Die Anzahl der gerauchten Zigaretten lag im Mittel bei 15 Zigaretten pro Tag. Die erreichte Punktzahl im Fagerström-Test lag zwischen 0 und 7 Punkten, der Median lag bei 3 Punkten. Die statistischen Daten $z u$ den beiden Probandenkollektiven sind in Tabelle 3 dargestellt.

\subsection{Allgemeine Anmerkungen}

Die Experimente wurden von allen Probanden weitestgehend gut vertragen. Die durch die Nikotingabe ausgelösten Nebenwirkungen hielten nur wenige Minuten an, durch die Stimulation kam es zu keinen nennenswerten Nebenwirkungen.

Die Baseline-MEP-Amplituden bei den jeweils selben Bedingungen waren zwischen Rauchern und Nichtrauchern statistisch nicht signifikant unterschiedlich (siehe Tabelle 4). Die Nikotingabe allein hatte keinen signifikanten Einfluss auf die Amplitude der MEP-Baselines (siehe Tabelle 5).

Die ANOVA ergab signifikante Effekte für die Faktoren Nikotin $(F(2,44)=7,200$; $p=0,002)$ und Zeitpunkt $(F(10,220)=3,083 ; p=0,001)$. Der Faktor Gruppe, die Interaktionen Nikotin $\times$ Gruppe, Zeitpunkt $\times$ Gruppe, Nikotin $\times$ Zeitpunkt und die Dreier-Interaktion Nikotin $\times$ Zeitpunkt $\times$ Gruppe waren statistisch nicht signifikant. Die Ergebnisse der ANOVA sind in Tabelle 6 dargestellt. 


\subsection{Beeinflussung der PAS-induzierten inhibitorischen kortikalen Erregbarkeitsveränderungen durch Nikotin bei Nichtrauchern}

\subsubsection{Untersuchung ohne Nikotin (Grundbedingung)}

In dieser Messung wurden die durch das inhibitorische PAS-Protokoll ausgelösten kortikalen Erregbarkeitsveränderungen, operationalisiert durch MEPAmplitudenmessungen, ohne den Einfluss von Nikotin untersucht. Die Untersuchungen ohne Nikotin werden im Folgenden auch Grundbedingung genannt. Bei den Nichtrauchern zeigte sich eine Abnahme der kortikalen Erregbarkeit. Für die durch inhibitorische PAS hervorgerufenen kortikalen Erregbarkeitsveränderungen ohne den Einfluss von Nikotin erbrachten die t-Tests bei Nichtrauchern signifikante Unterschiede in den MEP-Amplituden gegenüber der Baseline bis einschließlich 120 Minuten nach Stimulation (mit Ausnahme nach 60 Minuten). Mittels Fisher's LSD ließen sich signifikante Unterschiede zu den Zeitpunkten 5, 15, 20, 25, 30 und 90 Minuten nachweisen. In Abbildung 2 ist der zeitliche Verlauf der MEP-Amplituden für die Grundbedingung ohne Nikotin durch die mit Quadraten verbundene Kurve dargestellt. Die Ergebnisse der gepaarten t-Tests und des Fisher's LSD sind in Tabelle 7 dargestellt.

\subsubsection{Vergleich der Untersuchungen ohne Nikotin und mit Nikotinnasenspray} In dieser Messung wurde der Einfluss von schnell anflutendem Nikotin in Form von Nasenspray auf die durch das inhibitorische PAS-Protokoll ausgelösten kortikalen Erregbarkeitsveränderungen, operationalisiert durch MEP-Amplitudenmessungen, im Vergleich zu der Grundbedingung ohne Nikotin untersucht.

Bei den Nichtrauchern zeigte sich nach Gabe von Nikotinnasenspray keine Abnahme der kortikalen Erregbarkeit durch das inhibitorische PAS-Protokoll. Sowohl die tTests als auch Fisher's LSD ergaben keine signifikanten Unterschiede der MEPAmplituden gegenüber der Baseline. Die Ergebnisse sind in Tabelle 8 dargestellt.

$\mathrm{Da}$ es bei den Nichtrauchern bei der Messung ohne Nikotin zu einer deutlichen kortikalen Erregbarkeitsverminderung kommt und diese sich durch die Gabe von Nikotinnasenspray aufheben ließ, ergaben sich konsequenterweise Unterschiede zwischen den Messungen unter Grund- und Nikotinspray-Bedingungen. Mittels gepaarter t-Tests ließen sich signifikante Unterschiede der MEP-Amplituden zwischen Grund- und Nikotinspray-Bedingungen bis 30 Minuten (mit Ausnahme nach 10 Minuten) und nochmals 90 Minuten nach Stimulation darstellen. Fisher's LSD 
erbrachte signifkante Unterschiede über den gesamten Zeitraum von 0 bis 90 Minuten. Die Ergebnisse der gepaarten t-Tests und des Fisher's LSD sind in Tabelle 9 dargestellt. Die Abbildung 2 zeigt die Änderung der MEP-Amplituden als Ausdruck der kortikalen Erregbarkeitsveränderungen im zeitlichen Verlauf bei Nichtrauchern ohne Nikotin und nach Gabe von Nikotinnasenspray.

Die Abbildungen beziehen sich im Folgenden nur auf die Ergebnisse der t-Tests.

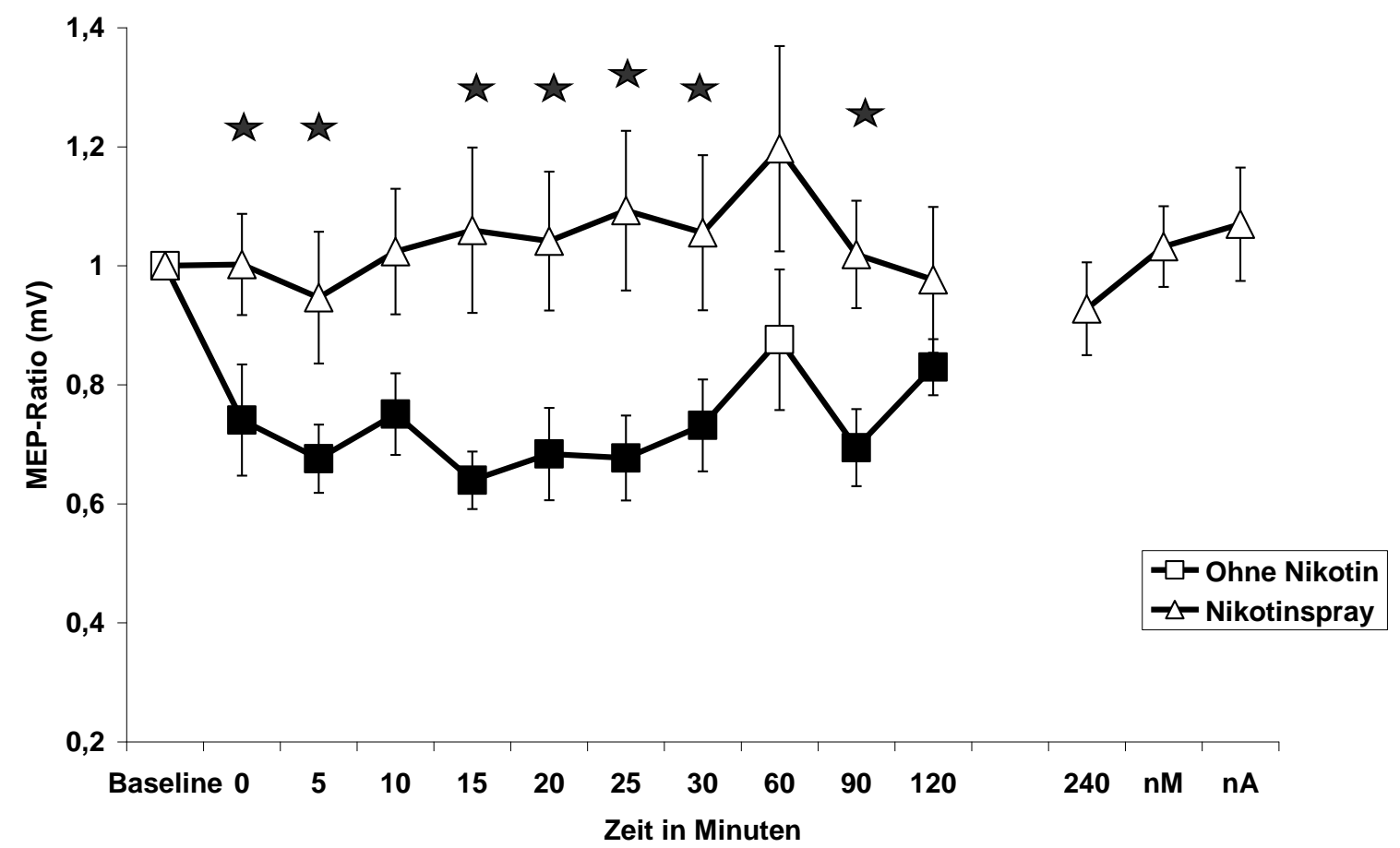

Abbildung 2: Zeitverlauf der MEP-Amplituden bei Nichtrauchern ohne Nikotin und mit Nikotinnasenspray.

Dargestellt in der obigen Grafik sind die mittleren MEP-Amplituden +/- Standardfehler (Fehlerbalken) zu den verschiedenen Zeitpunkten im Vergleich zur MEP-Baseline (MEP-Ratio) bei Anwendung des inhibitorischen PASProtokolles ohne Nikotin und nach Gabe von Nikotinnasenspray. Ausgefüllte Symbole kennzeichnen signifikante Veränderungen der MEP-Amplituden nach inhibitorischer PAS gegenüber Baselineniveau. Die mit einem Stern markierten Symbole stellen signifikante Veränderungen der MEP-Amplitude durch Nikotinnasenspray gegenüber der Grundbedingung ohne Nikotin bei identischem Zeitfenster dar. Signifikanzniveau: $p<0,05$.

MEP: Motorisch evoziertes Potential; MEP-Ratio: MEP-Baseline/MEP-Amplitude zu den verschiedenen Zeitpunkten; nA: nächster Abend; nM: nächster Morgen.

\subsubsection{Vergleich der Untersuchungen ohne Nikotin und mit Nikotinpflaster} In dieser Messung wurde der Einfluss eines kontinuierlich hohen Nikotinspiegels durch ein transdermales Pflaster auf die durch das inhibitorische PAS-Protokoll ausgelösten kortikalen Erregbarkeitsveränderungen, operationalisiert durch MEP- 
Amplitudenmessungen, im Vergleich zu der Grundbedingung ohne Nikotin untersucht.

Bei den Nichtrauchern zeigte sich unter Nikotinpflaster keine Abnahme der kortikalen Erregbarkeit durch das inhibitorische PAS-Protokoll. Sowohl die gepaarten t-Tests als auch Fisher's LSD erbrachten keine signifikanten Unterschiede der MEPAmplituden gegenüber der Baseline. Die Ergebnisse sind in Tabelle 10 dargestellt.

$\mathrm{Da}$ es bei den Nichtrauchern ohne Nikotin zu einer deutlichen kortikalen Erregbarkeitsverminderung kommt und diese sich durch die Gabe eines Nikotinpflasters aufheben ließ, ergaben sich konsequenterweise Unterschiede zwischen der Grund- und der Nikotinpflaster-Bedingung. Mittels gepaarter t-Tests ließen sich signifikante Unterschiede der MEP-Amplituden zwischen Grund- und Nikotinpflaster-Bedingungen von 5 bis 30 Minuten nach Stimulation darstellen. Fisher's LSD erbrachte nur für den Zeitpunkt 25 Minuten nach Stimulation einen signifikanten Unterschied. Die Ergebnisse der gepaarten t-Tests und des Fisher's LSD sind in Tabelle 11 dargestellt. Die Abbildung 3 zeigt die Änderung der MEPAmplituden als Ausdruck der kortikalen Erregbarkeitsveränderungen im zeitlichen Verlauf bei Nichtrauchern ohne Nikotin und nach Applikation eines Nikotinpflasters. 


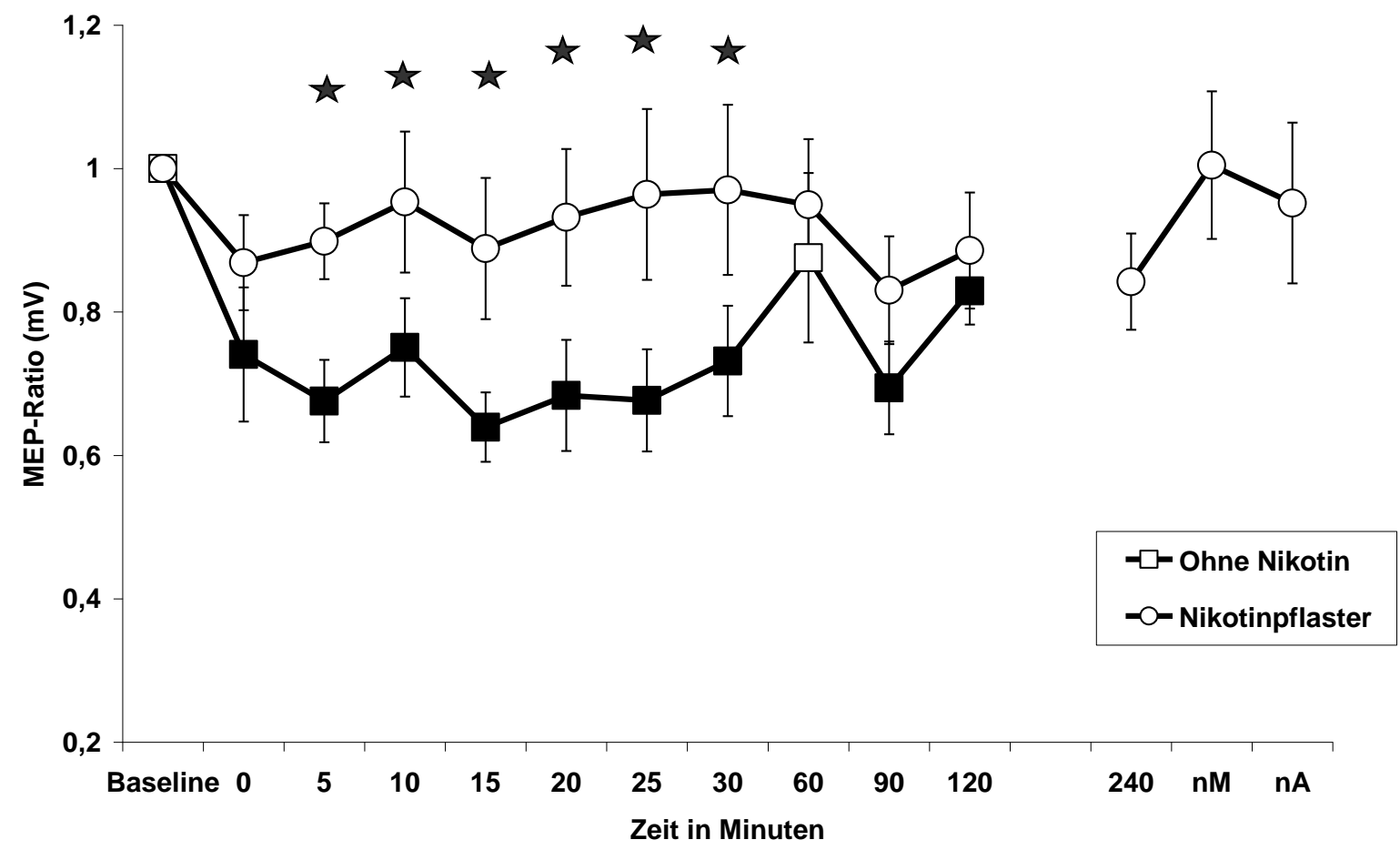

Abbildung 3: Zeitverlauf der MEP-Amplituden bei Nichtrauchern ohne Nikotin und mit Nikotinpflaster.

Dargestellt in der obigen Grafik sind die mittleren MEP-Amplituden +/- Standardfehler (Fehlerbalken) zu den verschiedenen Zeitpunkten im Vergleich zur MEP-Baseline (MEP-Ratio) bei Anwendung des inhibitorischen PASProtokolles ohne Nikotin und nach Applikation eines Nikotinpflasters. Ausgefüllte Symbole kennzeichnen signifikante Veränderungen der MEP-Amplituden nach inhibitorischer PAS gegenüber Baselineniveau. Die mit einem Stern markierten Symbole stellen signifikante Veränderungen der MEP-Amplitude durch Nikotinpflaster gegenüber der Grundbedingung ohne Nikotin bei identischem Zeitfenster dar. Signifikanzniveau: $p<0,05$.

MEP: Motorisch evoziertes Potential; MEP-Ratio: MEP-Baseline/MEP-Amplitude zu den verschiedenen Zeitpunkten; nA: nächster Abend; nM: nächster Morgen.

\subsubsection{Vergleich der Untersuchung mit Nikotinspray und Nikotinpflaster}

In dieser Messung wurde der Einfluss von schnell anflutendem Nikotin in Form von Nasenspray im Vergleich zu einem kontinuierlich hohen Nikotinspiegel durch ein transdermales Pflaster auf die durch das inhibitorische PAS-Protokoll ausgelösten kortikalen Erregbarkeitsveränderungen, operationalisiert durch MEPAmplitudenmessungen, untersucht.

Bei den Nichtrauchern ergaben sich bei beiden Nikotinbedingungen keine signifikanten Änderungen der MEP-Amplituden gegenüber der Baseline. Zwischen den beiden verschiedenen Nikotinapplikationsformen ergaben die t-Tests nach 0 und nach 90 Minuten signifikante Unterschiede. Mittels Fisher's LSD war nach 60 Minuten ein signifikanter Unterschied zwischen Nikotinspray und Nikotinpflaster 
nachzuweisen. Die Ergebnisse der gepaarten t-Tests und des Fisher's LSD sind in Tabelle 12 dargestellt. Die Abbildung 4 zeigt die Änderung der MEP-Amplituden als Ausdruck der kortikalen Erregbarkeitsveränderungen im zeitlichen Verlauf bei Nichtrauchern nach Gabe von Nikotinspray und Nikotinpflaster.

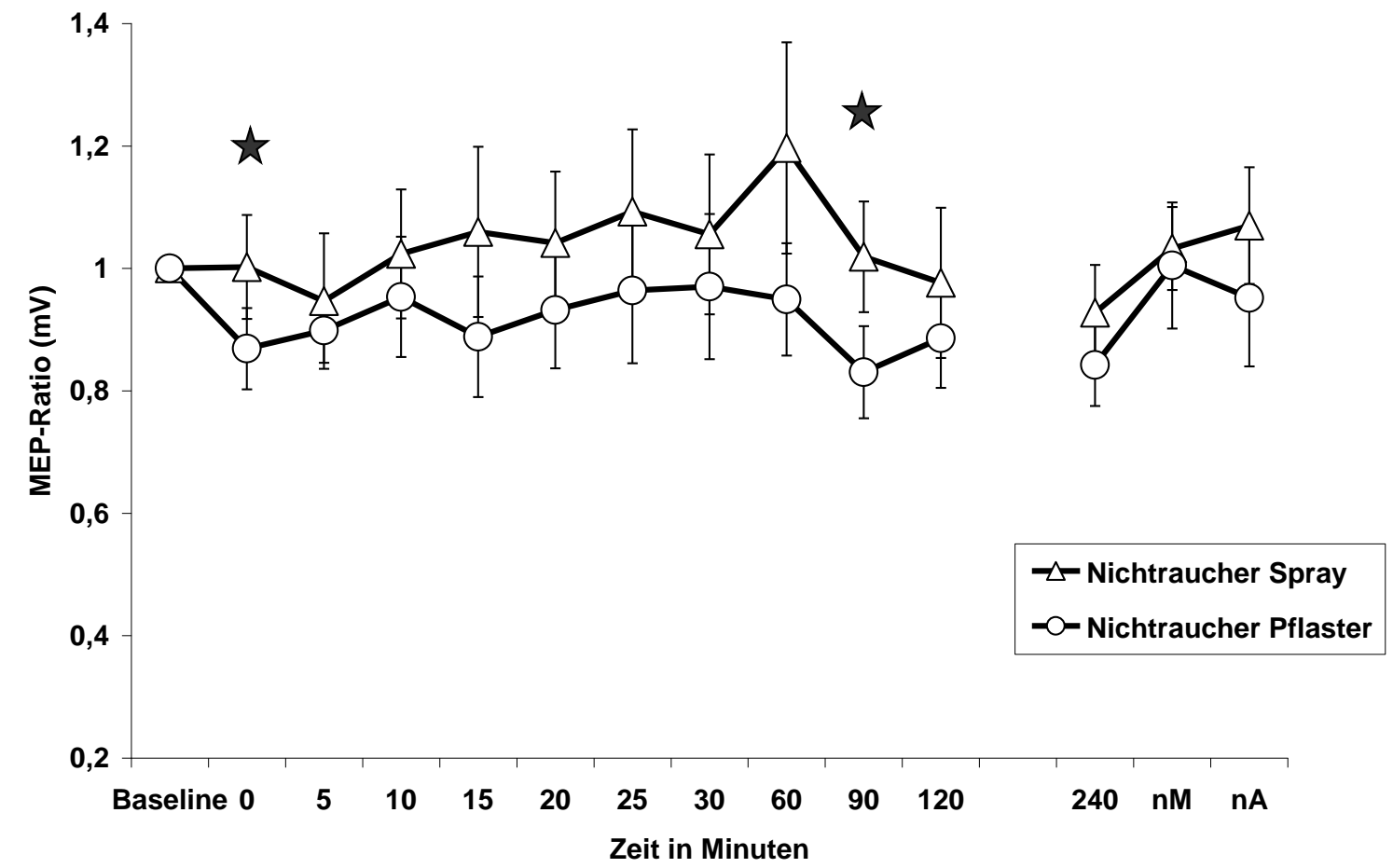

\section{Abbildung 4: Zeitverlauf der MEP-Amplituden bei Nichtrauchern mit Nikotinspray und Nikotinpflaster.}

Dargestellt in der obigen Grafik sind die mittleren MEP-Amplituden +/- Standardfehler (Fehlerbalken) zu den verschiedenen Zeitpunkten im Vergleich zu der MEP-Baseline (MEP-Ratio) bei Anwendung des inhibitorischen PAS-Protokolles bei Nichtrauchern nach Gabe von Nikotinnasenspray und Nikotinpflaster. Die mit einem Stern markierten Symbole stellen signifikante Veränderungen der MEP-Amplituden zwischen Nikotinspray- und Nikotinpflaster-Bedingungen bei identischem Zeitfenster dar. Signifikanzniveau: $p<0,05$.

MEP: Motorisch evoziertes Potential; MEP-Ratio: MEP-Baseline/MEP-Amplitude zu den verschiedenen Zeitpunkten; nA: nächster Abend; nM: nächster Morgen.

\subsubsection{Fazit}

Durch die Anwendung des inhibitorischen PAS-Protokolles kommt es bei Nichtrauchern ohne den Einfluss des neuromodulatorisch wirksamen Nikotins (Grundbedingung) zu einer Abnahme der kortikalen Erregbarkeit. Die inhibitorischen Nacheffekte der PAS werden bei Nichtrauchern durch die Gabe von Nikotin, sowohl in Form von Nikotinspray als auch durch ein Nikotinpflaster, aufgehoben. Zwischen den beiden Applikationsformen, im Sinne von schnell anflutendem Nikotin in Form von Nasenspray gegenüber einem kontinuierlich hohen Nikotinspiegel durch ein 
transdermales Pflaster, ergaben sich nach 0 und nach 90 Minuten nach Stimulation statistisch signifikante Unterschiede.

\subsection{Beeinflussung der PAS-induzierten inhibitorischen kortikalen Erregbarkeitsveränderungen durch Nikotin bei Rauchern}

3.4.1 Untersuchung ohne Nikotin (Grundbedingung)

In dieser Messung wurden die durch das inhibitorische PAS-Protokoll ausgelösten kortikalen Erregbarkeitsveränderungen, operationalisiert durch MEPAmplitudenmessungen, ohne den Einfluss von Nikotin (Grundbedingung) untersucht. Bei den Rauchern zeigte sich ohne Nikotin eine Abnahme der kortikalen Erregbarkeit. Für die durch inhibitorische PAS hervorgerufenen kortikalen Erregbarkeitsveränderungen ohne den Einfluss von Nikotin erbrachten die t-Tests bei Rauchern signifikante Unterschiede in den MEP-Amplituden gegenüber der Baseline bis 20 Minuten nach Stimulation (mit Ausnahme nach 15 Minuten). Fisher's LSD zeigte signifikante Unterschiede nach 5 und nach 20 Minuten. In Abbildung 5 ist der zeitliche Verlauf der MEP-Amplituden für die Grundbedingung ohne Nikotin durch die mit Quadraten verbundene Kurve dargestellt. Die Ergebnisse der gepaarten t-Tests und des Fisher's LSD sind in Tabelle 13 dargestellt.

\subsubsection{Vergleich der Untersuchungen ohne Nikotin und mit Nikotinnasenspray}

In dieser Messung wurde der Einfluss von schnell anflutendendem Nikotin in Form von Nasenspray auf die kortikalen Erregbarkeitsveränderungen, operationalisiert durch MEP-Amplitudenmessungen, im Vergleich zu der Grundbedingung ohne Nikotin untersucht.

Bei den Rauchern ergaben die t-Tests nach der Gabe von Nikotinspray signifikante Unterschiede der MEP-Amplituden gegenüber der Baseline nach 5 und nach 120 Minuten nach Stimulation und dann wieder am nächsten Tag. Fisher's LSD zeigte nur für die Messungen am nächsten Tag signifikante Unterschiede. Die Ergebnisse der gepaarten t-Tests und des Fisher's LSD sind in Tabelle 14 dargestellt.

Die inhibitorischen Effekte der PAS hielten bei Rauchern nach Gabe von Nikotinnasenspray initial kürzer an als bei der Grundbedingung ohne Nikotin, es kam dann jedoch zu einer erneuten spät auftretenden Erregbarkeitsverminderung ab 60 Minuten nach Stimulation bis zum nächsten Abend anhaltend. Mittels gepaarter tTests ließen sich signifikante Unterschiede der MEP-Amplituden zwischen der 
Grund- und der Nikotinspray-Bedingung nach 20 Minuten nachweisen. Fisher's LSD zeigte keine signifikanten Unterschiede zwischen den beiden Bedingungen. Die Ergebnisse der gepaarten t-Tests und des Fisher's LSD sind in Tabelle 15 dargestellt.

Die Abbildung 5 zeigt die Änderung der MEP-Amplituden als Ausdruck der kortikalen Erregbarkeitsveränderungen im zeitlichen Verlauf bei Rauchern ohne Nikotin und nach Gabe von Nikotinspray.

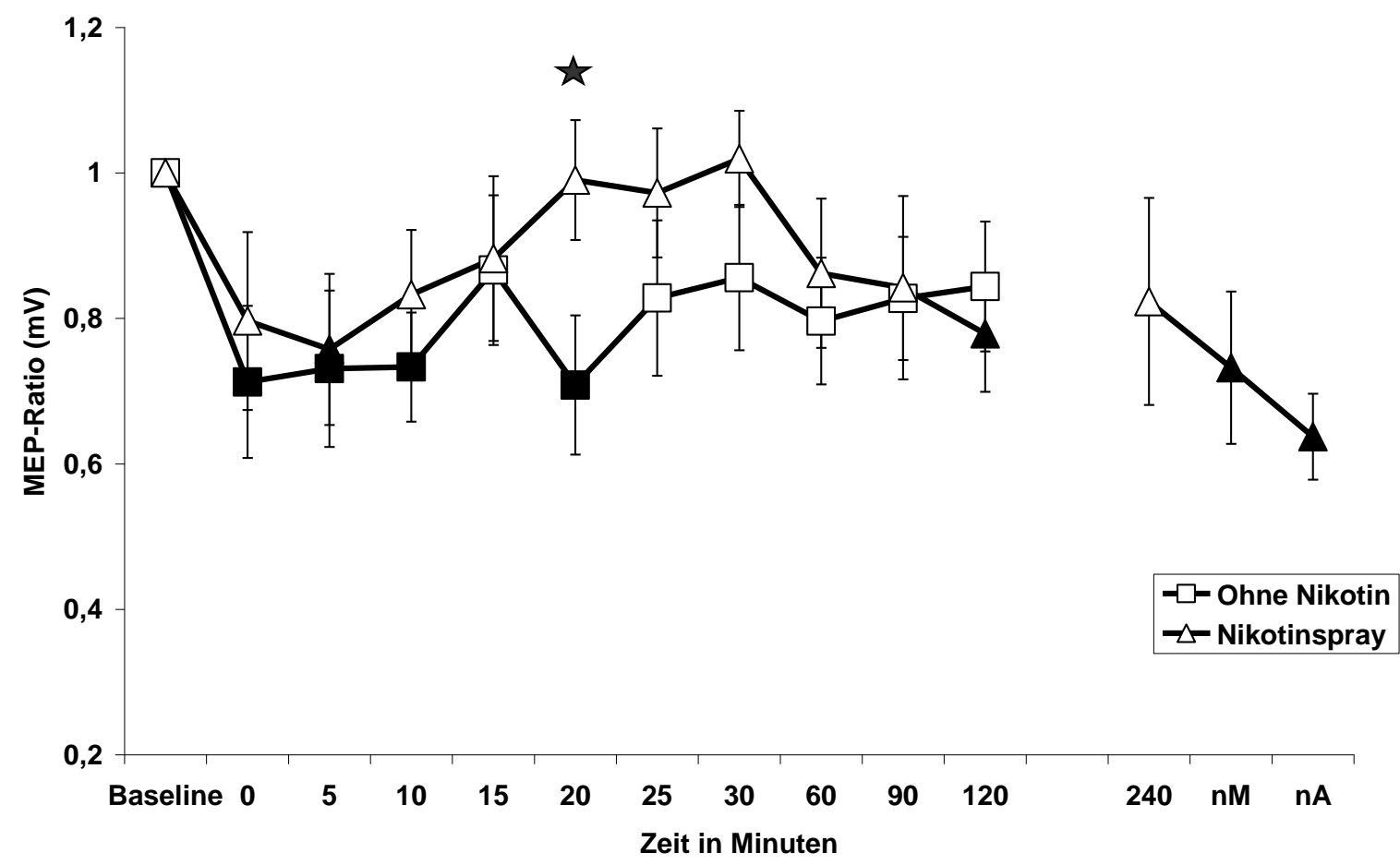

Abbildung 5: Zeitverlauf der MEP-Amplituden bei Rauchern ohne Nikotin und mit Nikotinnasenspray.

Dargestellt in der obigen Grafik sind die mittleren MEP-Amplituden +/- Standardfehler (Fehlerbalken) zu den verschiedenen Zeitpunkten im Vergleich zu der MEP-Baseline (MEP-Ratio) bei Anwendung des inhibitorischen PAS-Protokolles ohne Nikotin und nach Gabe von Nikotinnasenspray. Ausgefüllte Symbole kennzeichnen signifikante Veränderungen der MEP-Amplituden nach inhibitorischer PAS gegenüber Baselineniveau. Die mit einem Stern markierten Symbole stellen signifikante Veränderungen der MEP-Amplitude durch Nikotinnasenspray gegenüber der Grundbedingung ohne Nikotin bei identischem Zeitfenster dar. Signifikanzniveau: $p<0,05$.

MEP: Motorisch evoziertes Potential; MEP-Ratio: MEP-Baseline/MEP-Amplitude zu den verschiedenen Zeitpunkten; nA: nächster Abend; nM: nächster Morgen.

\subsubsection{Vergleich der Untersuchungen ohne Nikotin und mit Nikotinpflaster}

In dieser Messung wurde der Einfluss eines kontinuierlich hohen Nikotinspiegels durch ein transdermales Nikotinpflaster auf die durch das inhibitorische PAS- 
Protokoll ausgelösten kortikalen Erregbarkeitsveränderungen, operationalisiert durch MEP-Amplitudenmessungen, im Vergleich zu der Grundbedingung ohne Nikotin untersucht.

Bei den Rauchern ergaben die t-Tests nach der Applikation des Nikotinpflasters signifikante Unterschiede der MEP-Amplituden gegenüber der Baseline von Minute 10 bis 20 nach der Stimulation und dann wieder nach 90 Minuten bis zum nächsten Morgen anhaltend. Mittels Fisher's LSD ließen sich signifikante Unterschiede nur nach 90 und 120 Minuten nachweisen. Die Ergebnisse der gepaarten t-Tests und des Fisher's LSD sind in Tabelle 16 dargestellt.

Die inhibitorischen Effekte der PAS unterscheiden sich bei Rauchern nach Applikation des Nikotinpflasters im Vergleich zu der Grundbedingung ohne Nikotin initial nicht, allerdings zeigt sich unter Nikotinpflaster-Bedingungen eine erneute spät auftretende Erregbarkeitsverminderung. In den gepaarten t-Tests und dem Fisher's LSD war der Unterschied der MEP-Amplituden zu den verschiedenen Zeitpunkten ohne Nikotin und nach Applikation eines Nikotinpflasters bei Rauchern jedoch statistisch nicht signifikant. Die Ergebnisse der gepaarten t-Tests und des Fisher's LSD sind in Tabelle 17 dargestellt. Die Abbildung 6 zeigt die Änderungen der MEPAmplituden als Ausdruck der kortikalen Erregbarkeitsveränderungen im zeitlichen Verlauf bei Rauchern ohne Nikotin und nach Applikation eines Nikotinpflasters. 


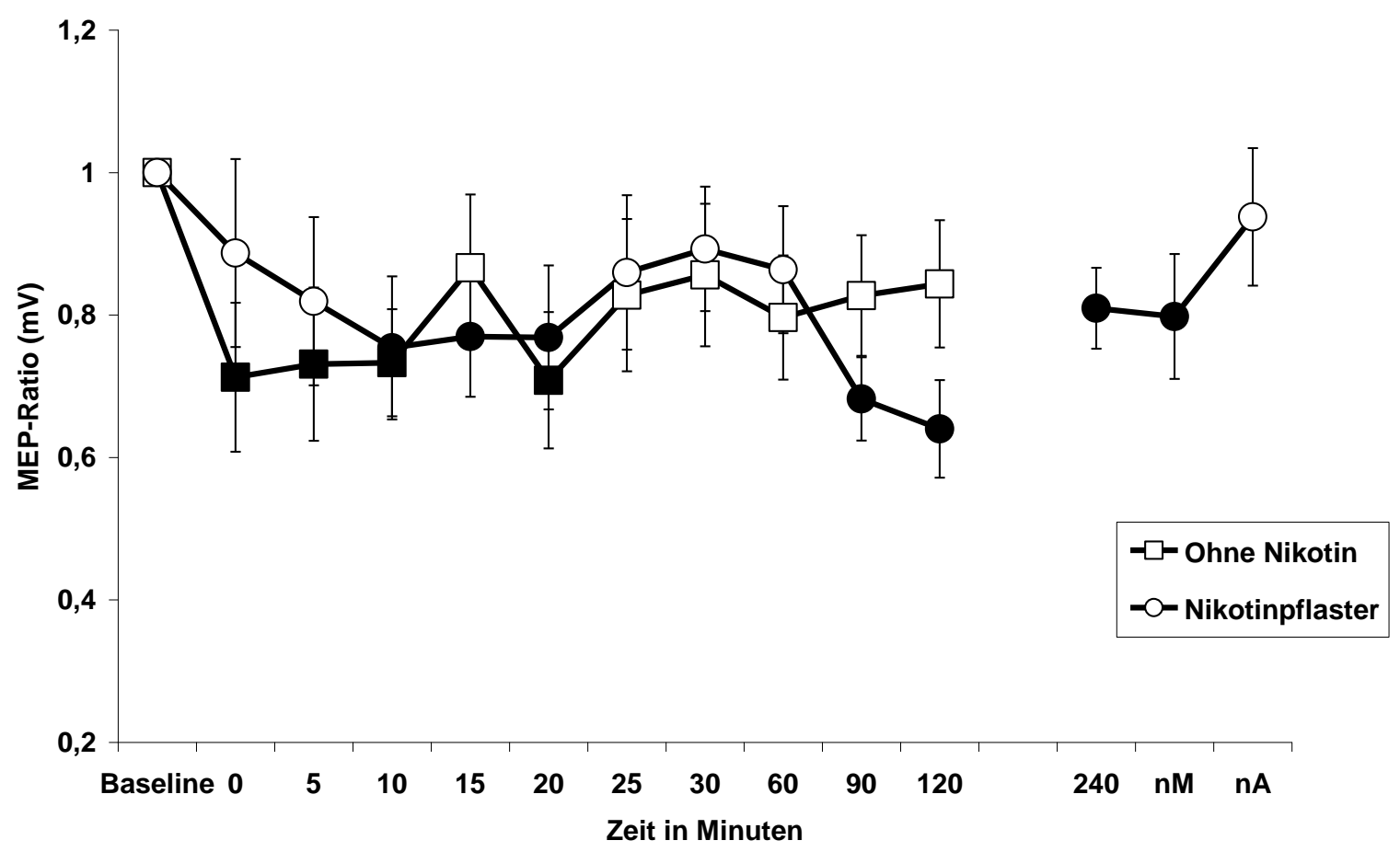

\section{Abbildung 6: Zeitverlauf der MEP-Amplituden bei Rauchern ohne Nikotin und mit Nikotinpflaster.}

Dargestellt in der obigen Grafik sind die mittleren MEP-Amplituden +/- Standardfehler (Fehlerbalken) zu den verschiedenen Zeitpunkten im Vergleich zu der MEP-Baseline (MEP-Ratio) bei Anwendung des inhibitorischen PAS-Protokolles ohne Nikotin und nach Applikation eines Nikotinpflasters. Ausgefüllte Symbole kennzeichnen signifikante Veränderungen der MEP-Amplituden nach inhibitorischer PAS gegenüber Baselineniveau. Bei Rauchern stellten sich keine signifikanten Veränderungen der MEP-Amplituden durch Nikotinpflaster gegenüber der Grundbedingung ohne Nikotin bei identischem Zeitfenster dar. Signifikanzniveau: $p<0,05$.

MEP: Motorisch evoziertes Potential; MEP-Ratio: MEP-Baseline/MEP-Amplitude zu den verschiedenen Zeitpunkten; nA: nächster Abend; nM: nächster Morgen.

\subsubsection{Vergleich der Untersuchungen mit Nikotinspray und Nikotinpflaster} In dieser Messung wurde der Einfluss von schnell anflutendem Nikotin in Form von Nasenspray im Vergleich zu einem kontinuierlich hohen Nikotinspiegel durch ein transdermales Pflaster auf die durch das inhibitorische PAS-Protokoll ausgelösten kortikalen Erregbarkeitsveränderungen, operationalisiert durch MEPAmplitudenmessungen, untersucht.

Nach Applikation eines Nikotinpflasters zeigte sich bei den Rauchern von 10 bis 20 Minuten nach Stimulation eine Abnahme der MEP-Amplituden, die nach Gabe von Nikotinspray nicht nachgewiesen werden konnte. Dieser unterschiedliche Trend war jedoch statistisch nicht signifikant. Erst am nächsten Abend ergab sich zwischen den beiden verschiedenen Nikotinapplikationsformen sowohl bei den t-Tests als auch 
beim Fisher's LSD ein statistisch signifikanter Unterschied in den MEP-Amplituden, da es unter der Nikotinspray-Bedingung zu einer erneuten kortikalen Inhibition kam, während unter Nikotinpflaster-Bedingung die MEP-Amplituden am nächsten Abend wieder Baseline-Niveau erreichten. Die Ergebnisse der gepaarten t-Tests und des Fisher's LSD sind in Tabelle 18 dargestellt. Die Abbildung 7 zeigt die Änderung der MEP-Amplituden als Ausdruck der kortikalen Erregbarkeitsveränderungen im zeitlichen Verlauf bei Rauchern nach Gabe von Nikotinspray und Nikotinpflaster.

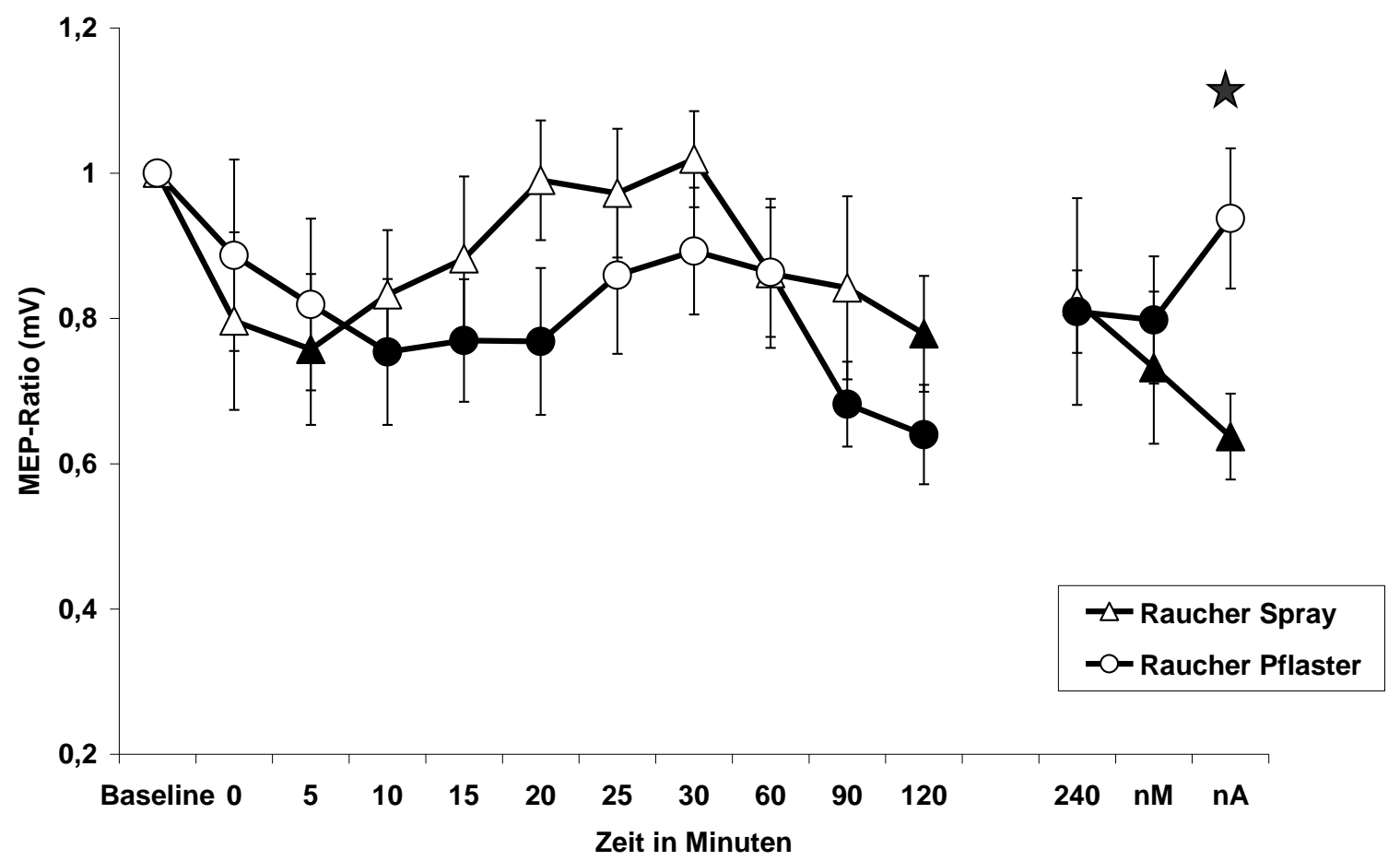

\section{Abbildung 7: Zeitverlauf der MEP-Amplituden bei Rauchern mit Nikotinspray und Nikotinpflaster.}

Dargestellt in der obigen Grafik sind die mittleren MEP-Amplituden +/- Standardfehler (Fehlerbalken) zu den verschiedenen Zeitpunkten im Vergleich zu der MEP-Baseline (MEP-Ratio) bei Anwendung des inhibitorischen PAS-Protokolles bei Rauchern nach Gabe von Nikotinnasenspray und Nikotinpflaster. Ausgefüllte Symbole kennzeichnen signifikante Veränderungen der MEP-Amplituden nach inhibitorischer PAS gegenüber Baselineniveau. Die mit einem Stern markierten Symbole stellen signifikante Unterschiede der MEP-Amplituden zwischen Nikotinspray- und Nikotinpflaster-Bedingungen bei identischem Zeitfenster dar. Signifikanzniveau: $p<$ 0,05 .

MEP: Motorisch evoziertes Potential; MEP-Ratio: MEP-Baseline/MEP-Amplitude zu den verschiedenen Zeitpunkten; nA: nächster Abend; nM: nächster Morgen.

\subsubsection{Fazit}

Durch die Anwendung des inhibitorischen PAS-Protokolles kommt es bei Rauchern ohne den Einfluss des neuromodulatorisch wirksamen Nikotins (Grundbedingung) zu 
einer Abnahme der kortikalen Erregbarkeit. Die inhibitorischen Nacheffekte der PAS hielten nach Gabe von Nikotinspray initial kürzer an, während es durch die Applikation eines Nikotinpflasters in den ersten 60 Minuten nach Stimulation zu keinen signifikanten Unterschieden im Vergleich zu der Grundbedingung kam. Sowohl durch Nikotinspray als auch durch Nikotinpflaster kam es bei den Rauchern zu einer später erneut auftretenden Abnahme der kortikalen Erregbarkeit im Vergleich zur Grundbedingung. Dieser unterschiedliche zeitliche Verlauf bei den verschiedenen Bedingungen ist jedoch, mit Ausnahme des Vergleichs von Grundbedingung und Nikotinspray nach 20 Minuten, statistisch nicht signifikant. Zwischen den beiden Applikationsformen, im Sinne von schnell anflutendem Nikotin in Form von Nasenspray gegenüber einem kontinuierlich hohen Nikotinspiegel durch ein transdermales Pflaster, ergab sich nur am nächsten Abend nach Stimulation ein statistisch signifikanter Unterschied.

\subsection{Vergleich der Beeinflussung der PAS-induzierten inhibitorischen kortikalen Erregbarkeitsveränderungen durch Nikotin bei Nichtrauchern und Rauchern}

\subsubsection{Untersuchung ohne Nikotin (Grundbedingung)}

Im Vergleich der beiden Gruppen stellt sich unter der Grundbedingung ohne Nikotin deskriptiv eine länger anhaltende kortikale Inhibition bei den Nichtrauchern (Änderungen der MEP-Amplitude bis 120 Minuten nach Stimulation) als bei den Rauchern (Änderungen der MEP-Amplitude nur bis 20 Minuten nach Stimulation) im Vergleich zu den Baseline-Werten dar. Dieser Unterschied zwischen den beiden Gruppen war allerdings sowohl in den unabhängigen t-Tests als auch im Fisher's LSD statistisch nicht signifikant. Die Ergebnisse der ungepaarten t-Tests und des Fisher's LSD sind in Tabelle 19 dargestellt. In Abbildung 8 sind die Veränderungen der MEP-Amplituden als Ausdruck der kortikalen Erregbarkeitsveränderungen unter den Grundbedingungen ohne Nikotin im zeitlichen Verlauf für die Nichtraucher und die Raucher im Vergleich dargestellt. 


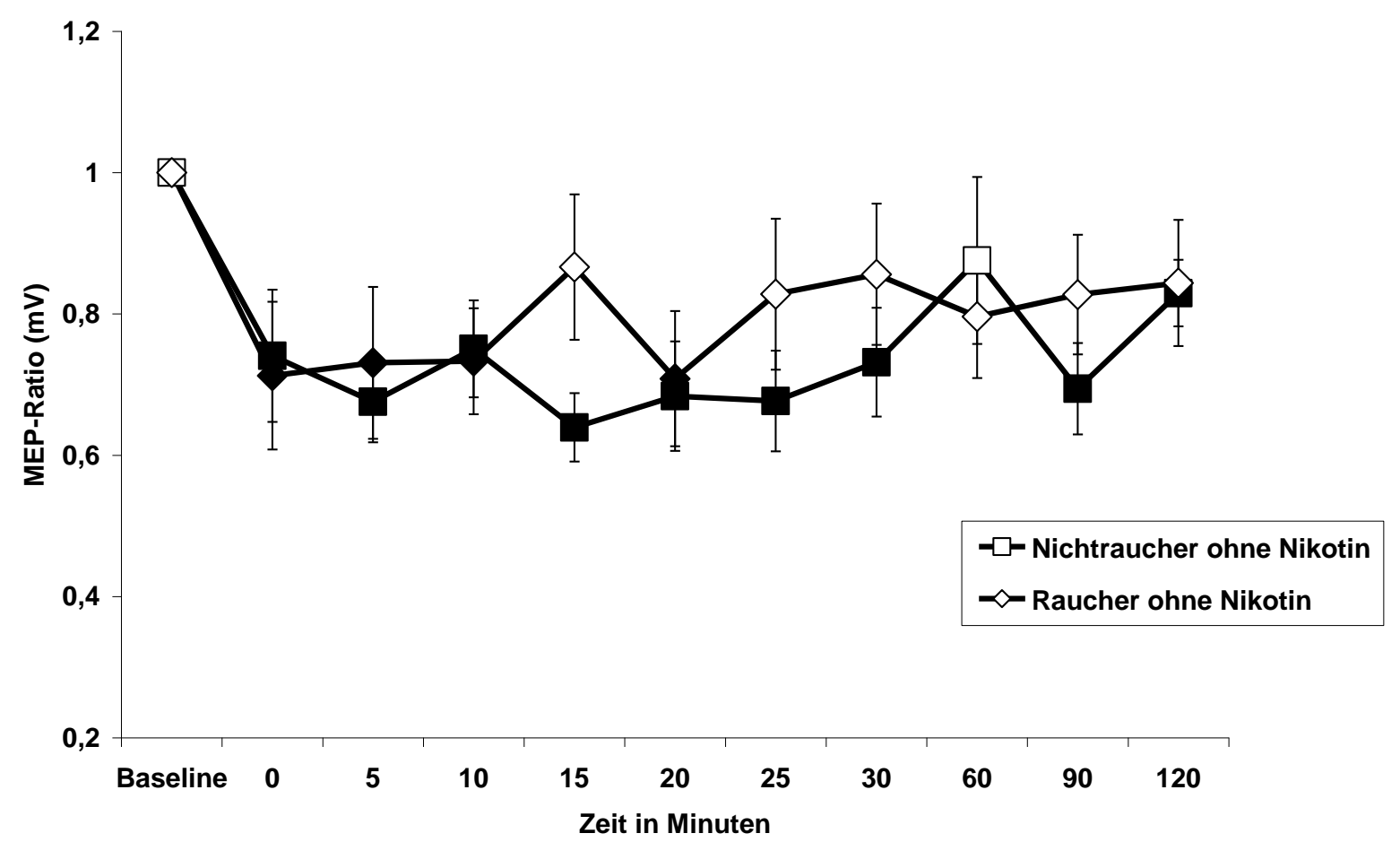

Abbildung 8: Zeitverlauf der MEP-Amplituden ohne Nikotin im Vergleich von Rauchern und Nichtrauchern.

Dargestellt in der obigen Grafik sind die mittleren MEP-Amplituden +/- Standardfehler (Fehlerbalken) zu den verschiedenen Zeitpunkten im Vergleich zu der MEP-Baseline (MEP-Ratio) bei Anwendung des inhibitorischen PAS-Protokolles ohne Nikotin. Ausgefüllte Symbole kennzeichnen signifikante Veränderungen der MEPAmplituden nach inhibitorischer PAS gegenüber Baselineniveau. Signifikante Unterschiede zwischen Rauchern und Nichtrauchern fanden sich ohne Nikotin nicht. Signifikanzniveau: $p<0,05$.

MEP: Motorisch evoziertes Potential; MEP-Ratio: MEP-Baseline/MEP-Amplitude zu den verschiedenen Zeitpunkten; nA: nächster Abend; nM: nächster Morgen.

\subsubsection{Untersuchung mit Nikotinnasenspray}

Nach Applikation von Nikotinnasenspray zeigen die Raucher eine kurz anhaltende und später erneut auftretende kortikale Inhibition, während die Nichtraucher keine signifikanten inhibitorischen Erregbarkeitsveränderungen ausbilden. Die Auswirkungen von Nikotinnasenspray auf die inhibitorischen Nacheffekte der PAS unterscheiden sich bei Rauchern und Nichtrauchern am Tag der Stimulation nicht signifikant, jedoch zeigen die Raucher am Folgetag der Stimulation eine kortikale Inhibition, die bei Nichtrauchern nicht nachzuweisen ist. Für die inhibitorischen Nacheffekte der PAS unter Nikotinnasenspray zeigten die unabhängigen t-Tests und der Fisher's LSD am nächsten Morgen und am nächsten Abend nach der Stimulation einen statistisch signifikanten Unterschied der MEP-Amplituden von Rauchern und Nichtrauchern. Fisher's LSD erbrachte zudem 60 Minuten nach Stimulation einen 
signifikanten Unterschied zwischen Rauchern und Nichtrauchern. Die Ergebnisse der unabhängigen t-Tests und des Fisher's LSD sind in Tabelle 20 dargestellt. In Abbildung 9 sind die Veränderungen der MEP-Amplituden als Ausdruck der kortikalen Erregbarkeitsveränderungen nach Gabe von Nikotinspray im zeitlichen Verlauf für die Nichtraucher und die Raucher im Vergleich dargestellt.

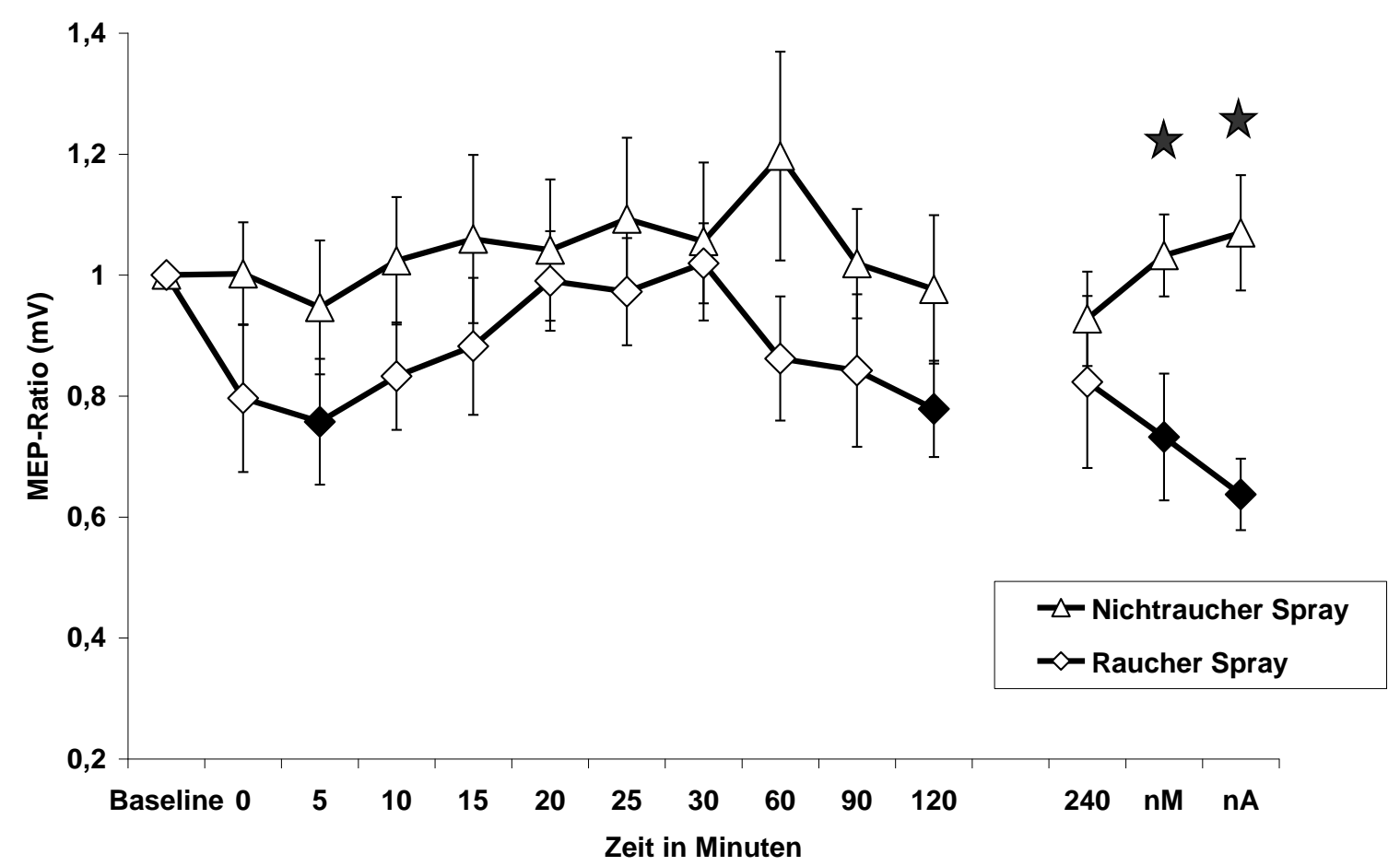

Abbildung 9: Zeitverlauf der MEP-Amplituden im Vergleich von Rauchern und Nichtrauchern nach Gabe von Nikotinnasenspray.

Dargestellt in der obigen Grafik sind die mittleren MEP-Amplituden +/- Standardfehler (Fehlerbalken) zu den verschiedenen Zeitpunkten im Vergleich zu der MEP-Baseline (MEP-Ratio) bei Anwendung des inhibitorischen PAS-Protokolles nach Gabe von Nikotinnasenspray. Ausgefültte Symbole kennzeichnen signifikante Veränderungen der MEP-Amplituden nach inhibitorischer PAS gegenüber Baselineniveau. Die mit einem Stern markierten Symbole stellen signifikante Veränderungen der MEP-Amplituden zwischen Rauchern und Nichtrauchern nach Gabe von Nikotinnasenspray dar. Signifikanzniveau: $p<0,05$.

MEP: Motorisch evoziertes Potential; MEP-Ratio: MEP-Baseline/MEP-Amplitude zu den verschiedenen Zeitpunkten; nA: nächster Abend; nM: nächster Morgen.

\subsubsection{Untersuchung mit Nikotinpflaster}

Nach Applikation eines transdermalen Nikotinpflasters zeigen die Raucher eine kortikale Inhibition, während die Nichtraucher keine signifikanten inhibitorischen Erregbarkeitsveränderungen ausbilden. Die Auswirkungen des transdermalen Nikotinpflasters auf die inhibitorischen Nacheffekte der PAS zeigen Unterschiede zwischen Rauchern und Nichtrauchern. Diese sind im t-Test nach 120 Minuten 
statistisch signifikant. Mittels Fisher's LSD ließen sich über den gesamten Zeitraum keine statistisch signifikanten Unterschiede zwischen Rauchern und Nichtrauchern nachweisen. Die Ergebnisse der unabhängigen t-Tests und des Fisher's LSD sind in Tabelle 21 dargestellt. In Abbildung 10 sind die Veränderungen der MEP-Amplituden als Ausdruck der kortikalen Erregbarkeitsveränderungen nach Applikation eines Nikotinpflasters im zeitlichen Verlauf für die Nichtraucher und die Raucher im Vergleich dargestellt.

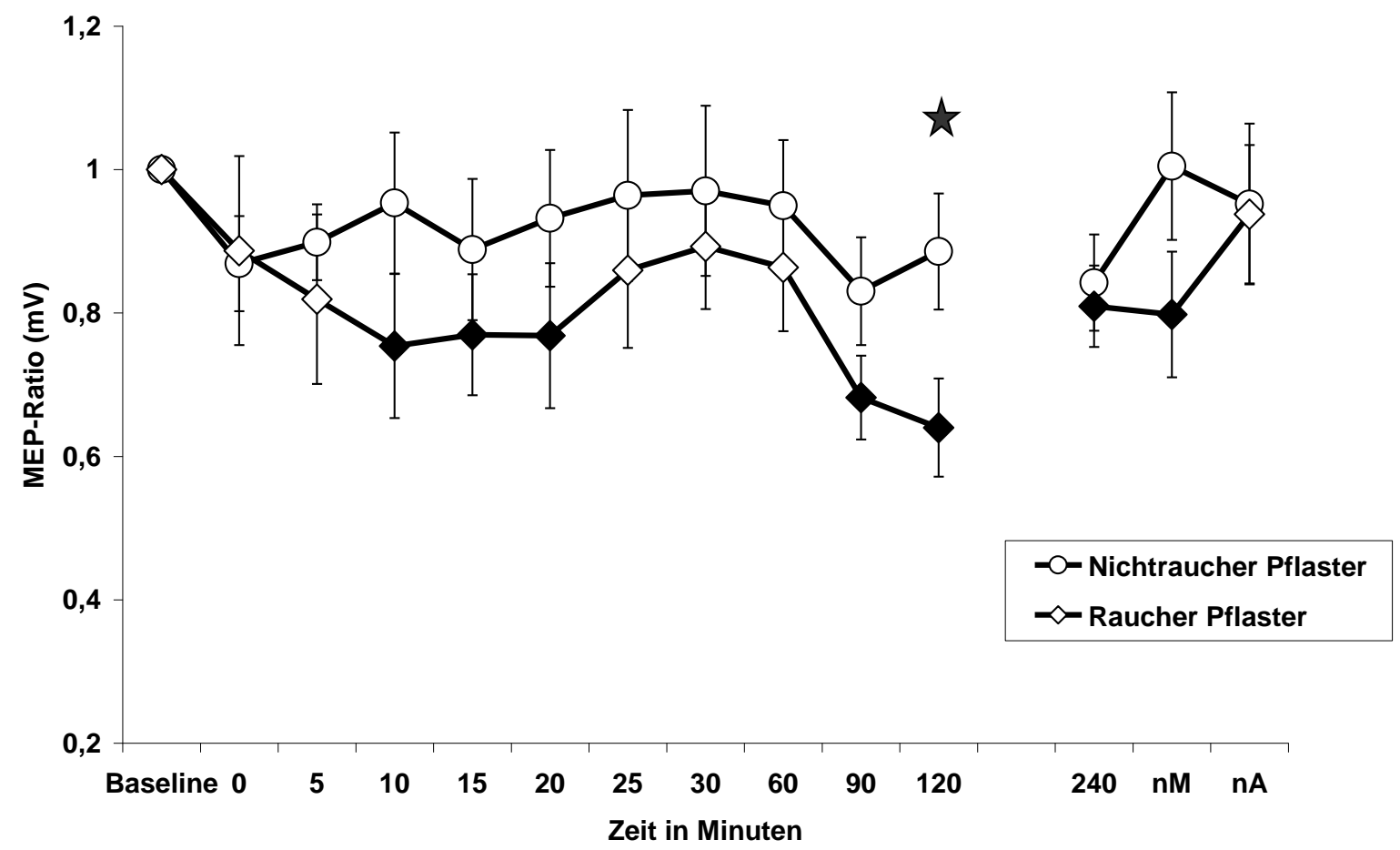

Abbildung 10: Zeitverlauf der MEP-Amplituden im Vergleich von Rauchern und Nichtrauchern nach Applikation eines Nikotinpflasters.

Dargestellt in der obigen Grafik sind die mittleren MEP-Amplituden +/- Standardfehler (Fehlerbalken) zu den verschiedenen Zeitpunkten im Vergleich zu der MEP-Baseline (MEP-Ratio) bei Anwendung des inhibitorischen PAS-Protokolles nach Applikation eines Nikotinpflasters. Ausgefüllte Symbole kennzeichnen signifikante Veränderungen der MEP-Amplituden nach inhibitorischer PAS gegenüber Baselineniveau. Die mit einem Stern markierten Symbole stellen signifikante Unterschiede zwischen Rauchern und Nichtrauchern nach Applikation eines Nikotinpflasters bei identischem Zeitfenster dar. Signifikanzniveau: $p<0,05$.

MEP: Motorisch evoziertes Potential; MEP-Ratio: MEP-Baseline/MEP-Amplitude zu den verschiedenen Zeitpunkten; nA: nächster Abend; nM: nächster Morgen.

\subsubsection{Fazit}

Ohne Nikotin zeigen sowohl Raucher als auch Nichtraucher die Fähigkeit zur Ausbildung von inhibitorischen kortikalen Erregbarkeitsveränderungen. Eine signifikante Erregbarkeitsverminderung gegenüber der Baseline zeigt sich bei 
Nichtrauchern fast über den gesamten Messzeitraum und ist bei Rauchern mit einer geringeren Effektivität und kürzer anhaltend nachzuweisen. Es zeigten sich keine signifikanten Unterschiede zwischen Rauchern und Nichtrauchern zu den einzelnen Zeitpunkten nach inhibitorischer PAS, so dass dem Raucherstatus allein nur ein schwacher Effekt zufällt.

Bei Nichtrauchern werden die inhibitorischen Nacheffekte der PAS durch die Gabe von Nikotinspray aufgehoben, während sie bei Rauchern initial kürzer anhalten, dann jedoch später erneut auftreten. Am Tag der Stimulation reagieren Raucher und Nichtraucher auf die Gabe von Nikotinspray nicht signifikant unterschiedlich, jedoch kommt es am Folgetag zu signifikanten Unterschieden zwischen den beiden Gruppen.

Während bei Nichtrauchern die Fähigkeit zur Ausbildung von inhibitorischen kortikalen Erregbarkeitsveränderungen durch die Applikation eines Nikotinpflasters vermindert wird, sind die inhibitorischen Nacheffekte der PAS bei Rauchern initial kürzer anhaltend, treten später jedoch erneut auf. Dieses unterschiedliche Ansprechen von Rauchern und Nichtrauchern auf die inhibitorische PAS nach Applikation eines Nikotinpflasters ist im t-Test nach 120 Minuten statistisch signifikant.

Da die Auswirkungen des Nikotins keine wesentlichen Unterschiede in Bezug auf die Verabreichungsweise in Form von Nasenspray oder transdermalem Pflaster zeigten, wird im Folgenden nicht mehr zwischen den verschiedenen Nikotinapplikationsformen unterschieden.

Da sich die Ergebnisse der explorativen t-Tests und des für multiple Paarvergleiche korrigierten Fisher's LSD nur geringfügig voneinander unterscheiden, beziehen sich die folgenden Aussagen auf die Ergebnisse der t-Tests. 


\section{Diskussion}

Die Ergebnisse dieser Studie zeigen, dass Nikotin einen Einfluss auf die Ausbildung von lang anhaltenden inhibitorischen kortikalen Erregbarkeitsveränderungen hat. Die bei Nichtrauchern ohne Nikotineinfluss durch das inhibitorische PAS-Protokoll ausgelöste kortikale Erregbarkeitsabnahme wird durch die Gabe von Nikotin vermindert bzw. aufgehoben. Bei Rauchern zeigte sich im Nikotinentzug ebenfalls eine kortikale Erregbarkeitsverminderung, die nach Nikotingabe initial kürzer anhielt, dann jedoch später erneut auftrat. Es ist daher anzunehmen, dass die Fähigkeit zur Ausbildung von inhibitorischen kortikalen Erregbarkeitsveränderungen durch langjährigen Nikotinkonsum beeinflusst wird. Auch wenn der genaue Mechanismus des Nikotineinflusses auf die kortikalen Erregbarkeitsveränderungen noch nicht vollständig geklärt ist, werden im Folgenden mögliche Wirkmechanismen und Einflussfaktoren auf die Messergebnisse genauer erläutert.

\subsection{Beeinflussung der PAS-induzierten inhibitorischen kortikalen Erregbarkeitsveränderungen durch Nikotin bei Nichtrauchern}

In unserer Studie kam es bei den Nichtrauchern nach Anwendung des inhibitorischen PAS-Protokolles ohne den Einfluss von Nikotin zu einer Abnahme der MEPAmplituden über einen Zeitraum von zwei Stunden. Unsere Ergebnisse entsprechen damit denen aus vorangegangenen Studien zur PAS ohne Medikamenteneinfluss (Stefan et al. 2000; Wolters et al. 2003). Unter Nikotineinfluss zeigten die MEPAmplituden gegenüber der Baseline keine signifikanten Änderungen nach Anwendung des inhibitorischen PAS-Protokolles, was einer verminderten bzw. fehlenden Ausbildung von inhibitorischer Neuroplastizität entspricht. Die Nichtraucher verloren also durch die Verabreichung von Nikotin in Form von Nasenspray oder transdermalem Pflaster die Fähigkeit zur Ausbildung inhibitorischer kortikaler Erregbarkeitsveränderungen. Diese verminderte Fähigkeit zur Ausbildung inhibitorischer kortikaler Erregbarkeitsveränderungen unter Nikotineinfluss zeigt sich auch im direkten Vergleich der MEP-Amplituden mit und ohne Nikotin zu den jeweiligen Zeitpunkten, die sich in signifikant unterschiedlichen Werten der MEPAmplituden an den jeweils selben Zeitpunkten darstellt. Gegenüber der Grundbedingung ohne Nikotin waren die MEP-Amplituden unter dem Einfluss eines Nikotinpflasters bis 30 Minuten nach Stimulation signifikant unterschiedlich, bei der 
Messung mit Nikotinspray zeigte sich sogar, mit Ausnahme nach 10 und nach 60 Minuten, bis 90 Minuten nach Stimulation ein signifikanter Unterschied.

Für die Auswirkungen des Nikotins auf die inhibitorischen kortikalen Erregbarkeitsveränderungen scheinen die Beeinflussung und Veränderung der intrazellulären Kalzium-Konzentration von Bedeutung zu sein. Die durch PAS ausgelösten Nacheffekte sind Kalzium-abhängig (Stefan et al. 2002) und für die Ausbildung von Neuroplastizität spielen intrazelluläre Kalzium-Konzentrationen eine wichtige Rolle, wobei hier vor allem die Höhe der intrazellulären KalziumKonzentration von Bedeutung ist. Eine leichtgradige Erhöhung führt zu LTD, eine starke Erhöhung zu LTP, während mittelgradige intrazelluläre Kalzium-Erhöhungen keine Plastizität zur Folge haben (Lisman 2001). Durch die Anwendung des inhibitorischen PAS-Protokolles werden vermutlich intrazelluläre KalziumKonzentrationen erreicht, die eine Verminderung der kortikalen Exzitabilität im Sinne eines LTD-Mechanismus zur Folge haben. Da auch Nikotin durch die Aktivierung nikotinerger a7-Rezeptoren über direkte und indirekte Mechanismen zu einer Erhöhung der intrazellulären Kalzium-Konzentration führt (Broide und Leslie 1999), kann durch zusätzliche Nikotingabe die Kalzium-Konzentration in einen Bereich gelangen, durch die weder LTP noch LTD ausgelöst wird, das so genannte no man's land (Lisman 2001). Nach dieser Hypothese läge die intrazelluläre KalziumKonzentration bei Nichtrauchern ohne Nikotineinfluss in einem Bereich, der LTD auslöst, während es durch den Nikotin-vermittelten zusätzlichen Kalzium-Einstrom zu einer Verschiebung des Systems in Richtung no man's land, ohne nachfolgende Veränderungen der Plastizität, kommt (Grundey et al. 2012 a; Thirugnanasambandam et al. 2011 a).

Durch dieses Erklärungsmodell ließen sich auch die unterschiedlichen Effekte von nikotinergem und globalem cholinergen Einfluss auf die inhibitorische Plastizität erklären. Kuo und Mitarbeiter konnten durch den Einsatz des Acetylcholinesterasehemmers Rivastigmin eine Verlängerung der durch PAS induzierten inhibitorischen kortikalen Erregbarkeitsveränderungen nachweisen (Kuo et al. 2007). Da durch Rivastigmin neben nikotinergen auch muskarinerge Acetylcholin-Rezeptoren beeinflusst werden und über letztere spannungsabhängige Kalzium-Kanäle inhibiert werden (Brown 2010), kann dieser Mechanismus einer starken Erhöhung der intrazellulären Kalzium-Konzentration durch nikotinerge 
Rezeptoren, und damit einer Verschiebung des Systems in Richtung no man's land entgegen wirken (Thirugnanasambandam et al. 2011 a).

\subsection{Beeinflussung der PAS-induzierten inhibitorischen kortikalen Erregbarkeitsveränderungen durch Nikotin bei Rauchern}

In unserer Studie kam es bei den Rauchern nach Anwendung des inhibitorischen PAS-Protokolles ohne den Einfluss von Nikotin zu einer Abnahme der MEPAmplituden über einen Zeitraum von 20 Minuten (mit Ausnahme nach 15 Minuten). Damit waren die kortikalen Erregbarkeitsveränderungen, sowohl im Vergleich zu den Nichtrauchern in unserer Studie als auch zu den Probandenkollektiven in verschiedenen Voruntersuchungen (Stefan et al. 2000; Wolters et al. 2003), bei denen Plastizitätsveränderungen von 60 bis 90 Minuten nach Stimulation auftraten, kürzer anhaltend. Durch die Verabreichung von Nikotin in Form von Nasenspray oder transdermalem Pflaster hielten die durch das PAS-Protokoll ausgelösten inhibitorischen Nacheffekte initial kürzer an, traten später jedoch erneut auf. Nach der Gabe von Nikotinnasenspray zeigten sich nach 5 und nach 120 Minuten sowie am nächsten Tag signifikante Unterschiede in den MEP-Amplituden gegenüber der Baseline. Nach Applikation des Nikotinpflasters waren signifikante Unterschiede von 10 bis 20 Minuten nach Stimulation und erneut von 90 Minuten nach Stimulation bis zum nächsten Morgen nachweisbar. Außer 20 Minuten nach der Gabe von Nikotinspray war der Unterschied zwischen der Grundbedingung ohne Nikotin und der Nikotingabe statistisch allerdings nicht signifikant.

Durch chronischen Nikotinkonsum kommt es zu einer Desensibilisierung der nAChRezeptoren (Quick und Lester 2002). Durch Desensibilisierung der Rezeptoren bei Rauchern sprechen diese auf Nikotin nicht so ausgeprägt an wie bei Nichtrauchern. Die Rezeptor-Desensibilisierung ist von der Dauer des Nikotinkonsums abhängig (Lester und Dani 1994) und je nach Verteilung der Rezeptor-Subtypen in verschiedenen Hirnregionen unterschiedlich stark ausgeprägt (Wooltorton et al. 2003). Diese Erkenntnisse können als Erklärung für die schlechter ausgeprägte Fähigkeit zur Ausbildung von inhibitorischen kortikalen Erregbarkeitsveränderungen bei Rauchern im Nikotinentzug heran gezogen werden, da durch chronischen Nikotinkonsum die nAChR desensibilisiert sind und daher der für die Ausbildung von kortikalen Erregbarkeitsveränderungen erforderliche Kalzium-Einstrom vermindert ist. Durch die zusätzliche Gabe von Nikotin wird durch Überstimulation der Rezeptoren der bei Rauchern pathologisch erniedrigte Kalzium-Einstrom erhöht, wodurch die 
partielle Restitution der inhibitorischen Nacheffekte durch die Nikotingabe erklärt wäre (Grundey et al. 2012 a).

\subsection{Vergleich der Beeinflussung der PAS-induzierten inhibitorischen kortikalen Erregbarkeitsveränderungen durch Nikotin bei Nichtrauchern und Rauchern}

In unserer Studie zeigten beide Gruppen eine kortikale Inhibition nach alleiniger Anwendung des inhibitorischen PAS-Protokolles (Grundbedingung), wobei diese bei Nichtrauchern deutlich stärker ausgeprägt war und länger anhielt als bei den Rauchern. Nach der Gabe von Nikotinnasenspray fand sich zwischen den beiden Gruppen am Tag der Stimulation kein signifikanter Unterschied, jedoch kam es am Folgetag bei den Rauchern zu einer erneuten kortikalen Erregbarkeitsabnahme, während die Nichtraucher keine Inhibition mehr zeigten. Nach der Applikation eines Nikotinpflasters bildeten die Nichtraucher keine inhibitorischen kortikalen Erregbarkeitsveränderungen aus, während die Raucher eine starke kortikale Inhibition zeigten. Somit scheint sich unsere initiale Annahme, dass Raucher mit Nikotin ähnlich auf inhibitorische Stimulationsprotokolle reagieren wie Nichtraucher ohne Nikotin, zu bestätigen.

Als Erklärung kann erneut die Hypothese von Lisman (2001) herangezogen werden. Demnach käme es durch die alleinige Anwendung des inhibitorischen PASProtokolles zu einer leichten Erhöhung der intrazellulären Kalzium-Konzentration und damit zur Auslösung von LTD bei beiden Gruppen. Der durch die Nikotingabe zusätzliche Kalzium-Einstrom über nikotinerge AChR führt bei Nichtrauchern zu einer mittelgradigen Erhöhung der intrazellulären Kalzium-Konzentration und damit zu einer Verschiebung des Systems in Richtung no man's land ohne nachfolgende Erregbarkeitsveränderungen (Thirugnanasambandam et al. 2011 a). Aufgrund der durch den chronischen Nikotinkonsum desensibilisierten Rezeptoren ist der durch eine zusätzliche Nikotingabe ausgelöste intrazelluläre Kalzium-Einstrom bei Rauchern geringer, so dass durch die nur leichte Erhöhung der intrazellulären Kalzium-Konzentration weiterhin eine kortikale Erregbarkeitsverminderung ausgelöst wird, die initial kürzer anhält, aber nicht ganz aufgehoben wird (Grundey et al. 2012 a).

Eine weitere mögliche Erklärung für das im Gegensatz zu Nichtrauchern nur kurzzeitige Ansprechen von Rauchern im Nikotinentzug auf das inhibitorische PASProtokoll könnte die Tatsache sein, dass trotz vorheriger zehnstündiger 
Nikotinkarenz residuelle Konzentrationen von Nikotin und dessen Metaboliten im Gehirn von Rauchern zu finden sind und die Stimulationsergebnisse daher mit beeinflussen. Ghosheh und Mitarbeiter konnten mit Versuchen an Ratten zeigen, dass es durch wiederholte Nikotingabe zu einer Akkumulation von Nikotin und dessen Metaboliten Cotinin und Nornicotin im Gehirn kommt und so die Konzentration von Nikotin im Gehirn diejenige im peripheren Blut um ein vielfaches übersteigt (Ghosheh et al. 2001). Möglicherweise liegen durch ständige niederschwellige Aktivierung von nAChR durch residuelle Nikotinkonzentrationen die Kalzium-Konzentrationen bei Rauchern von vornherein höher, und damit eher in Richtung no man's land (Lisman 2001), so dass ohne Nikotin die kortikalen Erregbarkeitsveränderungen bei Rauchern durch die inhibitorische PAS nicht so ausgeprägt sind wie bei Nichtrauchern. Durch die Nikotinkarenz fallen die residuellen Nikotinspiegel am Folgetag zunehmend ab, so dass nur noch die durch die PAS ausgelöste leichtgradige Erhöhung der Kalzium-Konzentration besteht, womit die am Folgetag der Stimulation erneut auftretende kortikale Erregbarkeitsabnahme erklärt wäre.

Da der Desensibilisierung von verschiedenen nAChR-Subtypen eine wichtige Rolle bei der Entstehung und Ausprägung von Neuroplastizität zuzukommen scheint, sollen diesbezüglich einige interessante Aspekte näher beleuchtet werden. Mehrere Studien belegen, dass Nikotin über die Aktivierung von a7-nAChRs eine wichtige Rolle bei der Ausbildung von kortikalen Erregbarkeitsveränderungen spielt. Durch den Einsatz eines a7-Rezeptor-Agonisten ließen sich LTP-Effekte verstärken (Lagostena et al. 2008) und bei Mäusen, denen der a7-Rezeptor fehlt, konnte Nikotin keine LTP-Mechanismen ausbilden (Welsby et al. 2007). Zu den von der Desensibilisierung und Hochregulation durch langfristige Nikotinexposition besonders betroffenen nAChR gehören die beiden im menschlichen Gehirn am häufigsten vorkommenden Subtypen, der $\alpha 7$ - und der a4 32 -Rezeptor (Buisson und Bertrand 2002; Wüllner et al. 2008). Der $\alpha 7$-Rezeptor befindet sich vor allem an glutamatergen Nervenendigungen, während GABAerge Neurone durch den a4 $\beta 2$-Rezeptor beeinflusst werden. Letzterer zeichnet sich durch eine hohe Nikotin-Affinität und langsame Desensibilisierungsrate aus, während die $\alpha 7$-Untereinheit weniger sensitiv in Bezug auf Aktivierung und Desensibilisierung durch Nikotin ist, aber die schnellste Kinetik bei der Desensibilisierung zeigt (Corringer et al. 1998; Fenster et al. 1997). Aufgrund dieser unterschiedlichen Eigenschaften der verschiedenen Rezeptor- 
Subtypen bezüglich Rezeptor-Aktivität und -Desensibilisierung kommt es durch nikotinergen Einfluss insgesamt zu einer erhöhten glutamatergen Transmission und verminderter GABAerger Inhibition (Mansvelder et al. 2002). Der erhöhte glutamaterge Einfluss zeigt sich auch in einer höheren Dichte an postsynaptischen NMDA-Rezeptoren bei Rauchern gegenüber Nichtrauchern (Mexal et al. 2005). Da Nikotin über den erhöhten glutamatergen und verminderten GABAergen Einfluss insgesamt eine exzitabilitätssteigernde Wirkung hat, lässt sich nachvollziehen, dass Nichtraucher nach einer Nikotingabe keine, beziehungsweise deutlich weniger, inhibitorische Erregbarkeitsveränderungen ausbilden als ohne Nikotin, während dieser Effekt bei Rauchern, die an diese durch Nikotin induzierten Veränderungen bereits adaptiert sind, deutlich geringer ist. Lang und Mitarbeiter beobachteten bei Rauchern während einer Nikotinkarenz eine kortikale Hypoexzitabilität, die auf eine Verstärkung inhibitorischer und Verminderung exzitatorischer Mechanismen während des Nikotinentzuges zurückgeführt wurde (Lang et al. 2008). Da die langfristige Nikotinexposition beide Rezeptor-Subtypen desensibilisiert, kann bei Rauchern nur durch eine zusätzliche akute Nikotingabe eine kortikale Erregbarkeitssteigerung ausgelöst werden, da diese zu einer Aktivierung von a4ß2-nAChRs führt, was über eine Supression von inhibitorischen Einflüssen an Pyramidenzellen insgesamt einen disinhibitorischen Effekt hat (Alkondon et al. 2000).

Neben ihrem Einfluss auf die kortikale Plastizität haben nikotinerge AChR auch bei der Entstehung und Aufrechterhaltung von Nikotinabhängigkeit eine bedeutende Rolle. So wurden in der Vergangenheit verschiedene Genloci identifiziert, die für verschiedene nAChR-Subtypen kodieren und mit einer erhöhten Anfälligkeit für eine Nikotinabhängigkeit in Zusammenhang stehen (Greenbaum und Lerer 2009; Li et al. 2005; Portugal und Gould 2008). Mäuse mit einer Punktmutation in dem Gen, welches für die a4-Untereinheit kodiert, reagieren sehr empfindlich auf Nikotin, daher ist die a4-Untereinheit bei der Toleranzentwicklung gegenüber Nikotin und bei der Entstehung Nikotin-induzierter Belohnungsmechanismen von Bedeutung (Tapper et al. 2004). Das Vorliegen des homozygoten 113 bp Allels, welches für den a7Rezeptor kodiert, war mit einem erhöhten Risiko für eine Nikotinabhängigkeit bei schizophrenen Patienten assoziiert (De Luca et al. 2004). Nikotinabhängige Knockout-Mäuse, denen der a7-Rezeptor fehlt, zeigen weniger Entzugssymptome als Mäuse mit der normalen Genvariante (Grabus et al. 2005; Salas et al. 2007). Das Fehlen des Adenosin $\mathrm{A}_{2 \mathrm{~A}}$-Rezeptors verhindert die Nikotin-induzierte Hochregulation 
des a7-nAChRs, während die Hochregulation des a4ß2-Rezeptors davon unbeeinträchtigt bleibt (Metaxas et al. 2013). Aufgrund dieser Erkenntnisse wird für den $\alpha 7$ - und den a4ß2-Rezeptor eine Hauptrolle bei der Entstehung von Nikotinabhängigkeit angenommen. Da die Hochregulation dieser beiden Rezeptoren als ein wichtiger Mechanismus in der Entstehung von Nikotinabhängigkeit angesehen wird, könnten vorbestehende genetische Variationen zur Entstehung von Nikotinabhängigkeit beitragen. Eine besondere Bedeutung wird auch dem CYP1A6Gen, welches an der Nikotin-Metabolisierung im Gehirn beteiligt ist, zugeschrieben. Fehlt durch einen Polymorphismus im CYP1A6-Gen das entsprechende Enzym teilweise oder vollständig, kommt es zu einer verminderten Metabolisierung von Nikotin. Die durch den langsameren Abbau erhöhten Nikotinspiegel können zur Toleranzentwicklung und damit zur Entstehung von Nikotinabhängigkeit beitragen (Malaiyandi et al. 2005). Bezüglich dieser theoretischen Überlegungen sollten zukünftige Studien sich mit genetischen Unterschieden bezüglich der Rezeptorverteilung und -aktivität zwischen Rauchern und Nichtrauchern beschäftigen.

\subsection{Vergleich mit Studien zur Auslösung PAS-induzierter exzitatorischer kortikaler Erregbarkeitsveränderungen durch Nikotin}

4.4.1 Neurophysiologische Grundlage der inhibitorischen und exzitatorischen PAS

Bei dem von uns angewendeten inhibitorischen PAS-Protokoll kommt es durch das festgelegte Inter-Stimulus-Intervall von $10 \mathrm{~ms}$ zwischen dem afferenten somatosensorischen Reiz und dem durch die transkranielle Magnetstimulation ausgelösten Reiz zu einem asynchronen Eintreffen der beiden Stimuli im Bereich des motorischen Kortex. Beim exzitatorischen PAS-Protokoll kommt es durch eine Verlängerung des Inter-Stimulus-Intervalles auf 25 ms zu einem nahezu synchronen Eintreffen der beiden Impulse im motorischen Kortex, was eine kortikale Erregbarkeitserhöhung zur Folge hat (Stefan et al. 2000).

4.4.2 Einfluss von Nikotin auf PAS-induzierte exzitatorische kortikale Erregbarkeitsveränderungen

Im Rahmen unseres Forschungsprojektes wurden in unserer Abteilung ebenfalls Versuche zum nikotinergen Einfluss auf die exzitatorische Plastizität durchgeführt. 
Hierbei zeigten die Nichtraucher eine verstärkte und verlängerte kortikale Erregbarkeitssteigerung nach der Gabe eines Nikotinpflasters (Thirugnanasambandam et al. 2011 a). Die Raucher waren während des Nikotinentzuges nicht in der Lage, exzitatorische Erregbarkeitsveränderungen auszubilden, nach der Applikation eines Nikotinpflasters kam es jedoch zu einer deutlichen kortikalen Erregbarkeitsteigerung (Grundey et al. 2012 a).

Die bereits oben genannte Hypothese der Desensibilisierung kann auch die Ergebnisse der exzitatorischen Stimulationsprotokolle erklären. Aufgrund der desensibilisierten Rezeptoren und dem daraus resultierenden unzureichenden Kalzium-Einstrom können Raucher ohne Nikotin keine kortikale Erregbarkeitssteigerung ausbilden, da durch eine lediglich moderate KalziumErhöhung keine Plastizitätsveränderungen erreicht werden (Lisman 2001). Erst durch die akute Nikotingabe werden die Rezeptoren überstimuliert und somit werden intrazelluläre Kalzium-Werte erreicht, die LTP möglich machen (Grundey et al. 2012 a).

Die bei Rauchern im Nikotinentzug bestehende Unfähigkeit, exzitatorische Erregbarkeitsveränderungen auszubilden, die erst durch Nikotingabe behoben werden kann, unterstützt die Hypothese, dass Nikotin bei abhängigen Rauchern zu einer Kompensation kognitiver Defizite beitragen soll (Grundey et al. 2012 a). Hierzu passend ließ sich in verschiedenen Studien belegen, dass ein Nikotinentzug bei abhängigen Rauchern mit verminderten kognitiven Fähigkeiten einhergeht und diese sich erst nach einer Nikotingabe wieder bessern (Atzori et al. 2008; Cole et al. 2010; Jacobsen et al. 2005). Es ließe sich daher spekulieren, dass die Effekte von Nikotin auf kognitive Fähigkeiten auf kortikalen Erregbarkeitsveränderungen beruhen. Es muss jedoch einschränkend festgestellt werden, dass es sich hierbei gegenwärtig um eine hypothetische Überlegung handelt. Studien, die explizit einen Zusammenhang zwischen kognitiven Fähigkeiten und kortikaler Plastizität untersuchen, fehlen bislang.

Ein weiterer interessanter Unterschied zwischen inhibitorischer und exzitatorischer gepaarter assoziativer Stimulation ergab sich im Rahmen unseres Forschungsprojektes in Bezug auf die beiden Nikotinapplikationsformen. So ließ sich bei den Nichtrauchern nach exzitatorischer Stimulation ein deutlicher Unterschied zwischen den beiden Nikotinapplikationsformen nachweisen. Die durch das exzitatorische Stimulationsprotokoll generierten Nacheffekte wurden durch schnell 
anflutendes Nikotin in Form von Nasenspray aufgehoben (Grundey et al. 2012 b), während diese durch einen kontinuierlich hohen Nikotinspiegel durch ein Pflaster verstärkt und verlängert wurden (Thirugnanasambandam et al. 2011 a). Im Gegensatz dazu kam es nach Anwendung des inhibitorischen PAS-Protokolles bei beiden Nikotinapplikationsformen zu einer Aufhebung bzw. Reduktion der inhibitorischen Nacheffekte (Grundey et al. 2012 b; Thirugnanasambandam et al. 2011 a).

Hinsichtlich exzitatorischer Plastizität zeigen die oben genannten Studien einen eindeutigen Einfluss der Nikotinapplikationsdauer. Durch das schnell anflutende und kurz wirkende Nikotinspray werden möglicherweise kurzfristig KalziumKonzentrationen erreicht, die die Grenze zur Auslösung von LTP überschreiten (Misonou et al. 2004), so dass es zu einer Aufhebung der exzitatorischen Nacheffekte der PAS durch Nikotinspray kommt (Grundey et al. 2012 b). Nikotinerge AChR reagieren auf Nikotineinfluss sehr schnell mit adaptiven Regulationsmechanismen, im Sinne einer Hoch- oder Herunterregulation, Desensibilisierung oder Zunahme der Rezeptordichte (Alkondon et al. 2000). Aufgrund dieser schnellen Kinetik könnte es auch bei Nichtrauchern durch den längerfristig erhöhten Nikotinspiegel durch ein Nikotinpflaster bereits zu einer Desensibilisierung der Rezeptoren kommen. Die Kalzium-Werte würden dadurch nach Pflasterapplikation in einem Bereich bleiben, in dem LTP ausgelöst wird (Lisman 2001), wodurch sich der beobachtete fokussierende Effekt eines Nikotinpflasters auf exzitatorische Stimulationsprotokolle bei Nichtrauchern erklären ließe (Thirugnanasambandam et al. 2011 a).

Unsere initiale Annahme, dass die Effekte auf die kortikale Plastizität nach Sprayapplikation ausgeprägter sind und nach Pflasterapplikation länger anhalten, bestätigte sich bei der inhibitorischen Stimulation nicht. Die stärkere Erhöhung der Kalzium-Konzentration mit der daraus folgenden Aufhebung der exzitatorischen Nacheffekte der PAS kann jedoch als eine ausgeprägtere Reaktion auf die Stimulation nach Sprayapplikation gewertet werden, so dass die oben genannte Hypothese auf exzitatorische Stimulationsprotokolle zuzutreffen scheint.

\subsection{Validität der PAS und weitere mögliche Einflussfaktoren auf die Untersuchungsergebnisse}

Seit der Etablierung der gepaarten assoziativen Stimulation (PAS) als Methode zur Auslösung von Neuroplastizität (Stefan et al. 2000), wurden viele weitere Studien zur 
Reproduzierbarkeit und Validität dieser Methode sowie möglicher Einflussfaktoren auf die Ergebnisse durchgeführt. Im Folgenden soll ein kurzer Überblick über den aktuellen Stand der Forschung sowie die Bedeutung für unsere Ergebnisse gegeben werden.

\subsubsection{Genetische Unterschiede}

Der Einfluss genetischer Unterschiede auf die Ausbildung von Neuroplastizität konnte unter anderem in einer Studie mit mono- und dizygoten Zwillingen bestätigt werden. Die interindividuelle Variabilität der Plastizität war bei monozygoten Zwillingen weniger ausgeprägt als bei dizygoten Zwillingspaaren (Missitzi et al. 2011).

Ein häufiger Polymorphismus in dem Gen, welches für den neurotrophen Wachstumsfaktor BDNF (brain-derived neurotrophic factor) kodiert, hat Einfluss auf die synaptische Fähigkeit zur Ausbildung von LTP und LTD. Der Val66MetPolymorphismus, bei dem es zum Austausch der Aminosäure Valin mit Methionin im Codon 66 kommt, ist bei etwa 30\% der Menschen nachzuweisen (Cramer 2008). Obwohl der BDNF-Polymorphismus der am meisten erforschte Genpolymorphismus in Bezug auf die Auswirkungen auf die Neuroplastizität ist, bleibt die Studienlage uneinheitlich. Zunächst schien es, als ob das Vorhandensein von Methionin generell mit einem schlechteren Ansprechen auf plastizitätsfördernde Stimulationsprotokolle einhergeht (Cheeran et al. 2008). So war ein schlechteres episodisches Gedächtnis sowie eine abnormale hippokampale Aktivität im fMRT mit dem Vorliegen des Val66Met-Polymorphismus assoziiert (Egan et al. 2003). Im Gegensatz dazu konnte vor kurzem gezeigt werden, dass gerade das Vorliegen des Methionin-Allels gegenüber dem Vorhandensein des Valin-Allels eine Verbesserung der exekutiven Funktionen nach einem schweren Schädel-Hirn-Trauma zur Folge hat (Krueger et al. 2011). Da die genetische Ausstattung zwischen Rauchern und Nichtrauchern keine großen Unterschiede aufweisen dürfte, spielt allein das Vorliegen des BDNFPolymorphismus für die Interpretation unserer Ergebnisse wahrscheinlich keine systematische Rolle. Bezogen auf unsere Untersuchung ist jedoch interessant, dass die BDNF-Level bei Rauchern niedriger sind als bei Nichtrauchern (Bhang et al. 2010) und es bei Rauchern durch eine Nikotinabstinenz zu einem Anstieg der BDNFProduktion kommt (Bhang et al. 2010; Kivinummi et al. 2011). Diese Veränderungen könnten sich auf die Fähigkeit zur Ausbildung von Neuroplastizität auswirken. 


\subsubsection{Inter- und intraindividuelle Variabilität}

Verschiedene Studien berichten, dass es eine beachtliche interindividuelle Variabilität bezüglich des Ansprechens auf die PAS gibt. Zum einen scheint es neben den Personen, die nach Anwendung eines exzitatorischen PAS-Protokolles erwartungsgemäß mit einem Anstieg der MEP-Amplituden reagieren, auch Personen zu geben, bei denen es zu einer Abnahme der MEP-Amplituden kommt. Der Anteil dieser nicht wie erwartet ansprechenden Probanden (Non-Responder) lag in der Studie von Müller-Dahlhaus und Mitarbeitern bei 48\% (Müller-Dahlhaus et al. 2008). In anderen Studien lag die Anzahl der Responder bei ca. 85\% (11 von 13 Probanden) (Wolters et al. 2003) bzw. bei ca. 77\% (13 von 17 Probanden) (Stefan et al. 2004). Diese genannten Studien wurden alle mit einem exzitatorischen Stimulationsprotokoll durchgeführt, mit hoher Wahrscheinlichkeit kann jedoch davon ausgegangen werden, dass diese Ergebnisse auf inhibitorische Stimulationsprotokolle übertragen werden können.

Neben dieser interindividuellen Variabilität konnten Fratello und Mitarbeiter nachweisen, dass es zudem intraindividuelle Unterschiede bei Messungen des gleichen Probanden an verschiedenen Tagen gibt (Fratello et al. 2006). Diese Erkenntnis ist auch für die Interpretation unserer Studie von Bedeutung, da bei jedem Probanden insgesamt drei Messungen an verschiedenen Tagen durchgeführt wurden. Allerdings zeigte sich, dass der Gruppeneffekt in den einzelnen Messungen trotz der intraindividuellen Unterschiede reproduzierbar war (Fratello et al. 2006) und somit eine Aussage über die Reaktion des Gesamtkollektivs der Nichtraucher und der Raucher zulässig ist.

\subsubsection{Abhängigkeit vom Lebensalter}

Die Fähigkeit zur Ausbildung von Neuroplastizität nimmt mit zunehmendem Lebensalter ab (Müller-Dahlhaus et al. 2008) und ist bei postmenopausalen Frauen noch deutlich schlechter ausgeprägt als bei Männern derselben Altersgruppe (Tecchio et al. 2008). Als ursächlich werden hier degenerative Vorgänge in cholinergen, dopaminergen und adrenergen neuronalen Netzwerken angenommen. In unserer Studie lag sowohl bei den Rauchern als auch bei den Nichtrauchern der Altersdurchschnitt bei 26 Jahren und damit in einem Bereich, in dem die durch plastizitätsinduzierende Stimulationsprotokolle ausgelösten kortikalen Erregbarkeitsveränderungen am ausgeprägtesten sind. Aufgrund des insgesamt 
jungen Durchschnittsalters sowie der fehlenden Altersdifferenz zwischen den beiden Gruppen ist diesbezüglich keine negative Beeinflussung auf die Ergebnisse unserer Messungen zu erwarten.

\subsubsection{Beeinflussung durch Nikotin}

Nikotin werden neuromodulatorische Fähigkeiten zugeschrieben, da es über die Aktivierung unterschiedlicher nAChR-Subtypen auf verschiedene Neurotransmittersysteme Einfluss nehmen kann. In unserer Studie wurde Nikotin in nur einer Dosierung eingesetzt. Daher kann bezüglich einer Dosisabhängigkeit für Nikotin bei der Ausbildung von kortikalen Erregbarkeitsveränderungen, wie sie bereits für andere Neurotransmitter, wie beispielsweise Dopamin (Monte-Silva et al. 2009; Monte-Silva et al. 2010; Thirugnanasambandam et al. 2011 b), belegt werden konnte, mit unseren Daten keine Aussage getroffen werden. Des Weiteren haben wir keine Plasma-Spiegel von Nikotin bestimmt, so dass interindividuelle Unterschiede in der Bioverfügbarkeit der Substanz nicht ausgeschlossen werden können. Zudem kommt einschränkend hinzu, dass in unserer Studie die Auswirkung einer einzelnen Nikotingabe untersucht wurde. Hierbei ist eine Unterscheidung zwischen primären Nikotineffekten und sekundären Effekten, die auf der Modulation von nikotinergen ACh-Rezeptoren, wie Desensibilisierung und Hochregulation, beruhen, nicht möglich. Die akuten und chronischen Nikotineffekte auf die Auslösung von LTP-Mechanismen beruhen auf unterschiedlichen Mechanismen (Fujii et al. 1999). Daher muss angenommen werden, dass sich eine Einzelgabe von Nikotin, wie sie in unserer Studie vorgenommen wurde, bei Nichtrauchern anders auswirkt als bei Rauchern, die eine chronische Exposition gegenüber dieser Substanz gewöhnt sind.

Zuletzt muss auch eine mangelnde Entspannung und Aufmerksamkeit während der Messungen als Folge der Nikotinkarenz als eine mögliche Ursache für die geringer ausgeprägte Fähigkeit zur Ausbildung von Neuroplastizität bei Rauchern in Betracht gezogen werden. Auch innerhalb der Gruppe der Raucher zeigte sich ein weniger einheitliches Verhalten als in der Nichtrauchergruppe. Dies kann ein möglicher Hinweis darauf sein, dass bereits latente Symptome eines Nikotinentzugs, wie Unruhe und Angespanntheit, vorhanden waren und damit Auswirkungen auf die Versuchsbedingungen nehmen konnten, da eine absolute Entspannung und Aufmerksamkeit während der Versuche als Grundvoraussetzung für die Aussagekraft der Versuche erforderlich war. 
Zusammenfassend lässt sich feststellen, dass Nikotin einen eindeutigen Einfluss auf die Auswirkungen des hier angewendeten Stimulationsprotokolles (PAS) hat. Diese Erkenntnis sollte in Zukunft bei der Anwendung von Stimulationsprotokollen zur Beeinflussung kortikaler Erregbarkeitsveränderungen Beachtung finden.

\subsubsection{Beeinflussung durch andere Neurotransmitter}

Die Effektivität und Reproduzierbarkeit der durch PAS ausgelösten kortikalen Erregbarkeitsveränderungen ist am höchsten, wenn die Versuche am Nachmittag durchgeführt werden (Sale et al. 2007). Als Erklärung hierfür werden zirkadiane Rhythmen von verschiedenen Hormonen und Neurotransmittern, die Einfluss auf die Neuroplastizität haben, angenommen. So verhindern beispielsweise sowohl das Hormon Melatonin (Collins und Davies 1997) als auch hohe Kortisol-Spiegel, welche physiologischerweise morgens die höchste Konzentration erreichen, die Ausbildung von LTP-ähnlicher Neuroplastizität (Sale et al. 2008). Für die Zukunft ist es für eine bessere Aussagekraft und Vergleichbarkeit wichtig, die Messungen zur gleichen Tageszeit und vorzugsweise am Nachmittag durchzuführen.

\subsection{Auswirkungen des nikotinergen Einflusses auf kognitive Leistungen}

Tierexperimentell konnte gezeigt werden, dass Nikotin bei Ratten Aufmerksamkeit und Arbeitsgedächtnis verbessert (Hahn und Stolerman 2002). Während einige Studien eine Besserung der kognitiven Leistungen und motorischen Fähigkeiten unter Nikotineinfluss nur bei Rauchern, beziehungsweise durch eine langfristige Gabe von Nikotin, erkennen konnten (Hindmarch et al. 1990; Sutherland et al. 2011), zeigten andere Studien eine Besserung der kognitiven Leistungen nach akuter Nikotingabe sowohl bei Rauchern als auch bei Nichtrauchern (Froeliger et al. 2009). Bei Nichtrauchern verbesserte Nikotin das episodische Gedächtnis (Jubelt et al. 2008), Aufmerksamkeit und Wahrnehmung (Barr et al. 2008). Bei abhängigen Rauchern geht eine Nikotinabstinenz mit eingeschränkten kognitiven Fähigkeiten einher, die sich, ebenso wie die affektiven Entzugssymptome, durch anschließende Nikotingabe wieder bessern (Atzori et al. 2008; Cole et al. 2010; Jacobsen et al. 2005).

Da die Fähigkeit zur Ausbildung von Neuroplastizität die neurophysiologische Grundlage für Lernen und Gedächtnisvorgänge darstellt, kann aufgrund der unter anderem in dieser Arbeit dargestellten nikotinergen Auswirkungen auf 
plastizitätsinduzierende Stimulationsprotokolle ein Effekt von Nikotin auf kognitive Fähigkeiten und Gedächtnisleistungen angenommen werden.

Da viele Effekte des Nikotins auf die Neuroplastizität über den a7-nAChR vermittelt werden, fällt diesem Rezeptor eine wichtige Rolle bei Lernvorgängen zu. Tatsächlich zeigten Knock-out-Mäuse, denen der a7-Rezeptor fehlt, eine reduzierte Lernfähigkeit und Präzision (Levin et al. 2009). Außerdem war eine defekte Variante des Gens, welches für den a7-Rezeptor kodiert, mit einem schlechteren episodischen Gedächtnis assoziiert (Dempster et al. 2006). Der Einsatz von Bupropion, einem nAChR-Antagonisten, führte zu einer Abschwächung bzw. Aufhebung der durch Nikotin induzierten Verbesserung von Gedächtnisleistungen (Biala und Kruk 2009). Derselbe Effekt ließ sich auch durch die chronische Gabe von KalziumkanalAntagonisten nachweisen (Biala und Kruk 2009; Woodside et al. 2004), so dass für die verbesserten kognitiven Leistungen nach Nikotingabe die durch nikotinerge Stimulation von nAChR ausgelöste Erhöhung der intrazellulären KalziumKonzentration eine Rolle spielen könnte.

Die bisherigen Studien beschäftigten sich vor allem mit dem nikotinergen Einfluss auf LTP-Mechanismen als Korrelat von Lernvorgängen. Da Nikotin bei Rauchern die Ausbildung von exzitatorischen kortikalen Erregbarkeitsveränderungen fördert (Grundey et al. 2012 a), wird dadurch die Hypothese unterstützt, dass Nikotin zur Kompensation kognitiver Defizite beitragen kann. Verfolgt man diesen Gedanken weiter, kann auch in der (partiellen) Aufhebung der inhibitorischen Plastizität durch Nikotin, wie wir sie in unserer Studie zeigen konnten, ein möglicher Einfluss von Nikotin auf kognitive Prozesse gesehen werden, da sich durch die Aufhebung der inhibitorischen Plastizität das Gesamtsystem in Richtung Erregbarkeitszunahme verschiebt und damit indirekt zur Verbesserung der kognitiven Leistungen beitragen kann (Thirugnanasambandam et al. 2011 a). In jüngerer Zeit fanden sich zudem Hinweise, dass auch inhibitorische Plastizität in Form von LTD bei bestimmten Formen von Hippokampus-assoziiertem Lernen und Gedächtnisvorgängen sowie bei der kognitiven Verarbeitung neuer Informationen eine Rolle spielt (Collingridge et al. 2010; Dong et al. 2013).

Hier muss jedoch noch einmal einschränkend erwähnt werden, dass diese Überlegungen gegenwärtig einen hypothetischen Charakter haben, da Studien, die direkt einen Zusammenhang zwischen kognitiven Fähigkeiten und Plastizität unter Nikotineinfluss untersuchen, bislang fehlen. 


\section{Zusammenfassung und Ausblick}

Nikotin gilt als die Abhängigkeit verursachende Komponente im Zigarettenrauch. Zudem hat Nikotin einen Einfluss auf die Ausbildung von lang anhaltenden kortikalen Erregbarkeitsveränderungen. Diese als neuroplastisch bezeichneten Veränderungen gelten als neurophysiologische Grundlage von Lern- und Gedächtnisprozessen. So konnte nachgewiesen werden, dass die kognitiven Fähigkeiten bei Rauchern im Nikotinentzug reduziert sind und diese erst nach einer Nikotingabe wieder erlangt werden. Obwohl bei Nichtrauchern die Datenlage nicht so eindeutig ist, konnten auch hier verbesserte kognitive Leistungen nach Nikotingabe nachgewiesen werden.

Im Rahmen dieser Arbeit sollte untersucht werden, in welchem Maße nikotinerge Acetylcholin-Rezeptoren bei der Induktion von inhibitorischen kortikalen Erregbarkeitsveränderungen im menschlichen Gehirn eine Rolle spielen. Daher führten wir Versuche mit dem für diese Rezeptoren spezifischen Liganden Nikotin durch. Wir untersuchten den Einfluss von schnell anflutendem Nikotin in Form von Nasenspray und eines kontinuierlich hohen Nikotinspiegels in Form eines Nikotinpflasters auf die durch gepaarte assoziative Stimulation (PAS) ausgelösten inhibitorischen kortikalen Erregbarkeitsveränderungen bei Rauchern und Nichtrauchern.

Bei der gepaarten assoziativen Stimulation (PAS) wird ein afferenter somatosensorischer Reiz des Nervus ulnaris im Bereich des Handgelenkes mit einem transkraniellen Magnetimpuls über dem entsprechenden Areal des motorischen Kortex kombiniert. Durch ein Inter-Stimulus-Intervall von $10 \mathrm{~ms}$ kommt es zu einer kortikalen Erregbarkeitsabnahme. Mittels transkranieller Magnetstimulation wurden die kortikalen Exzitabilitätsveränderungen über die Änderung der MEP-Amplituden im Musculus abductor digiti minimi erfasst.

Ohne Nikotin hatten sowohl Nichtraucher als auch Raucher die Fähigkeit zur Ausbildung inhibitorischer kortikaler Exzitabilitätsveränderungen, wobei diese bei Rauchern im Nikotinentzug deutlich schlechter ausgeprägt war als bei Nichtrauchern. Bei Nichtrauchern wurden die inhibitorischen Nacheffekte der PAS durch Nikotin aufgehoben bzw. vermindert, während sie bei Rauchern initial kürzer anhielten, später jedoch erneut auftraten.

Unsere Ergebnisse zeigen, dass Nikotin eine wichtige Rolle bei der Ausbildung von inhibitorischen kortikalen Erregbarkeitsveränderungen spielt. Da diese als 
neuroplastisch bezeichneten Veränderungen als neurophysiologisches Korrelat für Lernvorgänge und Gedächtnis angesehen werden, lässt sich ein hierdurch vermittelter Einfluss von Nikotinabhängigkeit und Nikotinentzug auf kognitive Prozesse annehmen. In der Vergangenheit wurde vielfach beschrieben, dass es nach Nikotingabe zu einer Besserung der kognitiven Leistungen bei Rauchern kommt, wobei hierfür vor allem der nikotinerge Einfluss auf die exzitatorische Plastizität verantwortlich gemacht wurde. In jüngerer Zeit zeigte sich jedoch, dass für bestimmte Formen von Lernen und kognitiver Verarbeitung auch die inhibitorische Plastizität eine wichtige Rolle spielt. Daraus ergibt sich für Nikotin möglicherweise zukünftig eine therapeutische Einsatzmöglichkeit bei neuropsychiatrischen Erkrankungen, die mit kognitiven Einschränkungen einhergehen, wie z. B. dem Morbus Alzheimer, für den ein cholinerges Defizit angenommen wird. Nikotin fungiert auch als Neuromodulator und nimmt unter anderem großen Einfluss auf das dopaminerge Belohnungssystem, womit sich der hohe Anteil an abhängigen Rauchern unter Patienten mit Schizophrenie, einer Erkrankung, für die ein dysfunktionelles dopaminerges System angenommen wird, erklären lässt. Der nikotinerge Einfluss auf das dopaminerge Belohnungssystem kann zudem als ein wichtiger Mechanismus bei der Entstehung von Nikotinabhängigkeit und der hohen Rückfallquote von abhängigen Rauchern nach einem Nikotinentzug angesehen werden.

Der Wirkmechanismus von Nikotin mit seiner Vielzahl von neuromodulatorischen Eigenschaften ist noch nicht vollständig verstanden, zumal die Nikotinwirkung durch genetische, ethnische und geschlechtsspezifische Unterschiede mit beeinflusst wird. Sicher scheint jedoch, dass die die Auswirkungen des Nikotins auf die Fähigkeit zur Ausbildung kortikaler Exzitabilitätsveränderungen und damit zur Beeinflussung von Lern- und Gedächtnisvorgängen über nikotinerge ACh-Rezeptoren vermittelt werden. Hierbei ist zu beachten, dass es von den nikotinergen ACh-Rezeptoren verschiedene Subtypen gibt und deren Verteilung, Funktion und Aktivitätsstatus von unterschiedlichen Faktoren, wie Alter, Genetik und chronischem Nikotinkonsum abhängig ist. Es kommt weiterhin hinzu, dass Nikotin neben nikotinergen auch an muskarinergen Acetylcholinrezeptoren wirkt und als Neuromodulator Einfluss auf die verschiedensten 
$\mathrm{Ob}$ die Unterschiede zwischen Rauchern und Nichtrauchern in der Ausbildung von Neuroplastizität auf vorbestehende Unterschiede zurückzuführen sind, die erst dazu führen, dass jemand abhängiger Raucher wird oder nicht, oder ob der langjährige Nikotinkonsum zu Veränderungen im Rezeptor- und Transmittersystem führt, konnte bisher nicht ausreichend geklärt werden.

Diesbezüglich sollten zukünftige Studien sich vor allem auf genetische Unterschiede zwischen Rauchern und Nichtrauchern, die Bedeutung unterschiedlicher RezeptorSubtypen sowie die unterschiedliche Rezeptor-Verteilung und -Dichte in verschiedenen Hirnarealen konzentrieren. Des Weiteren wäre für die Zukunft interessant, ob der Einfluss von Nikotin auf kortikale Exzitabilitätsveränderungen eine Dosisabhängigkeit aufweist, wie sie bereits für andere Neurotransmitter, wie z. B. Dopamin, nachgewiesen werden konnte. Sicher ist jedoch bereits, dass Nikotin einen bedeutsamen Einfluss auf die Effekte nimmt, die durch zerebrale Stimulationsprotokolle wie die PAS ausgelöst werden. Diese Erkenntnis sollte in Zukunft bei der Anwendung und Interpretation von Hirnstimulationstechniken Beachtung finden. 


\section{Tabellenanhang: Tabellen 3-21}

\begin{tabular}{|c|c|c|}
\hline & Raucher & Nichtraucher \\
Anzahl & 12 & 12 \\
\hline Anzahl (\%) Frauen & & \\
Alter (MW+/- SD) & $5(41,66 \%)$ & $7(58,33 \%)$ \\
in Jahren & $25,75+/-2,92$ & $25,91+/-2,1$ \\
\hline $\begin{array}{c}\text { Anzahl gerauchter Zigaretten/Tag } \\
\text { (MW +/- SD) }\end{array}$ & 15 Zigaretten \\
\hline Punkte im Fagerström-Test & $(14,58+/-5,05)$ & -- \\
\hline (MW +/- SD) & 3 Punkte & -- \\
\hline
\end{tabular}

Tabelle 3: Raucher und Nichtraucher nach Anzahl, Geschlecht, Alter, Anzahl gerauchter Zigaretten pro Tag und Punktzahl im Fagerström-Test.

MW: Mittelwert; SD: Standardabweichung

\begin{tabular}{|c|c|c|c|}
\hline MEP-Amplitude & $\mathbf{t}$ & $\mathbf{d f}$ & $\mathbf{p}$ \\
\hline Grundbedingung R - NR & $-0,319$ & 22 & 0,753 \\
\hline Vor Pflaster R - NR & $-0,084$ & 22 & 0,934 \\
\hline Nach Pflaster R - NR & $-0,226$ & 22 & 0,823 \\
Vor Spray R - NR & 0,453 & 22 & 0,655 \\
\hline Nach Spray R - NR & 0,19 & 22 & 0,851 \\
\hline
\end{tabular}

Tabelle 4: Ergebnisse der unabhängigen t-Tests für den Vergleich der Raucher und Nichtraucher bezüglich der MEP-Amplituden unter den verschiedenen Bedingungen.

Die MEP-Amplituden unter den verschiedenen Bedingungen (Grundbedingung, vor und nach Pflaster, vor und nach Spray) unterscheiden sich bei Rauchern und Nichtrauchern nicht.

df: Freiheitsgrade; MEP: Motorisch evoziertes Potential; NR: Nichtraucher; p: Signifikanzniveau $(<0,05)$; R: Raucher; $t$ : $t$-Wert.

\begin{tabular}{|c|c|c|c|}
\hline Bedingung & t & df & P \\
\hline Nichtraucher: BL vor Pflaster - BL nach Pflaster & $-0,667$ & 11 & 0,518 \\
\hline Nichtraucher BL vor Spray - BL nach Spray & 0,983 & 11 & 0,347 \\
\hline Raucher: BL vor Pflaster - BL nach Pflaster & $-2,098$ & 11 & 0,06 \\
\hline Raucher: BL vor Spray - BL nach Spray & $-0,601$ & 11 & 0,56 \\
\hline
\end{tabular}

Tabelle 5: Ergebnisse der gepaarten t-Tests für den Einfluss von Nikotin auf die Baseline-MEPAmplituden.

Die MEP-Amplituden der Baselines unterscheiden sich vor und nach Nikotingabe (in Form von Nasenspray oder Pflaster) nicht signifkant innerhalb der jeweiligen Gruppe (Raucher oder Nichtraucher).

BL: Baseline; df: Freiheitsgrade; $p$ : Signifikanzniveau (<0,05); $t$ : $t$-Wert. 


\begin{tabular}{|c|c|c|c|}
\hline & $\mathbf{d f}$ & $\mathbf{F}$ & $\mathbf{p}$ \\
\hline Gruppe & 1 & 1,195 & 0,286 \\
\hline Nikotin & 2 & 7,200 & $0,002^{*}$ \\
\hline Zeitpunkt & 10 & 3,083 & $0,001^{*}$ \\
\hline Nikotin x Gruppe & 2 & 2,581 & 0,087 \\
\hline Zeitpunkt x Gruppe & 10 & 0,901 & 0,533 \\
\hline Nikotin x Zeitpunkt & 20 & 1,321 & 0,160 \\
\hline Nikotin x Zeitpunkt x Gruppe & 20 & 0,796 & 0,719 \\
\hline
\end{tabular}

Tabelle 6: Ergebnisse der Messwiederholungs-ANOVA

Die mit einem Stern $\left(^{*}\right)$ markierten Werte sind statistisch signifikant $(p<0,05)$.

ANOVA: Varianzanalyse, df:Freiheitsgrade, F: F-Wert, p: Signifikanzniveau.

\begin{tabular}{|c|c|c|c|c|c|c|}
\hline \multirow{2}{*}{$\begin{array}{c}\text { Nichtraucher ohne } \\
\text { Nikotin } \\
\text { (Grundbedingung) }\end{array}$} & \multicolumn{3}{|c|}{ t-Test } & \multicolumn{3}{|c|}{ Fisher's LSD } \\
\hline & $\mathbf{t}$ & df & $\mathbf{p}$ & $\begin{array}{c}\text { Mittlere } \\
\text { Differenz }\end{array}$ & $\begin{array}{l}\text { Kritische } \\
\text { Differenz }\end{array}$ & $\mathbf{p}$ \\
\hline Baseline - 0 Minuten & 2,662 & 11 & 0,022 * & $-0,259$ & 0,264 & 0,0545 \\
\hline Baseline - 5 Minuten & 5,429 & 11 & 0,000 * & $-0,324$ & 0,264 & 0,0162 * \\
\hline Baseline - 10 Minuten & 3,492 & 11 & $0,005^{*}$ & $-0,249$ & 0,264 & 0,0643 \\
\hline Baseline - 15 Minuten & 7,168 & 11 & 0,000 * & $-0,361$ & 0,264 & $0,0075^{*}$ \\
\hline Baseline - 20 Minuten & 3,922 & 11 & 0,002 * & $-0,316$ & 0,264 & 0,0190 * \\
\hline Baseline - 25 Minuten & 4,354 & 11 & 0,001 * & $-0,323$ & 0,264 & 0,0166 * \\
\hline Baseline - 30 Minuten & 3,346 & 11 & $0,007^{*}$ & $-0,268$ & 0,264 & 0,0466 * \\
\hline Baseline - 60 Minuten & 1,011 & 11 & 0,334 & $-0,124$ & 0,264 & 0,3560 \\
\hline Baseline - 90 Minuten & 4,539 & 11 & 0,001 * & $-0,306$ & 0,264 & 0,0234 * \\
\hline Baseline - 120 Minuten & 3,487 & 11 & $0,005^{*}$ & $-0,171$ & 0,264 & 0,2057 \\
\hline
\end{tabular}

Tabelle 7: Ergebnisse der gepaarten t-Tests und des Fisher's LSD für die Messungen ohne Nikotin (Grundbedingung) bei Nichtrauchern.

Die MEP-Amplituden der verschiedenen Zeitpunkte wurden mit der zugehörigen Baseline verglichen. Die mit einem Stern $\left(^{*}\right)$ markierten Werte geben einen statistisch signifikanten Unterschied $(p<0,05)$ an. $d f$ : Freiheitsgrade; LSD: geringster signifikanter Unterschied; $p$ : Signifikanzniveau; $t$ : $t$-Wert. 


\begin{tabular}{|c|c|c|c|c|c|c|}
\hline \multirow{2}{*}{$\begin{array}{c}\text { Nichtraucher mit } \\
\text { Nikotinspray }\end{array}$} & \multicolumn{3}{|c|}{ t-Test } & \multicolumn{3}{|c|}{ Fisher's LSD } \\
\hline & t & df & p & $\begin{array}{l}\text { Mittlere } \\
\text { Differenz }\end{array}$ & $\begin{array}{l}\text { Kritische } \\
\text { Differenz }\end{array}$ & p \\
\hline Baseline - 0 Minuten & $-0,679$ & 11 & 0,511 & 0,057 & 0,264 & 0,6728 \\
\hline Baseline - 5 Minuten & 0,120 & 11 & 0,906 & $-0,018$ & 0,264 & 0,8961 \\
\hline Baseline - 10 Minuten & $-0,294$ & 11 & 0,774 & 0,029 & 0,264 & 0,8307 \\
\hline Baseline - 15 Minuten & $-0,439$ & 11 & 0,669 & 0,060 & 0,264 & 0,6535 \\
\hline Baseline - 20 Minuten & $-0,459$ & 11 & 0,655 & 0,053 & 0,264 & 0,6952 \\
\hline Baseline - 25 Minuten & $-0,666$ & 11 & 0,519 & 0,090 & 0,264 & 0,5028 \\
\hline Baseline - 30 Minuten & $-0,459$ & 11 & 0,655 & 0,059 & 0,264 & 0,6590 \\
\hline Baseline - 60 Minuten & $-1,419$ & 11 & 0,184 & 0,252 & 0,264 & 0,0615 \\
\hline Baseline - 90 Minuten & $-0,693$ & 11 & 0,503 & 0,062 & 0,264 & 0,6431 \\
\hline Baseline - 120 Minuten & 0,036 & 11 & 0,972 & $-0,008$ & 0,264 & 0,9508 \\
\hline Baseline - 240 Minuten & 0,891 & 11 & 0,392 & $-0,072$ & 0,264 & 0,5912 \\
\hline Baseline - nächster Morgen & $-0,459$ & 11 & 0,655 & $-0,032$ & 0,264 & 0,8101 \\
\hline Baseline - nächster Abend & $-0,704$ & 11 & 0,496 & $-0,070$ & 0,264 & 0,6042 \\
\hline
\end{tabular}

Tabelle 8: Ergebnisse der gepaarten t-Tests und des Fisher's LSD für die Messungen mit Nikotinspray bei Nichtrauchern.

Die MEP-Amplituden der verschiedenen Zeitpunkte wurden mit der zugehörigen Baseline verglichen. Hierbei ergaben sich keine signifikanten Unterschiede.

df: Freiheitsgrade; LSD: geringster signifikanter Unterschied; $p$ : Signifikanzniveau $(p<0,05)$; $t$ : $t$-Wert.

\begin{tabular}{|c|c|c|c|c|c|c|}
\hline \multirow{2}{*}{$\begin{array}{l}\text { Nichtraucher: } \\
\text { Grundbedingung vs. } \\
\text { Nikotinspray }\end{array}$} & \multicolumn{3}{|c|}{ t-Test } & \multicolumn{3}{|c|}{ Fisher's LSD } \\
\hline & $\mathbf{t}$ & df & $p$ & $\begin{array}{c}\text { Mittlere } \\
\text { Differenz }\end{array}$ & $\begin{array}{l}\text { Kritische } \\
\text { Differenz }\end{array}$ & $\mathbf{p}$ \\
\hline 0 Minuten & $-2,706$ & 11 & 0,020 * & $-0,316$ & 0,264 & 0,0191 * \\
\hline 5 Minuten & $-2,637$ & 11 & 0,023 * & $-0,307$ & 0,264 & 0,0230 * \\
\hline 10 Minuten & $-2,189$ & 11 & 0,051 & $-0,278$ & 0,264 & 0,0391 * \\
\hline 15 Minuten & $-3,355$ & 11 & 0,006 * & $-0,421$ & 0,264 & 0,0018 * \\
\hline 20 Minuten & $-2,764$ & 11 & 0,018 * & $-0,369$ & 0,264 & 0,0062 * \\
\hline 25 Minuten & $-3,273$ & 11 & $0,007^{*}$ & $-0,414$ & 0,264 & 0,0022 * \\
\hline 30 Minuten & $-2,726$ & 11 & 0,020 * & $-0,328$ & 0,264 & 0,0151 * \\
\hline 60 Minuten & $-1,748$ & 11 & 0,108 & $-0,376$ & 0,264 & 0,0053 * \\
\hline 90 Minuten & $-3,079$ & 11 & 0,010 * & $-0,368$ & 0,264 & 0,0064 * \\
\hline 120 Minuten & $-1,253$ & 11 & 0,236 & $-0,162$ & 0,264 & 0,2278 \\
\hline
\end{tabular}

Tabelle 9: Ergebnisse der gepaarten t-Tests und des Fisher's LSD bei Nichtrauchern im Vergleich von Grund- und Nikotinspray-Bedingung.

Die MEP-Amplituden der verschiedenen Zeitpunkte mit Nikotinspray wurden mit den entsprechenden Zeitpunkten der Grundbedingung verglichen. Die mit einem Stern $\left({ }^{*}\right)$ markierten Werte geben einen statistisch signifikanten Unterschied $(p<0,05)$ an.

df: Freiheitsgrade; LSD: geringster signifikanter Unterschied; $p$ : Signifikanzniveau; $t$ t-Wert. 


\begin{tabular}{|c|c|c|c|c|c|c|}
\hline \multirow{2}{*}{$\begin{array}{l}\text { Nichtraucher mit } \\
\text { Nikotinpflaster }\end{array}$} & \multicolumn{3}{|c|}{ t-Test } & \multicolumn{3}{|c|}{ Fisher's LSD } \\
\hline & $\mathbf{t}$ & df & $\mathbf{p}$ & $\begin{array}{l}\text { Mittlere } \\
\text { Differenz }\end{array}$ & $\begin{array}{l}\text { Kritische } \\
\text { Differenz }\end{array}$ & $\mathbf{p}$ \\
\hline Baseline - 0 Minuten & 1,899 & 11 & 0,084 & $-0,131$ & 0,264 & 0,3303 \\
\hline Baseline - 5 Minuten & 1,844 & 11 & 0,092 & $-0,101$ & 0,264 & 0,4515 \\
\hline Baseline - 10 Minuten & 0,455 & 11 & 0,658 & $-0,047$ & 0,264 & 0,7294 \\
\hline Baseline - 15 Minuten & 1,089 & 11 & 0,300 & $-0,112$ & 0,264 & 0,4074 \\
\hline Baseline - 20 Minuten & 0,685 & 11 & 0,508 & $-0,068$ & 0,264 & 0,6137 \\
\hline Baseline - 25 Minuten & 0,291 & 11 & 0,777 & $-0,036$ & 0,264 & 0,7888 \\
\hline Baseline - 30 Minuten & 0,241 & 11 & 0,814 & $-0,030$ & 0,264 & 0,8254 \\
\hline Baseline - 60 Minuten & 0,530 & 11 & 0,607 & $-0,051$ & 0,264 & 0,7071 \\
\hline Baseline - 90 Minuten & 2,170 & 11 & 0,053 & $-0,170$ & 0,264 & 0,2077 \\
\hline Baseline - 120 Minuten & 1,356 & 11 & 0,202 & $-0,107$ & 0,264 & 0,4290 \\
\hline Baseline - 240 Minuten & 1,793 & 11 & 0,101 & $-0,133$ & 0,264 & 0,3224 \\
\hline Baseline - nächster Morgen & $-0,044$ & 11 & 0,966 & $-0,059$ & 0,264 & 0,6595 \\
\hline Baseline - nächster Abend & 0,413 & 11 & 0,688 & 0,102 & 0,264 & 0,4475 \\
\hline
\end{tabular}

Tabelle 10: Ergebnisse der gepaarten t-Tests und des Fisher's LSD für die Messungen mit Nikotinpflaster bei Nichtrauchern.

Die MEP-Amplituden der verschiedenen Zeitpunkte wurden mit der zugehörigen Baseline verglichen. Hierbei ergaben sich keine statistisch signifikanten Unterschiede.

df: Freiheitsgrade; LSD: geringster signifikanter Unterschied; $p$ : Signifikanzniveau $(p<0,05)$; $t$ : $t$-Wert.

\begin{tabular}{|c|c|c|c|c|c|c|}
\hline $\begin{array}{c}\text { Nichtraucher: } \\
\text { Grundbedingung vs. }\end{array}$ & \multicolumn{3}{|c|}{ t-Test } & \multicolumn{3}{c|}{ Fisher's LSD } \\
\hline Nikotinpflaster & $\mathbf{t}$ & $\mathbf{d f}$ & $\mathbf{p}$ & Miftlere & Kritische & \\
\hline 0 Minuten & $-1,207$ & 11 & 0,253 & 0,128 & 0,264 & 0,3415 \\
\hline 5 Minuten & $-2,637$ & 11 & $0,023^{*}$ & 0,223 & 0,264 & 0,0982 \\
\hline 10 Minuten & $-2,492$ & 11 & $0,030^{*}$ & 0,203 & 0,264 & 0,1324 \\
\hline 15 Minuten & $-2,885$ & 11 & $0,015^{*}$ & 0,249 & 0,264 & 0,0648 \\
\hline 20 Minuten & $-2,427$ & 11 & $0,034^{*}$ & 0,248 & 0,264 & 0,0653 \\
\hline 25 Minuten & $-2,509$ & 11 & $0,029^{*}$ & 0,287 & 0,264 & 0,0332 * \\
\hline 30 Minuten & $-2,221$ & 11 & $0,048^{*}$ & 0,239 & 0,264 & 0,0767 \\
\hline 60 Minuten & $-0,639$ & 11 & 0,536 & 0,074 & 0,264 & 0,5842 \\
\hline 90 Minuten & $-1,493$ & 11 & 0,164 & 0,136 & 0,264 & 0,3125 \\
\hline 120 Minuten & $-0,552$ & 11 & 0,592 & 0,064 & 0,264 & 0,6349 \\
\hline
\end{tabular}

Tabelle 11: Ergebnisse der gepaarten t-Tests und des Fisher's LSD bei Nichtrauchern im Vergleich von Grund- und Nikotinpflaster-Bedingung.

Die MEP-Amplituden der verschiedenen Zeitpunkte mit Nikotinpflaster wurden mit den entsprechenden Zeitpunkten der Grundbedingung verglichen. Die mit einem Stern $\left(^{*}\right)$ markierten Werte zeigen einen statistisch signifikanten Unterschied $(p<0,05)$ an.

df: Freiheitsgrade; LSD: geringster signifikanter Unterschied; $p$ : Signifikanzniveau; $t$ : $t$-Wert. 


\begin{tabular}{|c|c|c|c|c|c|c|}
\hline \multirow{2}{*}{$\begin{array}{l}\text { Nichtraucher: } \\
\text { Nikotinspray vs. } \\
\text { Nikotinpflaster }\end{array}$} & \multicolumn{3}{|c|}{ t-Test } & \multicolumn{3}{|c|}{ Fisher's LSD } \\
\hline & $\mathbf{t}$ & df & $\mathbf{p}$ & $\begin{array}{c}\text { Mittlere } \\
\text { Differenz }\end{array}$ & $\begin{array}{l}\text { Kritische } \\
\text { Differenz }\end{array}$ & p \\
\hline 0 Minuten & 2,680 & 11 & 0,021 * & $-0,188$ & 0,264 & 0,1630 \\
\hline 5 Minuten & 0,895 & 11 & 0,390 & $-0,084$ & 0,264 & 0,5336 \\
\hline 10 Minuten & 0,608 & 11 & 0,556 & $-0,075$ & 0,264 & 0,5757 \\
\hline 15 Minuten & 1,254 & 11 & 0,236 & $-0,172$ & 0,264 & 0,2016 \\
\hline 20 Minuten & 0,785 & 11 & 0,449 & $-0,121$ & 0,264 & 0,3700 \\
\hline 25 Minuten & 0,808 & 11 & 0,436 & $-0,126$ & 0,264 & 0,3483 \\
\hline 30 Minuten & 0,765 & 11 & 0,460 & $-0,089$ & 0,264 & 0,5081 \\
\hline 60 Minuten & 1,556 & 11 & 0,148 & $-0,303$ & 0,264 & 0,0248 * \\
\hline 90 Minuten & 2,222 & 11 & 0,048 * & $-0,232$ & 0,264 & 0,0850 \\
\hline 120 Minuten & 0,602 & 11 & 0,559 & $-0,098$ & 0,264 & 0,4658 \\
\hline 240 Minuten & 0,459 & 11 & 0,654 & $-0,061$ & 0,264 & 0,6508 \\
\hline Nächster Morgen & 0,212 & 11 & 0,835 & 0,027 & 0,264 & 0,8412 \\
\hline Nächster Abend & 0,769 & 11 & 0,457 & $-0,172$ & 0,264 & 0,2014 \\
\hline
\end{tabular}

Tabelle 12: Ergebnisse der gepaarten t-Tests und des Fisher's LSD bei Nichtrauchern im Vergleich von Nikotinspray und Nikotinpflaster.

Die MEP-Amplituden der Messungen mit Nikotinspray und Nikotinpflaster wurden zu den verschiedenen Zeitpunkten verglichen. Die mit einem Stern $\left({ }^{*}\right)$ markierten Werte zeigen einen statistisch signifikanten Unterschied $(p<0,05)$ an.

df: Freiheitsgrade; LSD: geringster signifikanter Unterschied; p: Signifikanzniveau; $t$ : $t$-Wert.

\begin{tabular}{|c|c|c|c|c|c|c|}
\hline \multirow{2}{*}{$\begin{array}{l}\text { Raucher ohne Nikotin } \\
\text { (Grundbedingung) }\end{array}$} & \multicolumn{3}{|c|}{ t-Test } & \multicolumn{3}{|c|}{ Fisher's LSD } \\
\hline & $\mathbf{t}$ & df & $\mathbf{p}$ & $\begin{array}{l}\text { Mittlere } \\
\text { Differenz }\end{array}$ & $\begin{array}{l}\text { Kritische } \\
\text { Differenz }\end{array}$ & p \\
\hline Baseline - 0 Minuten & 2,782 & 11 & 0,018 * & $-0,254$ & 0,264 & 0,0592 \\
\hline Baseline - 5 Minuten & 2,503 & 11 & 0,029 * & $-0,293$ & 0,264 & 0,0299 * \\
\hline Baseline - 10 Minuten & 3,553 & 11 & $0,005^{*}$ & $-0,261$ & 0,264 & 0,0529 \\
\hline Baseline - 15 Minuten & 1,730 & 11 & 0,112 & $-0,207$ & 0,264 & 0,1254 \\
\hline Baseline - 20 Minuten & 3,102 & 11 & 0,010 * & $-0,267$ & 0,264 & 0,0475 * \\
\hline Baseline - 25 Minuten & 1,647 & 11 & 0,128 & $-0,177$ & 0,264 & 0,1894 \\
\hline Baseline - 30 Minuten & 1,440 & 11 & 0,178 & $-0,146$ & 0,264 & 0,2780 \\
\hline Baseline - 60 Minuten & 2,026 & 11 & 0,068 & $-0,204$ & 0,264 & 0,1302 \\
\hline Baseline - 90 Minuten & 1,980 & 11 & 0,073 & $-0,177$ & 0,264 & 0,1889 \\
\hline Baseline - 120 Minuten & 1,751 & 11 & 0,108 & $-0,110$ & 0,264 & 0,4125 \\
\hline
\end{tabular}

Tabelle 13: Ergebnisse der gepaarten t-Tests und des Fisher's LSD für die Messungen ohne Nikotin (Grundbedingung) bei Rauchern.

Die MEP-Amplituden der verschiedenen Zeitpunkte wurden mit der zugehörigen Baseline verglichen. Die mit einem Stern $\left(^{*}\right)$ markierten Werte geben einen statistisch signifikanten Unterschied $(p<0,05)$ an.

df: Freiheitsgrade; LSD: geringster signifikanter Unterschied; $p$ : Signifikanzniveau; $t$ : $t$-Wert. 


\begin{tabular}{|c|c|c|c|c|c|c|}
\hline \multirow[b]{2}{*}{$\begin{array}{l}\text { Raucher mit } \\
\text { Nikotinspray }\end{array}$} & \multicolumn{3}{|c|}{ t-Test } & \multicolumn{3}{|c|}{ Fisher's LSD } \\
\hline & $\mathbf{t}$ & df & p & $\begin{array}{c}\text { Mittlere } \\
\text { Differenz }\end{array}$ & $\begin{array}{l}\text { Kritische } \\
\text { Differenz }\end{array}$ & p \\
\hline Baseline - 0 Minuten & 1,665 & 11 & 0,124 & $-0,204$ & 0,264 & 0,1309 \\
\hline Baseline - 5 Minuten & 2,334 & 11 & 0,040 * & $-0,243$ & 0,264 & 0,0718 \\
\hline Baseline - 10 Minuten & 1,882 & 11 & 0,087 & $-0,167$ & 0,264 & 0,2145 \\
\hline Baseline - 15 Minuten & 1,041 & 11 & 0,320 & $-0,118$ & 0,264 & 0,3819 \\
\hline Baseline - 20 Minuten & 0,117 & 11 & 0,909 & $-0,010$ & 0,264 & 0,9429 \\
\hline Baseline - 25 Minuten & 0,309 & 11 & 0,763 & $-0,027$ & 0,264 & 0,8389 \\
\hline Baseline - 30 Minuten & $-0,291$ & 11 & 0,776 & 0,019 & 0,264 & 0,8861 \\
\hline Baseline - 60 Minuten & 1,345 & 11 & 0,206 & $-0,138$ & 0,264 & 0,3055 \\
\hline Baseline - 90 Minuten & 1,251 & 11 & 0,237 & $-0,158$ & 0,264 & 0,2418 \\
\hline Baseline - 120 Minuten & 2,776 & 11 & 0,018 * & $-0,221$ & 0,264 & 0,1008 \\
\hline Baseline - 240 Minuten & 1,242 & 11 & 0,240 & $-0,177$ & 0,264 & 0,1895 \\
\hline Baseline - nächster Morgen & 2,555 & 11 & 0,027 * & 0,268 & 0,264 & 0,0471 * \\
\hline Baseline - nächster Abend & 6,146 & 11 & 0,000 * & 0,363 & 0,264 & 0,0072 * \\
\hline
\end{tabular}

Tabelle 14: Ergebnisse der gepaarten t-Tests und des Fisher's LSD für die Messungen mit Nikotinspray bei Rauchern.

Die MEP-Amplituden der verschiedenen Zeitpunkte wurden mit der zugehörigen Baseline verglichen. Die mit einem Stern $\left(^{*}\right)$ markierten Werte geben einen statistisch signifikanten Unterschied $(p<0,05)$ an. df: Freiheitsgrade; LSD: geringster signifikanter Unterschied; $p$ : Signifikanzniveau; $t: t$-Wert.

\begin{tabular}{|c|c|c|c|c|c|c|}
\hline Raucher: & \multicolumn{3}{|c|}{ t-Test } & \multicolumn{3}{c|}{ Fisher's LSD } \\
Grundbedingung vs. & & & & Mittlere & Kritische \\
Nikotinspray & $\mathbf{t}$ & $\mathbf{d f}$ & $\mathbf{p}$ & Differenz & Differenz & $\mathbf{p}$ \\
\hline 0 Minuten & $-0,804$ & 11 & 0,438 & $-0,051$ & 0,264 & 0,7058 \\
\hline 5 Minuten & $-0,268$ & 11 & 0,794 & $-0,050$ & 0,264 & 0,7100 \\
\hline 10 Minuten & $-1,095$ & 11 & 0,297 & $-0,094$ & 0,264 & 0,4864 \\
\hline 15 Minuten & $-0,531$ & 11 & 0,606 & $-0,089$ & 0,264 & 0,5099 \\
\hline 20 Minuten & $-3,484$ & 11 & $0,005 *$ & $-0,258$ & 0,264 & 0,0561 \\
\hline 25 Minuten & $-1,465$ & 11 & 0,171 & $-0,149$ & 0,264 & 0,2672 \\
\hline 30 Minuten & $-1,649$ & 11 & 0,127 & $-0,165$ & 0,264 & 0,2195 \\
\hline 60 Minuten & $-0,308$ & 11 & 0,764 & $-0,066$ & 0,264 & 0,6248 \\
\hline 0 Minuten & $-0,078$ & 11 & 0,939 & $-0,019$ & 0,264 & 0,8858 \\
\hline 120 Minuten & 0,436 & 11 & 0,671 & 0,111 & 0,264 & 0,4108 \\
\hline
\end{tabular}

Tabelle 15: Ergebnisse der gepaarten t-Tests und des Fisher's LSD bei Rauchern im Vergleich von Grund- und Nikotinspray-Bedingung.

Die MEP-Amplituden der verschiedenen Zeitpunkte mit Nikotinspray wurden mit den entsprechenden Zeitpunkten der Grundbedingung verglichen. Die mit einem Stern $\left({ }^{*}\right)$ markierten Werte geben einen statistisch signifikanten Unterschied $(p<0,05)$ an.

df: Freiheitsgrade; LSD: geringster signifikanter Unterschied; $p$ : Signifikanzniveau; $t$ : -Wert. 


\begin{tabular}{|c|c|c|c|c|c|c|}
\hline \multirow{2}{*}{$\begin{array}{c}\text { Raucher mit } \\
\text { Nikotinpflaster }\end{array}$} & \multicolumn{3}{|c|}{ t-Test } & \multicolumn{3}{|c|}{ Fisher's LSD } \\
\hline & $\mathbf{t}$ & df & p & $\begin{array}{c}\text { Mittlere } \\
\text { Differenz }\end{array}$ & $\begin{array}{l}\text { Kritische } \\
\text { Differenz }\end{array}$ & p \\
\hline Baseline -0 Minuten & 0,857 & 11 & 0,409 & $-0,113$ & 0,264 & 0,4012 \\
\hline Baseline - 5 Minuten & 1,531 & 11 & 0,154 & $-0,181$ & 0,264 & 0,1797 \\
\hline Baseline - 10 Minuten & 2,449 & 11 & 0,032 * & $-0,246$ & 0,264 & 0,0678 \\
\hline Baseline - 15 Minuten & 2,726 & 11 & 0,020 * & $-0,230$ & 0,264 & 0,0875 \\
\hline Baseline - 20 Minuten & 2,290 & 11 & 0,043 * & $-0,232$ & 0,264 & 0,0858 \\
\hline Baseline - 25 Minuten & 1,295 & 11 & 0,222 & $-0,140$ & 0,264 & 0,2974 \\
\hline Baseline - 30 Minuten & 1,228 & 11 & 0,245 & $-0,107$ & 0,264 & 0,4256 \\
\hline Baseline - 60 Minuten & 1,529 & 11 & 0,154 & $-0,136$ & 0,264 & 0,3115 \\
\hline Baseline - 90 Minuten & 5,439 & 11 & 0,000 * & $-0,318$ & 0,264 & 0,0184 * \\
\hline Baseline - 120 Minuten & 5,263 & 11 & 0,000 * & $-0,360$ & 0,264 & $0,0077^{*}$ \\
\hline Baseline - 240 Minuten & 3,356 & 11 & 0,006 * & $-0,191$ & 0,264 & 0,1572 \\
\hline Baseline - nächster Morgen & 2,307 & 11 & 0,042 * & 0,202 & 0,264 & 0,1336 \\
\hline Baseline - nächster Abend & 0,645 & 11 & 0,532 & 0,062 & 0,264 & 0,6440 \\
\hline
\end{tabular}

Tabelle 16: Ergebnisse der gepaarten t-Tests und des Fisher's LSD bei Rauchern für die Messungen mit Nikotinpflaster.

Die MEP-Amplituden der verschiedenen Zeitpunkte wurden mit der zugehörigen Baseline verglichen. Die mit einem Stern $\left({ }^{*}\right)$ markierten Werte geben einen statistisch signifikanten Unterschied $(p<0,05)$ an. df: Freiheitsgrade; LSD: geringster signifikanter Unterschied; $p$ : Signifikanzniveau; $t$ : $t$-Wert.

\begin{tabular}{|c|c|c|c|c|c|c|}
\hline \multirow{2}{*}{$\begin{array}{c}\text { Raucher: } \\
\text { Grundbedingung vs. } \\
\text { Nikotinpflaster }\end{array}$} & \multicolumn{3}{|c|}{ t-Test } & \multicolumn{3}{|c|}{ Fisher's LSD } \\
\hline & $\mathbf{t}$ & df & $\mathbf{p}$ & $\begin{array}{c}\text { Mittlere } \\
\text { Differenz }\end{array}$ & $\begin{array}{l}\text { Kritische } \\
\text { Differenz }\end{array}$ & $\mathbf{p}$ \\
\hline 0 Minuten & $-0,977$ & 11 & 0,349 & 0,141 & 0,264 & 0,2942 \\
\hline 5 Minuten & $-0,268$ & 11 & 0,794 & 0,112 & 0,264 & 0,4059 \\
\hline 10 Minuten & $-0,188$ & 11 & 0,855 & 0,015 & 0,264 & 0,9124 \\
\hline 15 Minuten & 0,618 & 11 & 0,549 & $-0,024$ & 0,264 & 0,8598 \\
\hline 20 Minuten & $-0,578$ & 11 & 0,575 & 0,036 & 0,264 & 0,7914 \\
\hline 25 Minuten & $-0,261$ & 11 & 0,799 & 0,036 & 0,264 & 0,7866 \\
\hline 30 Minuten & $-0,336$ & 11 & 0,743 & 0,039 & 0,264 & 0,7732 \\
\hline 60 Minuten & $-0,329$ & 11 & 0,748 & 0,068 & 0,264 & 0,6158 \\
\hline 90 Minuten & 1,668 & 11 & 0,124 & $-0,141$ & 0,264 & 0,2957 \\
\hline 120 Minuten & 1,799 & 11 & 0,100 & $-0,250$ & 0,264 & 0,0642 \\
\hline
\end{tabular}

Tabelle 17: Ergbnisse der gepaarten t-Tests und des Fisher's LSD bei Rauchern im Vergleich von Grund- und Nikotinpflaster-Bedingung.

Die MEP-Amplituden der verschiedenen Zeitpunkte mit Nikotinpflaster wurden mit den entsprechenden Zeitpunkten der Grundbedingung verglichen. Hierbei ergaben sich keine signifikanten Unterschiede. df: Freiheitsgrade; LSD: geringster signifikanter Unterschied; $p$ : Signifikanzniveau $(p<0,05)$; $t$ : $t$-Wert. 


\begin{tabular}{|c|c|c|c|c|c|c|}
\hline \multirow{2}{*}{$\begin{array}{c}\text { Raucher: } \\
\text { Nikotinspray vs. } \\
\text { Nikotinpflaster }\end{array}$} & \multicolumn{3}{|c|}{ t-Test } & \multicolumn{3}{|c|}{ Fisher's LSD } \\
\hline & $\mathbf{t}$ & df & p & $\begin{array}{c}\text { Mittlere } \\
\text { Differenz }\end{array}$ & $\begin{array}{l}\text { Kritische } \\
\text { Differenz }\end{array}$ & p \\
\hline 0 Minuten & 0,563 & 11 & 0,585 & 0,090 & 0,264 & 0,5018 \\
\hline 5 Minuten & 0,460 & 11 & 0,655 & 0,062 & 0,264 & 0,6460 \\
\hline 10 Minuten & $-0,582$ & 11 & 0,573 & $-0,079$ & 0,264 & 0,5578 \\
\hline 15 Minuten & $-0,776$ & 11 & 0,454 & $-0,113$ & 0,264 & 0,4034 \\
\hline 20 Minuten & $-1,628$ & 11 & 0,132 & $-0,222$ & 0,264 & 0,0997 \\
\hline 25 Minuten & $-0,998$ & 11 & 0,340 & $-0,113$ & 0,264 & 0,4015 \\
\hline 30 Minuten & $-1,136$ & 11 & 0,280 & $-0,127$ & 0,264 & 0,3473 \\
\hline 60 Minuten & 0,012 & 11 & 0,990 & 0,002 & 0,264 & 0,9898 \\
\hline 90 Minuten & $-1,333$ & 11 & 0,210 & $-0,160$ & 0,264 & 0,2344 \\
\hline 120 Minuten & $-1,803$ & 11 & 0,099 & $-0,139$ & 0,264 & 0,3030 \\
\hline 240 Minuten & 0,090 & 11 & 0,929 & $-0,014$ & 0,264 & 0,9183 \\
\hline Nächster Morgen & 0,754 & 11 & 0,466 & 0,066 & 0,264 & 0,6263 \\
\hline Nächster Abend & 2,990 & 11 & 0,012 * & 0,300 & 0,264 & 0,0259 * \\
\hline
\end{tabular}

Tabelle 18: Ergebnisse der gepaarten t-Tests und des Fisher's LSD bei Rauchern im Vergleich von Nikotinspray und Nikotinpflaster.

Die MEP-Amplituden der Messungen mit Nikotinspray und Nikotinpflaster wurden zu den verschiedenen Zeitpunkten verglichen. Die mit einem Stern $\left(^{*}\right)$ markierten Werte zeigen statistisch signifikante Unterschiede $(p<$ $0,05)$ zwischen Nikotinspray- und Nikotinpflaster-Bedingung bei Rauchern an.

df: Freiheitsgrade; LSD: geringster signifikanter Unterschied; p: Signifikanzniveau; $t$ : $t$-Wert.

\begin{tabular}{|c|c|c|c|c|c|c|}
\hline $\begin{array}{c}\text { Ohne Nikotin: } \\
\text { Raucher vs. }\end{array}$ & \multicolumn{3}{|c|}{ t-Test } & \multicolumn{3}{c|}{ Fisher's LSD } \\
\hline Nichtraucher & $\mathbf{t}$ & $\mathbf{d f}$ & $\mathbf{p}$ & Mittlere & Kritische \\
\hline 0 Minuten & $-0,223$ & 22 & 0,826 & $-0,005$ & 0,264 & 0,9711 \\
\hline 5 Minuten & 0,449 & 22 & 0,658 & $-0,032$ & 0,264 & 0,8147 \\
\hline 10 Minuten & $-0,169$ & 22 & 0,867 & 0,012 & 0,264 & 0,9314 \\
\hline 15 Minuten & 1,594 & 22 & 0,125 & $-0,154$ & 0,264 & 0,2530 \\
\hline 20 Minuten & 0,156 & 22 & 0,877 & $-0,049$ & 0,264 & 0,7146 \\
\hline 25 Minuten & 1,130 & 22 & 0,270 & $-0,146$ & 0,264 & 0,2773 \\
\hline 30 Minuten & 0,971 & 22 & 0,342 & $-0,122$ & 0,264 & 0,3645 \\
\hline 60 Minuten & $-0,346$ & 22 & 0,732 & 0,080 & 0,264 & 0,5545 \\
\hline 90 Minuten & 1,277 & 22 & 0,215 & $-0,129$ & 0,264 & 0,3391 \\
\hline 120 Minuten & 0,139 & 22 & 0,891 & $-0,060$ & 0,264 & 0,6554 \\
\hline
\end{tabular}

Tabelle 19: Ergebnisse der unabhängigen t-Tests und des Fisher's LSD für die Grundbedingung ohne Nikotin im Vergleich von Rauchern und Nichtrauchern.

Die MEP-Amplituden der verschiedenen Zeitpunkte von Rauchern und Nichtrauchern unter Grundbedingungen (ohne Nikotin) wurden verglichen. Hierbei ergaben sich keine signifikanten Unterschiede.

df: Freiheitsgrade; LSD: geringster signifikanter Unterschied; $p$ : Signifikanzniveau $(p<0,05)$; $t$ : $t$-Wert. 


\begin{tabular}{|c|c|c|c|c|c|c|}
\hline \multirow{2}{*}{$\begin{array}{l}\text { Nikotinspray: Raucher vs. } \\
\text { Nichtraucher }\end{array}$} & \multicolumn{3}{|c|}{ t-Test } & \multicolumn{3}{|c|}{ Fisher's LSD } \\
\hline & $\mathbf{t}$ & df & p & $\begin{array}{c}\text { Mittlere } \\
\text { Differenz }\end{array}$ & $\begin{array}{l}\text { Kritische } \\
\text { Differenz }\end{array}$ & p \\
\hline 0 Minuten & $-1,727$ & 22 & 0,098 & 0,260 & 0,264 & 0,0534 \\
\hline 5 Minuten & $-1,451$ & 22 & 0,161 & 0,225 & 0,264 & 0,0949 \\
\hline 10 Minuten & $-1,388$ & 22 & 0,179 & 0,196 & 0,264 & 0,1458 \\
\hline 15 Minuten & $-0,970$ & 22 & 0,343 & 0,178 & 0,264 & 0,1859 \\
\hline 20 Minuten & $-0,425$ & 22 & 0,675 & 0,062 & 0,264 & 0,6431 \\
\hline 25 Minuten & $-0,711$ & 22 & 0,484 & 0,118 & 0,264 & 0,3825 \\
\hline 30 Minuten & $-0,266$ & 22 & 0,793 & 0,040 & 0,264 & 0,7657 \\
\hline 60 Minuten & $-1,887$ & 22 & 0,072 & 0,390 & 0,264 & 0,0039 * \\
\hline 90 Minuten & $-1,400$ & 22 & 0,175 & 0,220 & 0,264 & 0,1025 \\
\hline 120 Minuten & $-1,415$ & 22 & 0,171 & 0,213 & 0,264 & 0,1142 \\
\hline 240 Minuten & $-0,637$ & 22 & 0,531 & 0,104 & 0,264 & 0,4381 \\
\hline Nächster Morgen & $-2,376$ & 22 & 0,027 * & 0,300 & 0,264 & 0,0261 * \\
\hline Nächster Abend & $-3,748$ & 22 & 0,001 * & 0,433 & 0,264 & 0,0014 * \\
\hline
\end{tabular}

Tabelle 20: Ergebnisse der unabhängigen t-Tests und des Fisher's LSD für Nikotinspray bei Rauchern und Nichtrauchern.

Die MEP-Amplituden der verschiedenen Zeitpunkte mit Nikotinspray von Rauchern und Nichtrauchern wurden verglichen. Die mit einem Stern (*) markierten Werte zeigen statistisch signifikante Unterschiede $(p<0,05)$ zwischen Rauchern und Nichtrauchern an.

df: Freiheitsgrade; LSD: geringster signifikanter Unterschied; p: Signifikanzniveau; $t$ : $t$-Wert. 


\begin{tabular}{|c|c|c|c|c|c|c|}
\hline \multirow{2}{*}{$\begin{array}{l}\text { Nikotinpflaster: Raucher } \\
\text { vs. Nichtraucher }\end{array}$} & \multicolumn{3}{|c|}{ t-Test } & \multicolumn{3}{|c|}{ Fisher's LSD } \\
\hline & $t$ & df & p & $\begin{array}{c}\text { Mittlere } \\
\text { Differenz }\end{array}$ & $\begin{array}{l}\text { Kritische } \\
\text { Differenz }\end{array}$ & p \\
\hline 0 Minuten & 0,121 & 22 & 0,905 & $-0,018$ & 0,264 & 0,8934 \\
\hline 5 Minuten & $-0,609$ & 22 & 0,548 & 0,079 & 0,264 & 0,5556 \\
\hline 10 Minuten & $-1,391$ & 22 & 0,178 & 0,200 & 0,264 & 0,1386 \\
\hline 15 Minuten & $-0,894$ & 22 & 0,381 & 0,119 & 0,264 & 0,3781 \\
\hline 20 Minuten & $-1,154$ & 22 & 0,261 & 0,164 & 0,264 & 0,2247 \\
\hline 25 Minuten & $-0,633$ & 22 & 0,533 & 0,104 & 0,264 & 0,4387 \\
\hline 30 Minuten & $-0,513$ & 22 & 0,613 & 0,078 & 0,264 & 0,5645 \\
\hline 60 Minuten & $-0,656$ & 22 & 0,519 & 0,086 & 0,264 & 0,5245 \\
\hline 90 Minuten & $-1,517$ & 22 & 0,143 & 0,148 & 0,264 & 0,2715 \\
\hline 120 Minuten & $-2,264$ & 22 & 0,034 * & 0,253 & 0,264 & 0,0602 \\
\hline 240 Minuten & $-0,728$ & 22 & 0,474 & 0,057 & 0,264 & 0,6705 \\
\hline Nächster Morgen & $-1,495$ & 22 & 0,149 & 0,262 & 0,264 & 0,0524 \\
\hline Nächster Abend & $-0,093$ & 22 & 0,927 & $-0,040$ & 0,264 & 0,7660 \\
\hline
\end{tabular}

Tabelle 21: Ergebnisse der unabhängigen t-Tests und des Fisher's LSD für Nikotinpflaster bei Rauchern und Nichtrauchern.

Die MEP-Amplituden der verschiedenen Zeitpunkte mit Nikotinpflaster von Rauchern und Nichtrauchern wurden verglichen. Die mit einem Stern (*) markierten Werte zeigen statistisch signifikante Unterschiede $(p<0,05)$ zwischen Rauchern und Nichtrauchern an.

df: Freiheitsgrade; LSD: geringster signifikanter Unterschied; p: Signifikanzniveau; $t$ : $t$-Wert. 


\section{Literaturverzeichnis}

Abbruzzese G, Trompetto C (2002): "Clinical and research methods for evaluating cortical excitability." J Clin Neurophysiol 19(4): 307-321

Alkondon M, Pereira EF, Almeida LE, Randall WR, Albuquerque EX (2000): "Nicotine at concentrations found in cigarette smokers activates and desensitizes nicotinic acetylcholine receptors in CA1 interneurons of rat hippocampus." Neuropharmacology 39(13): 2726-2739

Atzori G, Lemmonds CA, Kotler ML, Durcan MJ, Boyle J (2008): "Efficacy of a nicotine (4 mg)-containing lozenge on the cognitive impairment of nicotine withdrawal." J Clin Psychopharmacol 2ㅇ(6): 667-674

Barker AT, Jalinous R, Freeston IL (1985): "Non-invasive magnetic stimulation of human motor cortex." Lancet 1985(1): 1106-1107

Barone JA (1999): "Domperidone: a peripherally acting dopamine2-receptor antagonist." Ann Pharmacother 33(4): 429-440

Barr RS, Culhane MA, Jubelt LE, Mufti RS, Dyer MA, Weiss AP, Deckersbach T, Kelly JF, Freudenreich O, Goff DC, et al. (2008): "The effects of transdermal nicotine on cognition in nonsmokers with schizophrenia and nonpsychiatric controls." Neuropsychopharmacology 33(3): 480-490

Bell SL, Taylor RC, Singleton EG, Henningfield JE, Heishman SJ (1999): "Smoking after nicotine deprivation enhances cognitive performance and decreases tobacco craving in drug abusers." Nicotine Tob Res 1(1): 45-52

Benowitz NL (1996): "Pharmacology of nicotine: addiction and therapeutics." Annu Rev Pharmacol Toxicol 36: 597-613

Benowitz NL (2008): "Clinical pharmacology of nicotine: implications for understanding, preventing, and treating tobacco addiction." Clin Pharmacol Ther 83(4): 531-541

Berardelli A, Inghilleri M, Rothwell JC, Romeo S, Curra A, Gilio F, Modugno N, Manfredi M (1998): "Facilitation of muscle evoked responses after repetitive cortical stimulation in man." Exp Brain Res 122(1): 79-84

Bhang SY, Choi SW, Ahn JH (2010): "Changes in plasma brain-derived neurotrophic factor levels in smokers after smoking cessation." Neurosci Lett $\underline{468(1): 7-11}$ 
Bi GQ, Poo MM (1998): "Synaptic modifications in cultured hippocampal neurons: dependence on spike timing, synaptic strength, and postsynaptic cell type." J Neurosci 18(24): 10464-10472

Biala G, Kruk M (2009): "Influence of bupropion and calcium channel antagonists on the nicotine-induced memory-related response of mice in the elevated plus maze." Pharmacol Rep 61(2): 236-244

Bliss TV, Lomo T (1973): "Long-lasting potentiation of synaptic transmission in the dentate area of the anaesthetized rabbit following stimulation of the perforant path." J Physiol 232(2): 331-356

Bliss TV, Collingridge GL (1993): "A synaptic model of memory: long-term potentiation in the hippocampus." Nature 361(6407): 31-39

Brigman JL, Wright T, Talani G, Prasad-Mulcare S, Jinde S, Seabold GK, Mathur P, Davis MI, Bock R, Gustin RM, et al. (2010): "Loss of GluN2B-containing NMDA receptors in CA1 hippocampus and cortex impairs long-term depression, reduces dendritic spine density, and disrupts learning." J Neurosci 30(13): 4590-4600

Broide RS, Leslie FM (1999): "The alpha7 nicotinic acetylcholine receptor in neuronal plasticity." Mol Neurobiol 20⑴: 1-16

Brown DA (2010): "Muscarinic acetylcholine receptors (mAChRs) in the nervous system: some functions and mechanisms." J Mol Neurosci 41(3): 340-346

Buisson B, Bertrand D (2002): "Nicotine addiction: the possible role of functional upregulation." Trends Pharmacol Sci 233(3): 130-136

Castro NG, Albuquerque EX (1995): "alpha-Bungarotoxin-sensitive hippocampal nicotinic receptor channel has a high calcium permeability." Biophys $\mathrm{J} \underline{68}(2)$ : 516-524

Cheeran B, Talelli P, Mori F, Koch G, Suppa A, Edwards M, Houlden H, Bhatia K, Greenwood R, Rothwell JC (2008): "A common polymorphism in the brainderived neurotrophic factor gene (BDNF) modulates human cortical plasticity and the response to rTMS." J Physiol $\underline{586}(\mathrm{Pt} 23): 5717-5725$

Chen R, Classen J, Gerloff C, Celnik P, Wassermann EM, Hallett M, Cohen LG (1997): "Depression of motor cortex excitability by low-frequency transcranial magnetic stimulation." Neurology $\underline{48(5): 1398-1403}$ 
Clarke PB, Reuben M (1996): "Release of [3H]-noradrenaline from rat hippocampal synaptosomes by nicotine: mediation by different nicotinic receptor subtypes from striatal [3H]-dopamine release." Br J Pharmacol 117(4): 595-606

Cole DM, Beckmann CF, Long CJ, Matthews PM, Durcan MJ, Beaver JD (2010): "Nicotine replacement in abstinent smokers improves cognitive withdrawal symptoms with modulation of resting brain network dynamics." Neuroimage 52(2): 590-599

Collingridge GL, Peineau S, Howland JG, Wang YT (2010): "Long-term depression in the CNS." Nat Rev Neurosci 11(7): 459-473

Collins DR, Davies SN (1997): "Melatonin blocks the induction of long-term potentiation in an N-methyl-D-aspartate independent manner." Brain Res 767(1): 162-165

Corrigall WA, Coen KM, Adamson KL (1994): "Self-administered nicotine activates the mesolimbic dopamine system through the ventral tegmental area." Brain Res $\underline{653}(1-2): 278-284$

Corringer PJ, Bertrand S, Bohler S, Edelstein SJ, Changeux JP, Bertrand D (1998): "Critical elements determining diversity in agonist binding and desensitization of neuronal nicotinic acetylcholine receptors." J Neurosci 18(2): 648-657

Corringer PJ, Sallette J, Changeux JP (2006): "Nicotine enhances intracellular nicotinic receptor maturation: a novel mechanism of neural plasticity?" $\mathrm{J}$ Physiol Paris 99(2-3): 162-171

Cramer SC (2008): "A window into the molecular basis of human brain plasticity." J Physiol 586(Pt 23): 5601

D'Alcantara P, Schiffmann SN, Swillens S (2003): "Bidirectional synaptic plasticity as a consequence of interdependent $\mathrm{Ca} 2+$-controlled phosphorylation and dephosphorylation pathways." Eur J Neurosci 17(12): 2521-2528

Dani JA, Heinemann S (1996): "Molecular and cellular aspects of nicotine abuse." Neuron 16(5): 905-908

Dani JA, De Biasi M (2001): "Cellular mechanisms of nicotine addiction." Pharmacol Biochem Behav 70(4): 439-446

Dani JA, Bertrand D (2007): "Nicotinic acetylcholine receptors and nicotinic cholinergic mechanisms of the central nervous system." Annu Rev Pharmacol Toxicol 47: 699-729 
Day BL, Dressler D, Maertens de Noordhout A, Marsden CD, Nakashima K, Rothwell JC, Thompson PD (1989): "Electric and magnetic stimulation of human motor cortex: surface EMG and single motor unit responses." J Physiol 412: 449-473

De Luca V, Wong AH, Muller DJ, Wong GW, Tyndale RF, Kennedy JL (2004): "Evidence of association between smoking and alpha7 nicotinic receptor subunit gene in schizophrenia patients." Neuropsychopharmacology $\underline{29}(8)$ : 1522-1526

Dempster EL, Toulopoulou T, McDonald C, Bramon E, Walshe M, Wickham H, Sham PC, Murray RM, Collier DA (2006): "Episodic memory performance predicted by the $2 b p$ deletion in exon 6 of the "alpha 7 -like" nicotinic receptor subunit gene." Am J Psychiatry 163(10): 1832-1834

Dong Z, Bai Y, Wu X, Li H, Gong B, Howland JG, Huang Y, He W, Li T, Wang YT (2013): "Hippocampal long-term depression mediates spatial reversal learning in the Morris water maze." Neuropharmacology $\underline{64}(1): 65-73$

Donoghue J, Hess G, Sanes JN: "Substrates and mechanisms for learning in motor cortex." In: Acquisition of motor behaviour in vertebrates (Bloedel J, Ebner T, Wise SP), MIT Cambridge/MA 1996: 363-386

Egan MF, Kojima M, Callicott JH, Goldberg TE, Kolachana BS, Bertolino A, Zaitsev E, Gold B, Goldman D, Dean M, et al. (2003): "The BDNF val66met polymorphism affects activity-dependent secretion of BDNF and human memory and hippocampal function." Cell 112(2): 257-269

Ernst M, Heishman SJ, Spurgeon L, London ED (2001): "Smoking history and nicotine effects on cognitive performance." Neuropsychopharmacology $\underline{25}(3)$ : 313-319

Fagerström KO, Schneider NG (1989): "Measuring nicotine dependence: a review of the Fagerstrom Tolerance Questionnaire." J Behav Med 12(2): 159-182

Fenster CP, Rains MF, Noerager B, Quick MW, Lester RA (1997): "Influence of subunit composition on desensitization of neuronal acetylcholine receptors at low concentrations of nicotine." J Neurosci 17(15): 5747-5759

Fratello F, Veniero D, Curcio G, Ferrara M, Marzano C, Moroni F, Pellicciari MC, Bertini M, Rossini PM, De Gennaro L (2006): "Modulation of corticospinal excitability by paired associative stimulation: reproducibility of effects and intraindividual reliability." Clin Neurophysiol $\underline{117(12): 2667-2674}$ 
Froeliger B, Gilbert DG, McClernon FJ (2009): "Effects of nicotine on novelty detection and memory recognition performance: double-blind, placebocontrolled studies of smokers and nonsmokers." Psychopharmacology (Berl) 205(4): 625-633

Fujii S, Sumikawa K (2001): "Nicotine accelerates reversal of long-term potentiation and enhances long-term depression in the rat hippocampal CA1 region." Brain Res $\underline{894}(2)$ : 340-346

Fujii S, Ji Z, Morita N, Sumikawa K (1999): "Acute and chronic nicotine exposure differentially facilitate the induction of LTP." Brain Res $\underline{846}(1): 137-143$

Ge S, Dani JA (2005): "Nicotinic acetylcholine receptors at glutamate synapses facilitate long-term depression or potentiation." J Neurosci 25(26): 6084-6091

Ghosheh O, Dwoskin LP, Li WK, Crooks PA (1999): "Residence times and half-lives of nicotine metabolites in rat brain after acute peripheral administration of [2'(14)C]nicotine." Drug Metab Dispos 277(12): 1448-1455

Ghosheh OA, Dwoskin LP, Miller DK, Crooks PA (2001): "Accumulation of nicotine and its metabolites in rat brain after intermittent or continuous peripheral administration of [2'-(14)C]nicotine." Drug Metab Dispos $\underline{29}$ (5): 645-651

Gotti C, Moretti M, Gaimarri A, Zanardi A, Clementi F, Zoli M (2007): "Heterogeneity and complexity of native brain nicotinic receptors." Biochem Pharmacol $\underline{74}(8)$ : 1102-1111

Govind AP, Vezina P, Green WN (2009): "Nicotine-induced upregulation of nicotinic receptors: underlying mechanisms and relevance to nicotine addiction." Biochem Pharmacol 78(7): 756-765

Grabus SD, Martin BR, Imad Damaj M (2005): "Nicotine physical dependence in the mouse: involvement of the alpha7 nicotinic receptor subtype." Eur $\mathrm{J}$ Pharmacol 515(1-3): 90-93

Greenbaum L, Lerer B (2009): "Differential contribution of genetic variation in multiple brain nicotinic cholinergic receptors to nicotine dependence: recent progress and emerging open questions." Mol Psychiatry 14(10): 912-945

Grundey J, Thirugnanasambandam N, Kaminsky K, Drees A, Skwirba AC, Lang N, Paulus W, Nitsche MA (2012 a): "Neuroplasticity in cigarette smokers is altered under withdrawal and partially restituted by nicotine exposition." J Neurosci $\underline{32}$ (12): 4156-4162 
Grundey J, Thirugnanasambandam N, Kaminsky K, Drees A, Skwirba AC, Lang N, Paulus W, Nitsche MA (2012 b): "Rapid effect of nicotine intake on neuroplasticity in non-smoking humans." Front Pharmacol $\underline{3}$ : 186

Grundey J, Freznosa S, Klinker F, Lang N, Paulus W, Nitsche MA (2013): "Cortical excitability in smoking and not smoking individuals with and without nicotine." Psychopharmacology (Berl), im Druck.

Gu Q (2002): "Neuromodulatory transmitter systems in the cortex and their role in cortical plasticity." Neuroscience 111(4): 815-835

Hahn B, Stolerman IP (2002): "Nicotine-induced attentional enhancement in rats: effects of chronic exposure to nicotine." Neuropsychopharmacology $\underline{27}(5)$ : 712-722

Heatherton TF, Kozlowski LT, Frecker RC, Fagerstrom KO (1991): "The Fagerstrom Test for Nicotine Dependence: a revision of the Fagerstrom Tolerance Questionnaire." Br J Addict 86(9): 1119-1127

Heishman SJ, Kleykamp BA, Singleton EG (2010): "Meta-analysis of the acute effects of nicotine and smoking on human performance." Psychopharmacology (Berl) 210(4): 453-469

Hindmarch I, Kerr JS, Sherwood N (1990): "Effects of nicotine gum on psychomotor performance in smokers and non-smokers." Psychopharmacology (Berl) 100(4): 535-541

Hukkanen J, Jacob P, 3rd, Benowitz NL (2005): "Metabolism and disposition kinetics of nicotine." Pharmacol Rev 57(1): 79-115

Jacob V, Brasier DJ, Erchova I, Feldman D, Shulz DE (2007): "Spike timingdependent synaptic depression in the in vivo barrel cortex of the rat." $J$ Neurosci $\underline{27}(6)$ : 1271-1284

Jacobsen LK, D'Souza DC, Mencl WE, Pugh KR, Skudlarski P, Krystal JH (2004): "Nicotine effects on brain function and functional connectivity in schizophrenia." Biol Psychiatry 55(8): 850-858

Jacobsen LK, Krystal JH, Mencl WE, Westerveld M, Frost SJ, Pugh KR (2005): "Effects of smoking and smoking abstinence on cognition in adolescent tobacco smokers." Biol Psychiatry $\underline{57}(1): 56-66$

Ji D, Lape R, Dani JA (2001): "Timing and location of nicotinic activity enhances or depresses hippocampal synaptic plasticity." Neuron 31(1): 131-141 
Jubelt LE, Barr RS, Goff DC, Logvinenko T, Weiss AP, Evins AE (2008): "Effects of transdermal nicotine on episodic memory in non-smokers with and without schizophrenia." Psychopharmacology (Berl) 199(1): 89-98

Kenney JW, Gould TJ (2008): "Modulation of hippocampus-dependent learning and synaptic plasticity by nicotine." Mol Neurobiol $\underline{38}(1): 101-121$

Kivinummi T, Kaste K, Rantamaki T, Castren E, Ahtee L (2011): "Alterations in BDNF and phospho-CREB levels following chronic oral nicotine treatment and its withdrawal in dopaminergic brain areas of mice." Neurosci Lett 491(2): 108112

Koester HJ, Sakmann B (1998): "Calcium dynamics in single spines during coincident pre- and postsynaptic activity depend on relative timing of backpropagating action potentials and subthreshold excitatory postsynaptic potentials." Proc Natl Acad Sci U S A 95(16): 9596-9601

Korchounov A, llic TV, Schwinge T, Ziemann U (2005): "Modification of motor cortical excitability by an acetylcholinesterase inhibitor." Exp Brain Res 164(3): 399405

Krueger F, Pardini M, Huey ED, Raymont V, Solomon J, Lipsky RH, Hodgkinson CA, Goldman D, Grafman J (2011): "The role of the Met66 brain-derived neurotrophic factor allele in the recovery of executive functioning after combatrelated traumatic brain injury." J Neurosci 31(2): 598-606

Kumari V, Gray JA, ffytche DH, Mitterschiffthaler MT, Das M, Zachariah E, Vythelingum GN, Williams SC, Simmons A, Sharma T (2003): "Cognitive effects of nicotine in humans: an fMRI study." Neuroimage 19(3): 1002-1013

Kuo MF, Grosch J, Fregni F, Paulus W, Nitsche MA (2007): "Focusing effect of acetylcholine on neuroplasticity in the human motor cortex." J Neurosci 27(52): 14442-14447

Kuo MF, Paulus W, Nitsche MA (2008): "Boosting focally-induced brain plasticity by dopamine." Cereb Cortex 18(3): 648-651

Lagostena L, Trocme-Thibierge C, Morain P, Cherubini E (2008): "The partial alpha7 nicotine acetylcholine receptor agonist S 24795 enhances long-term potentiation at CA3-CA1 synapses in the adult mouse hippocampus." Neuropharmacology $\underline{54}(4)$ : 676-685 
Lang N, Hasan A, Sueske E, Paulus W, Nitsche MA (2008): "Cortical hypoexcitability in chronic smokers? A transcranial magnetic stimulation study." Neuropsychopharmacology 33(10): 2517-2523

Lester RA, Dani JA (1994): "Time-dependent changes in central nicotinic acetylcholine channel kinetics in excised patches." Neuropharmacology $\underline{33}(1)$ : 27-34

Levin ED, Petro A, Rezvani AH, Pollard N, Christopher NC, Strauss M, Avery J, Nicholson J, Rose JE (2009): "Nicotinic alpha7- or beta2-containing receptor knockout: effects on radial-arm maze learning and long-term nicotine consumption in mice." Behav Brain Res 196(2): 207-213

Li MD, Beuten J, Ma JZ, Payne TJ, Lou XY, Garcia V, Duenes AS, Crews KM, Elston RC (2005): "Ethnic- and gender-specific association of the nicotinic acetylcholine receptor alpha4 subunit gene (CHRNA4) with nicotine dependence." Hum Mol Genet 14(9): 1211-1219

Linden DJ (1994): "Long-term synaptic depression in the mammalian brain." Neuron 12(3): $457-472$

Lisman JE (2001): "Three Ca2+ levels affect plasticity differently: the LTP zone, the LTD zone and no man's land." J Physiol 532(Pt 2): 285

Malaiyandi V, Sellers EM, Tyndale RF (2005): "Implications of CYP2A6 genetic variation for smoking behaviors and nicotine dependence." Clin Pharmacol Ther $\underline{77}(3): 145-158$

Mansvelder HD, McGehee DS (2000): "Long-term potentiation of excitatory inputs to brain reward areas by nicotine." Neuron $\underline{27}(2)$ : 349-357

Mansvelder HD, Keath JR, McGehee DS (2002): "Synaptic mechanisms underlie nicotine-induced excitability of brain reward areas." Neuron 33(6): 905-919

Maskos U, Molles BE, Pons S, Besson M, Guiard BP, Guilloux JP, Evrard A, Cazala P, Cormier A, Mameli-Engvall M, et al. (2005): "Nicotine reinforcement and cognition restored by targeted expression of nicotinic receptors." Nature 436(7047): 103-107

McGehee DS, Heath MJ, Gelber S, Devay P, Role LW (1995): "Nicotine enhancement of fast excitatory synaptic transmission in CNS by presynaptic receptors." Science 269(5231): 1692-1696 
McKay BE, Placzek AN, Dani JA (2007): "Regulation of synaptic transmission and plasticity by neuronal nicotinic acetylcholine receptors." Biochem Pharmacol 74(8): 1120-1133

Metaxas A, Al-Hasani R, Farshim P, Tubby K, Berwick A, Ledent C, Hourani S, Kitchen I, Bailey A (2013): "Genetic deletion of the adenosine A2A receptor prevents nicotine-induced upregulation of alpha7, but not alpha4beta2* nicotinic acetylcholine receptor binding in the brain." Neuropharmacology $\underline{71}$ : 228-236

Mexal S, Frank M, Berger R, Adams CE, Ross RG, Freedman R, Leonard S (2005): "Differential modulation of gene expression in the NMDA postsynaptic density of schizophrenic and control smokers." Brain Res Mol Brain Res 139(2): 317332

Misonou H, Mohapatra DP, Park EW, Leung V, Zhen D, Misonou K, Anderson AE, Trimmer JS (2004): "Regulation of ion channel localization and phosphorylation by neuronal activity." Nat Neurosci $\underline{7}(7)$ : 711-718

Missitzi J, Gentner R, Geladas N, Politis P, Karandreas N, Classen J, Klissouras V (2011): "Plasticity in human motor cortex is in part genetically determined." $\mathrm{J}$ Physiol 589(Pt 2): 297-306

Monte-Silva K, Kuo MF, Thirugnanasambandam N, Liebetanz D, Paulus W, Nitsche MA (2009): "Dose-dependent inverted U-shaped effect of dopamine (D2-like) receptor activation on focal and nonfocal plasticity in humans." J Neurosci 29(19): 6124-6131

Monte-Silva K, Liebetanz D, Grundey J, Paulus W, Nitsche MA (2010): "Dosagedependent non-linear effect of L-dopa on human motor cortex plasticity." J Physiol 588(Pt 18): 3415-3424

Müller-Dahlhaus JF, Orekhov Y, Liu Y, Ziemann U (2008): "Interindividual variability and age-dependency of motor cortical plasticity induced by paired associative stimulation." Exp Brain Res 187(3): 467-475

Nitsche MA, Nitsche MS, Klein CC, Tergau F, Rothwell JC, Paulus W (2003): "Level of action of cathodal DC polarisation induced inhibition of the human motor cortex." Clin Neurophysiol 114(4): 600-604

Partridge JG, Apparsundaram S, Gerhardt GA, Ronesi J, Lovinger DM (2002): "Nicotinic acetylcholine receptors interact with dopamine in induction of striatal long-term depression." J Neurosci 22 (7): 2541-2549 
Perkel DJ, Petrozzino JJ, Nicoll RA, Connor JA (1993): "The role of Ca2+ entry via synaptically activated NMDA receptors in the induction of long-term potentiation." Neuron 11(5): 817-823

Picciotto MR, Zoli M, Rimondini R, Lena C, Marubio LM, Pich EM, Fuxe K, Changeux JP (1998): "Acetylcholine receptors containing the beta2 subunit are involved in the reinforcing properties of nicotine." Nature 391(6663): 173-177

Portugal GS, Gould TJ (2008): "Genetic variability in nicotinic acetylcholine receptors and nicotine addiction: converging evidence from human and animal research." Behav Brain Res 193(1): 1-16

Quick MW, Lester RA (2002): "Desensitization of neuronal nicotinic receptors." J Neurobiol $\underline{53}(4):$ 457-478

Rioult-Pedotti MS, Friedman D, Hess G, Donoghue JP (1998): "Strengthening of horizontal cortical connections following skill learning." Nat Neurosci 1(3): 230234

Rioult-Pedotti MS, Friedman D, Donoghue JP (2000): "Learning-induced LTP in neocortex." Science 290(5491): 533-536

Sacco KA, Termine A, Seyal A, Dudas MM, Vessicchio JC, Krishnan-Sarin S, Jatlow PI, Wexler BE, George TP (2005): "Effects of cigarette smoking on spatial working memory and attentional deficits in schizophrenia: involvement of nicotinic receptor mechanisms." Arch Gen Psychiatry 62 (6): 649-659

Salas R, Main A, Gangitano D, De Biasi M (2007): "Decreased withdrawal symptoms but normal tolerance to nicotine in mice null for the alpha7 nicotinic

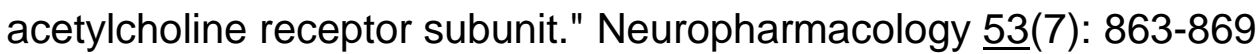

Sale MV, Ridding MC, Nordstrom MA (2007): "Factors influencing the magnitude and reproducibility of corticomotor excitability changes induced by paired associative stimulation." Exp Brain Res 181(4): 615-626

Sale MV, Ridding MC, Nordstrom MA (2008): "Cortisol inhibits neuroplasticity induction in human motor cortex." J Neurosci 28 (33): 8285-8293

Schilström B, Svensson HM, Svensson TH, Nomikos GG (1998): "Nicotine and food induced dopamine release in the nucleus accumbens of the rat: putative role of alpha7 nicotinic receptors in the ventral tegmental area." Neuroscience 85(4): 1005-1009 
Seguela P, Wadiche J, Dineley-Miller K, Dani JA, Patrick JW (1993): "Molecular cloning, functional properties, and distribution of rat brain alpha 7: a nicotinic cation channel highly permeable to calcium." J Neurosci 13(2): 596-604

Stefan K, Kunesch E, Cohen LG, Benecke R, Classen J (2000): "Induction of plasticity in the human motor cortex by paired associative stimulation." Brain $123 \mathrm{Pt} \mathrm{3}: 572-584$

Stefan K, Kunesch E, Benecke R, Cohen LG, Classen J (2002): "Mechanisms of enhancement of human motor cortex excitability induced by interventional paired associative stimulation." J Physiol $\underline{543}(\mathrm{Pt} \mathrm{2}):$ 699-708

Stefan K, Wycislo M, Classen J (2004): "Modulation of associative human motor cortical plasticity by attention." J Neurophysiol 92(1): 66-72

Sutherland MT, Ross TJ, Shakleya DM, Huestis MA, Stein EA (2011): "Chronic smoking, but not acute nicotine administration, modulates neural correlates of working memory." Psychopharmacology (Berl)

Swayne OB, Teo JT, Greenwood RJ, Rothwell JC (2009): "The facilitatory effects of intermittent theta burst stimulation on corticospinal excitability are enhanced by nicotine." Clin Neurophysiol 120(8): 1610-1615

Tapper AR, McKinney SL, Nashmi R, Schwarz J, Deshpande P, Labarca C, Whiteaker P, Marks MJ, Collins AC, Lester HA (2004): "Nicotine activation of alpha4* receptors: sufficient for reward, tolerance, and sensitization." Science 306(5698): 1029-1032

Tecchio F, Zappasodi F, Pasqualetti P, De Gennaro L, Pellicciari MC, Ercolani M, Squitti R, Rossini PM (2008): "Age dependence of primary motor cortex plasticity induced by paired associative stimulation." Clin Neurophysiol 119(3): 675-682

Thirugnanasambandam N, Grundey J, Adam K, Drees A, Skwirba AC, Lang N, Paulus W, Nitsche MA (2011 a): "Nicotinergic impact on focal and non-focal neuroplasticity induced by non-invasive brain stimulation in non-smoking humans." Neuropsychopharmacology $\underline{36}(4):$ 879-886

Thirugnanasambandam N, Grundey J, Paulus W, Nitsche MA (2011 b): "DoseDependent Nonlinear Effect of L-DOPA on Paired Associative StimulationInduced Neuroplasticity in Humans." J Neurosci 31(14): 5294-5299 
Vezina P, McGehee DS, Green WN (2007): "Exposure to nicotine and sensitization of nicotine-induced behaviors." Prog Neuropsychopharmacol Biol Psychiatry 31(8): $1625-1638$

Waters AJ, Sutton SR (2000): "Direct and indirect effects of nicotine/smoking on cognition in humans." Addict Behav 25(1): 29-43

Weise D, Schramm A, Stefan K, Wolters A, Reiners K, Naumann M, Classen J (2006): "The two sides of associative plasticity in writer's cramp." Brain $\underline{129}(\mathrm{Pt}$ 10): $2709-2721$

Welsby PJ, Rowan MJ, Anwyl R (2007): "Beta-amyloid blocks high frequency stimulation induced LTP but not nicotine enhanced LTP." Neuropharmacology 53(1): 188-195

Westfall TC, Grant H, Perry H (1983): "Release of dopamine and 5hydroxytryptamine from rat striatal slices following activation of nicotinic cholinergic receptors." Gen Pharmacol 14(3): 321-325

Wolters A, Sandbrink F, Schlottmann A, Kunesch E, Stefan K, Cohen LG, Benecke R, Classen J (2003): "A temporally asymmetric Hebbian rule governing plasticity in the human motor cortex." J Neurophysiol 89(5): 2339-2345

Wonnacott S (1997): "Presynaptic nicotinic ACh receptors." Trends Neurosci 20(2): 92-98

Woodside BL, Borroni AM, Hammonds MD, Teyler TJ (2004): "NMDA receptors and voltage-dependent calcium channels mediate different aspects of acquisition and retention of a spatial memory task." Neurobiol Learn Mem 81(2): 105-114

Wooltorton JR, Pidoplichko VI, Broide RS, Dani JA (2003): "Differential desensitization and distribution of nicotinic acetylcholine receptor subtypes in midbrain dopamine areas." J Neurosci $\underline{23}$ (8): 3176-3185

Wüllner U, Gündisch D, Herzog H, Minnerop $M$, Joe A, Warnecke $M$, Jessen F, Schutz C, Reinhardt M, Eschner W, et al. (2008): "Smoking upregulates alpha4beta2* nicotinic acetylcholine receptors in the human brain." Neurosci Lett $430(1): 34-37$

Yamazaki Y, Jia Y, Hamaue N, Sumikawa K (2005): "Nicotine-induced switch in the nicotinic cholinergic mechanisms of facilitation of long-term potentiation induction." Eur J Neurosci 22 (4): 845-860

Yang X, Criswell HE, Breese GR (1996): "Nicotine-induced inhibition in medial septum involves activation of presynaptic nicotinic cholinergic receptors on 
gamma-aminobutyric acid-containing neurons." J Pharmacol Exp Ther 276(2): 482-489

Zhu PJ, Chiappinelli VA (1999): "Nicotine modulates evoked GABAergic transmission in the brain." J Neurophysiol 82(6): 3041-3045 


\section{Eidesstattliche Versicherung}

Hiermit versichere ich an Eides statt, dass ich diese Arbeit selbstständig und ohne Anwendung anderer als der angegebenen Hilfsmittel verfasst habe.

Die Datenerhebung und -auswertung erfolgte eigenständig unter Supervision von Frau Dr. med. Jessica Grundey und Frau Dr. rer. nat. Nivethida Thirugnanasambandam. Teile der erhobenen Daten sind bereits in den folgenden Artikeln veröffentlicht worden:

Grundey J, Thirugnanasambandam N, Kaminsky K, Drees A, Skwirba AC, Lang N, Paulus W, Nitsche MA (2012 a): "Neuroplasticity in cigarette smokers is altered under withdrawal and partially restituted by nicotine exposition." J Neurosci $\underline{32}$ (12): 4156-4162

Grundey J, Thirugnanasambandam N, Kaminsky K, Drees A, Skwirba AC, Lang N, Paulus W, Nitsche MA (2012 b): "Rapid effect of nicotine intake on neuroplasticity in non-smoking humans." Front Pharmacol $\underline{3}: 186$

Thirugnanasambandam N, Grundey J, Adam K, Drees A, Skwirba AC, Lang N, Paulus W, Nitsche MA (2011 a): "Nicotinergic impact on focal and non-focal neuroplasticity induced by non-invasive brain stimulation in non-smoking humans." Neuropsychopharmacology 36(4): 879-886. 


\section{Danksagung}

Mein Dank gilt besonders meinem Doktorvater Prof. Dr. med. Michael Nitsche für die gute Betreuung sowie die Anregungen und Ideen, die zum Gelingen dieser Arbeit geführt haben.

Zudem möchte ich mich bei meiner Betreuerin Frau Dr. med. Jessica Grundey von der Abteilung Klinische Neurophysiologie Göttingen für ihre engagierte sowohl fachliche als auch persönliche Unterstützung und die Hilfe bei der statistischen Auswertung bedanken.

Des Weiteren möchte ich Frau Dr. rer. nat. Nivethida Thirugnanasambandam von der Abteilung Klinische Neurophysiologie Göttingen für die lehrreichen Ratschläge und ihre unermüdliche Unterstützung herzlich danken. 